\title{
The development of a novel technique to evaluate binding between probiotic bacteria and phospholipids, and the creation of a dairy-based food product rich in milk bioactives
}

\author{
A Thesis Presented to the Faculty of \\ California Polytechnic State University \\ San Luis Obispo
}

\begin{abstract}
In Partial Fulfillment of the Requirements for the Degree of
Master of Science in Agriculture, with specialization in Dairy Products Technology
\end{abstract}

By Megan Ann Cleveland

February 2011 
(C)2011

Megan Ann Cleveland

ALL RIGHTS RESERVED 


\section{COMMITTEE MEMBERSHIP}

TITLE: The development of a novel technique to evaluate binding between probiotic bacteria and phospholipids, and the creation of a dairy-based food product rich in milk bioactives
AUTHOR:
Megan Ann Cleveland

DATE SUBMITTED: $\quad$ February 2011

COMMITTEE CHAIR: $\quad$ Rafael Jimenez-Flores, $\mathrm{PhD}$

COMMITTEE MEMBER: $\quad$ Margaret Rice, PhD

COMMITTEE MEMBER: Amy Lammert, PhD 


\begin{abstract}
The development of a novel technique to evaluate binding between probiotic bacteria and phospholipids, and the creation of a dairy-based food product rich in milk bioactives
\end{abstract}

\begin{abstract}
Megan Ann Cleveland
Probiotic bacteria are increasingly prevalent in food and nutritional products
\end{abstract} today. These remarkable microorganisms are capable of imparting exceptional health benefits on their host, including prevention of infection by pathogens and stimulation of immune system function. Their most common mode of delivery is through dairy products (e.g. yogurt), which are also one of their preferred habitats. The interactions between probiotic bacteria and dairy systems have been studied, but are still not well discerned. There is a need for better understanding of these associations, as well as those surrounding the mode of bacterial transfer from the food product to the human gastrointestinal tract. Discoveries into the optimal means of probiotic transport to the body may lead to great advancements in both the design of probiotic foods and their exploitation in the support of human health.

Much of the previous research on probiotic bacteria has explored their possible means of adherence in the intestine, as well their strengths in the promotion of human health. Studies relating to their interaction with dairy products are lacking, however, thus this work aims to elucidate some of these aspects. The primary endeavor of this thesis was to develop a technique to quantify the binding affinity of probiotic lactic acid bacteria for milk phospholipids. An additional objective was to exploit these bacteria, as 
well as dairy ingredients rich in bioactive molecules, in the creation of a highly nutritious food product.

In these experiments, a collection of methods were used in progression in order to arrive at a novel protocol to assess binding with excellent reproducibility and simplicity. These included various membrane blotting techniques, as well as thin-layer chromatography. Essentially, phospholipids from both animal-derived standards and milk extracts were applied to a surface (e.g. PVDF membrane), and bacteria were incubated with them to allow binding reactions. The lactic acid bacteria selected for the final assays consisted of four strains of Lactobacillus, including L. reuteri (SD2112 and T-1), L. acidophilus, and L. casei (LC-10). Their adhesion to phospholipids was detected by either colorimetric or fluorescent labeling systems. To illustrate this, the final method developed was a procedure in which bacteria fluorescently stained with acridine orange were allowed to bind to dots of PVDF membrane coated with phospholipids. The results of this study showed that lactic acid bacteria undeniably exhibit selective binding affinity for phospholipids as opposed to other lipids such as triglycerides. The bacteria demonstrated significantly greater binding for a phospholipid extract from milk as opposed to individual phospholipid standards from other sources $(\mathrm{p}<0.05)$. Nonetheless, adhesion to all phospholipids was substantially greater than that to triglycerides. These findings, as well as the development of this method, should prove valuable in future research regarding the associations of probiotics with dairy systems.

An additional purpose of this thesis was to design a dairy-based food product containing ingredient sources rich in milk bioactives. A gel-type product was created using primarily colostrum, buttermilk powder, and whey protein isolate, as well as 
selected strains of Lactobacillus. With the inclusion of immunoglobulin-rich colostrum, the product was analyzed alongside fluid milk and colostrum in order to quantify and compare these bioactive molecules. An enzyme-linked immunosorbent assay (ELISA) was used to complete this, and the results revealed concentrations that would be expected by the literature. Specifically, immunoglobulin G (IgG) was quantified by interpolation from a bovine IgG standard regression curve. The results showed that the concentration of IgG in the gel was nearly twice that of colostrum, and almost eight-fold higher than that of milk. This indicates that use of bioactive-rich substances, such as colostrum, in a food product may serve as a means of delivering more concentrated doses of bioactives than their respective ingredients.

The research completed in this thesis is significant in that it contributes a valuable method to the elucidation of bacterial binding interactions with milk components, and also demonstrates the successful application of dairy ingredients to an innovative food product high in beneficial compounds. The insight provided by these studies could encourage further work in improving the understanding of probiotic delivery and advancing the development of bioactive-rich food products.

Keywords: probiotics, lactic acid bacteria, phospholipids, immunoglobulins, milk bioactives 


\section{ACKNOWLEDGEMENTS}

I would like to thank my committee-Dr. Rafael Jimenez-Flores, Dr. Peggy Rice, and Dr. Amy Lammert—for their support and guidance in my journey through graduate school. I am thankful for the opportunity I have had to grow as a scientist and as a person.

I would also like to thank the students and staff of the Dairy Products Technology Center. I am especially grateful for the unfailing friendship and support of Xiomara Elias, as well as Viki Jai, Liz Ng, Nidhi Bansal, Dan Zhao, Joshua Goldman, and the rest of the graduate students.

I am very thankful for the financial support provided by the California Dairy Research Foundation (CDRF), the California State University Agricultural Research Initiative (CSU ARI), and Cal Poly C3RP.

Finally, I am extremely grateful for the unfailing friendship, love, and support of Andrew and April Rock, Laura and Brian Gonzalez, and my loving, gracious Lord Jesus Christ. 


\section{TABLE OF CONTENTS}

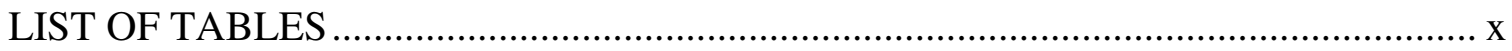

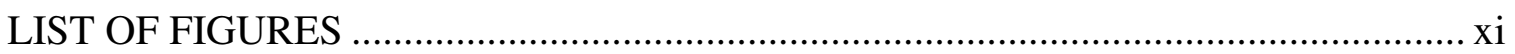

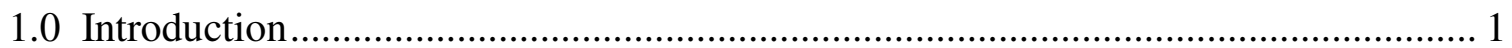

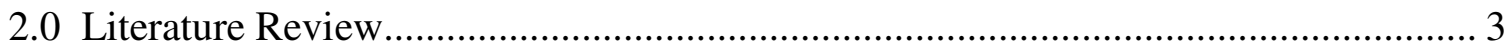

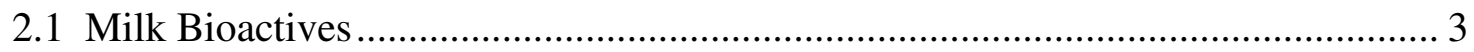

2.1.1 Overview of Milk Bioactives................................................................. 3

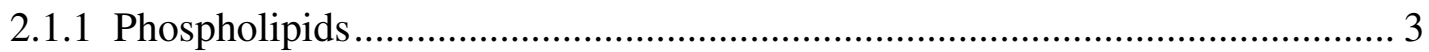

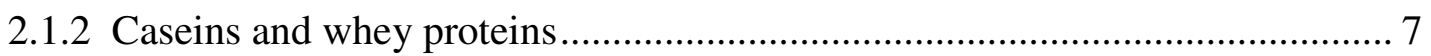

2.1.3 Immunoglobulins and colostrum ............................................................. 9

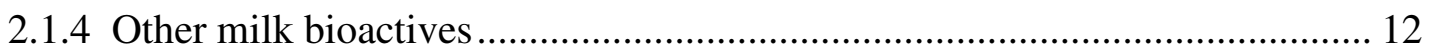

2.1.5 Bioactive delivery systems ................................................................... 13

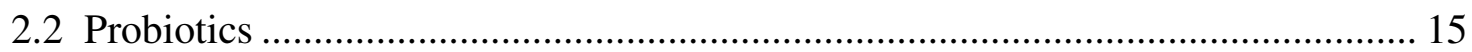

2.2.1 Definition, background, \& characteristics ………....................................... 15

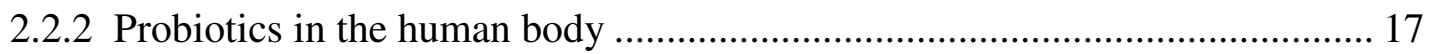

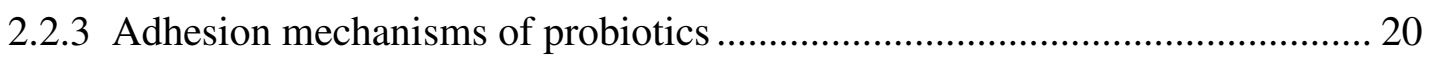

2.2.4 Probiotic adhesion and disease prevention ………………......................... 26

2.3 Techniques for analysis of bioactives ............................................................. 27

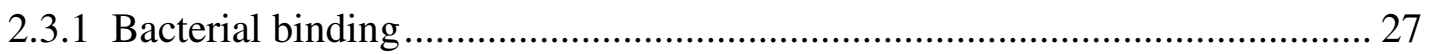

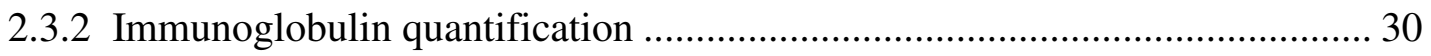

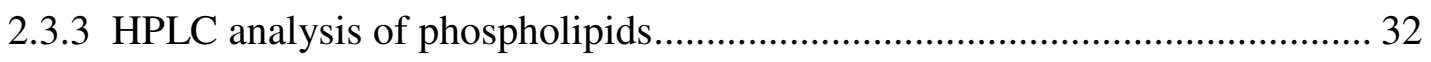

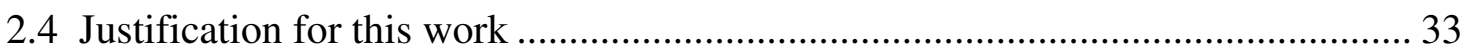

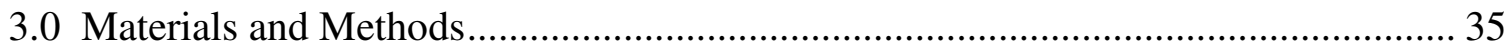

3.1 Development of a method to measure binding between lactic acid bacteria and

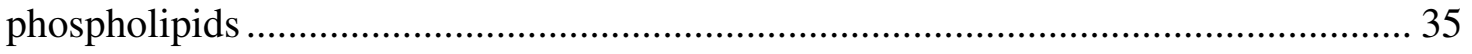

3.1.1 Creation of parent and working stocks of lactic acid bacteria ........................ 35

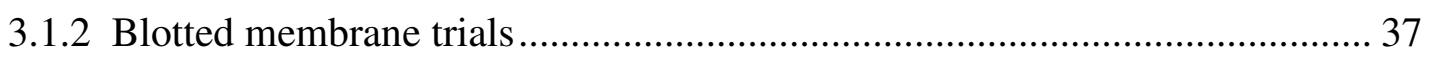

3.1.3 Thin-layer chromatography (TLC) trials ..................................................... 41

3.1.4 HPLC analysis of phospholipids................................................................. 43

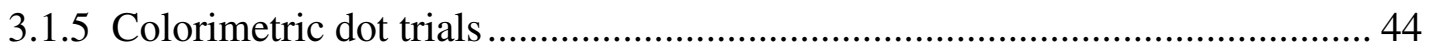

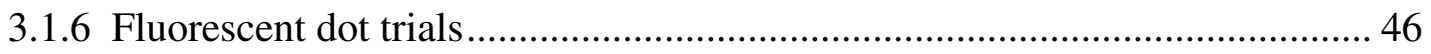

3.2 Development and analysis of a dairy-based, bioactive-rich gel ............................ 48

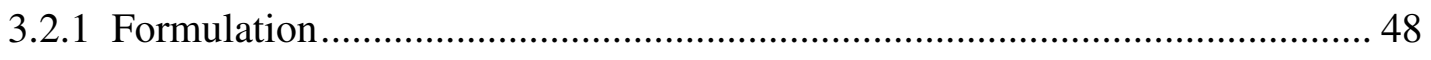

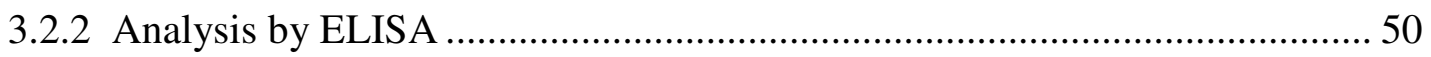




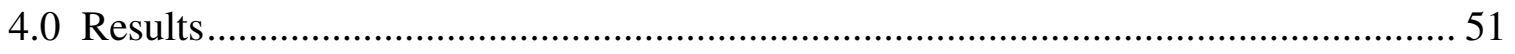

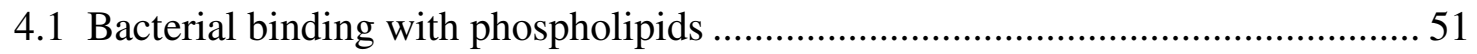

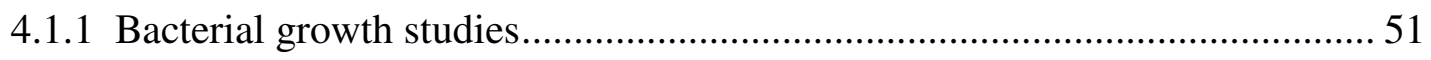

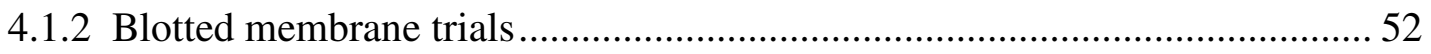

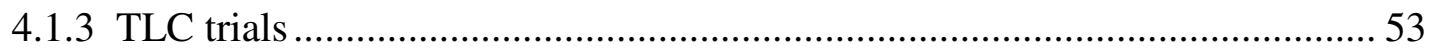

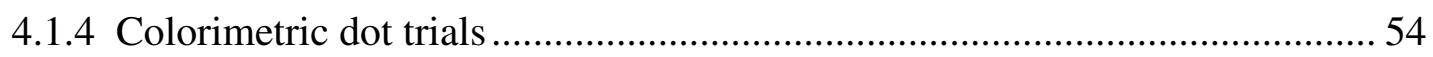

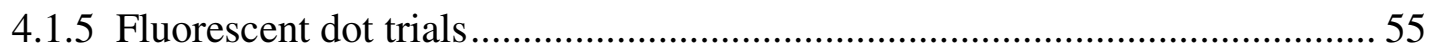

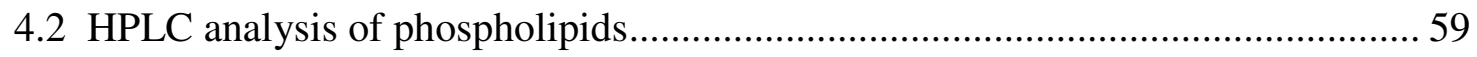

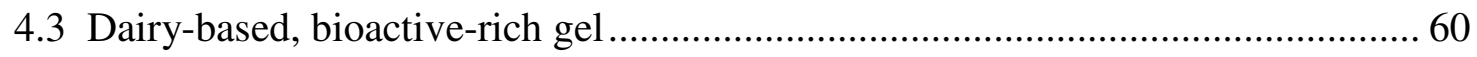

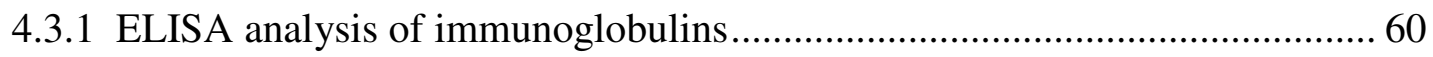

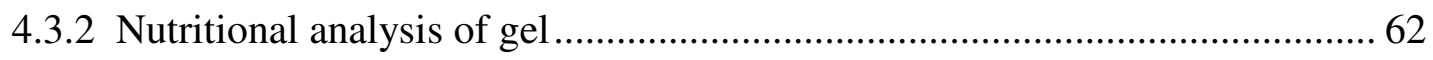

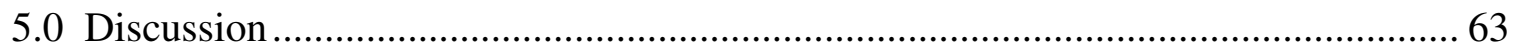

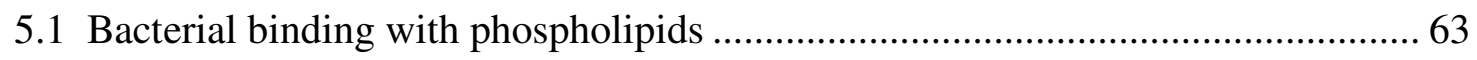

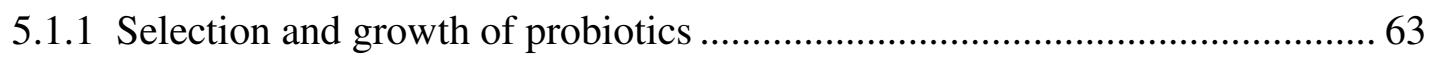

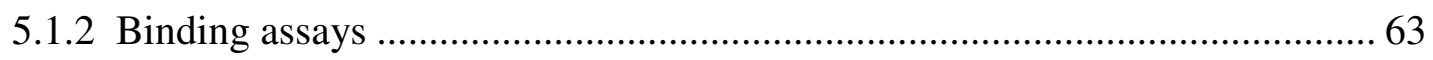

5.2 Formulation and analysis of a dairy-based, bioactive-rich gel ............................. 72

5.2.1 ELISA analysis of immunoglobulins......................................................... 74

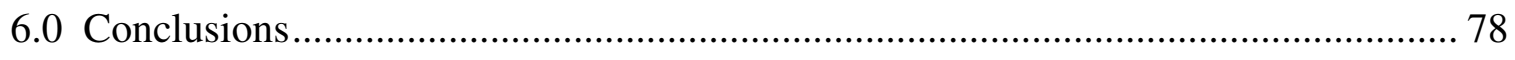

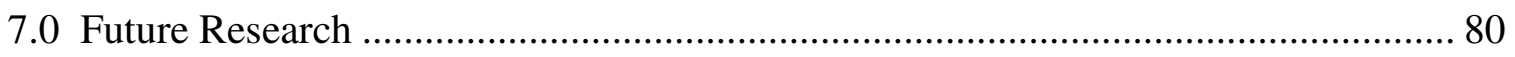

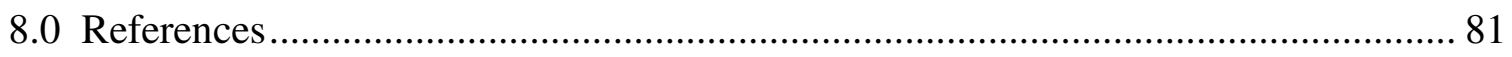

Appendix A: Growth study of lactic acid bacteria.................................................... 89

Appendix B: Raw data for fluorescent dots ....................................................... 90

Appendix C: HPLC analysis of milk-derived phospholipid extract ............................ 91

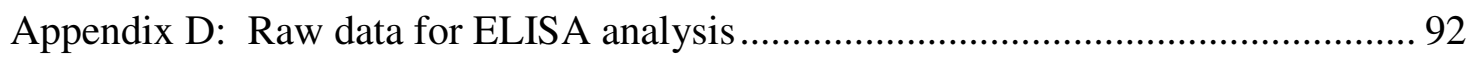

Appendix E: Statistical Analysis by Minitab 16 - Fluorescent dots ............................ 93

Appendix F: Statistical Analysis by Minitab 16 - ELISA analysis.............................. 96

Appendix G: Buffer formulas ............................................................................. 98 


\section{LIST OF TABLES}

Table

Page

Immunoglobulin subtypes and concentrations in milk...............10

Lactobacillus species and applications............................. 36

Phospholipid types and applications............................. 40

3.3 Dairy-based gel formulation....................................49

Fluorescent dots analyzed by Tukey's test for comparison..............58

4.2 Phospholipid concentrations in milk PL extract....................59

4.3 Immunoglobulin $\mathrm{G}(\mathrm{IgG})$ concentrations of ELISA samples...........61 


\section{LIST OF FIGURES}

Figure

Page

General glycerophospholipid structure and subtypes.................5

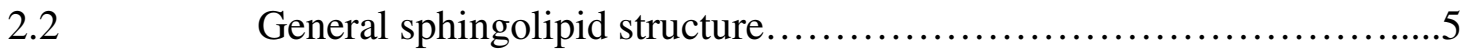

2.3 Bacterial binding with MFGM.................................29

2.4 HPLC chromatogram of milk phospholipid extract..................33

Illustration of blotted membrane method............................40

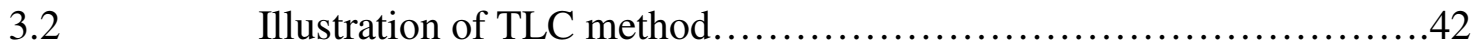

3.3 Illustration of colorimetric dot method............................45

Illustration of fluorescent dot method.............................48

4.1 Lactobacillus growth over 18 hours.............................51

Colorimetric blotted membranes to assess bacterial binding..........52

Fluorescent blotted membranes..................................52

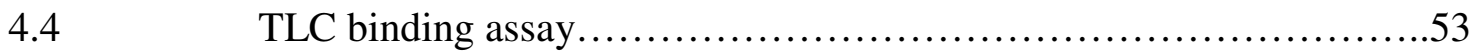

Colorimetric dot assay.........................................

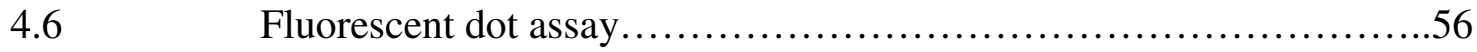

Comparison of bacterial binding to lipids..........................57

$4.8 \quad$ Fluorescent dot residual plots.................................... 58

4.9 Chromatogram from HPLC analysis of PL mixture..................59

4.10 Standard curve resulting from ELISA analysis of bovine IgG.........60

4.11 ELISA plate after colorimetric development with OPD..............61

4.12 Residual plots resulting from ELISA analysis of bovine IgG standards.61

Nutrition analysis of gel by Genesis.............................62 
Finished colostrum-based gel ready for packaging..................62 


\subsection{Introduction}

Milk and dairy products are exceptional sources of an array of biologically active compounds that can confer important benefits on human health. Some of these include immunoglobulins, whey proteins and peptides, polar lipids (e.g. phospholipids), and lactic acid bacteria. Probiotics, which include many types of lactic acid bacteria, are capable of augmenting the normal community of microflora in the human body and can impart considerable health benefits. Numerous studies have been completed that demonstrate some of the remarkable properties of milk bioactives, such as antimicrobial, anticarcinogenic, neurological, and immune system enhancing effects. Due to the increasing consumer knowledge of the positive impact of functional foods on health, there is a demand for more and better food products to effectively deliver these unique compounds.

Understanding the interactions between bioactive constituents and their delivery matrix may improve the success of the means by which they are transported to the human body. Specifically, discovering the associations among probiotic lactic acid bacteria, dairy products, and the intestine is likely to prove valuable in the design of dairy foods that provide optimal probiotic benefits. Thus far, research on probiotics has focused primarily on their effects in the host and few studies have concentrated in depth on their interaction with dairy products. To describe these relationships, as well as the mechanisms by which lactic acid bacteria may transfer from the dairy product to the intestine, the means of probiotic interactions with both mediums must be exposed. Existing research has described adhesion mechanisms of probiotics in the intestine by means of certain proteins such as mucins and S-layer proteins (Kirjavainen et al. 1998; 
Deepika and Charalampopoulos 2010). Some studies have also been conducted that reveal the presence of binding between the bacteria and certain components of the milk fat globule membrane (Bachiero et al. 2007; Brisson et al. 2010).

The primary purpose of this thesis was to develop a method to quantify binding between probiotic lactic acid bacteria and milk phospholipids. A secondary objective of these studies was to apply some of the highly bioactive dairy ingredients to the creation of a high-value food product. Expectations for this work relate to these purposes, and include the detection of naturally selective binding between probiotic bacteria and phospholipids, as well as the successful use of dairy in a bioactive food product. Insight into the associations between probiotics and lipids could be used in science-based decisions regarding their selection, as well as that of other ingredients, for inclusion in food product formulations. The hope is that this research will contribute to the current relatively small base of knowledge about these complex interactions, and encourage further studies that prove beneficial to the advancement of probiotic delivery through dairy foods. 


\subsection{Literature Review}

\subsection{Milk Bioactives}

\subsubsection{Overview of Milk Bioactives}

Milk is a rich source of biologically active molecules which can have an important impact on human health. Some types of bioactive compounds include certain peptides and proteins, oligosaccharides, lactoferrin, lysozyme, minor lipids, and immunoglobulins (Park 2009). One of the rich sources of bioactives is the milk fat globule membrane (MFGM), which surrounds fat globules in milk and contributes to their emulsification and protection. The MFGM's complex structure consists of distinct, highly bioactive collections of polar lipids (40\%) and minor proteins $(60 \%)$ (Keenan et al. 1988; Fox and McSweeney 1998; Dewettinck et al. 2008). Milk bioactives such as these can have numerous positive impacts on the function and health of the gastrointestinal tract and the immune system. More specific examples of their capabilities include improved immune response, bolstered phagocyte activity, enhanced growth of bifidobacteria in the intestine, increased natural killer cell activity, provision of passive immunity, and reduced attachment of bacteria and viruses in the intestine (Park 2009). Some of the primary bioactives of interest in this review include phospholipids, caseins and whey proteins, and immunoglobulins.

\subsubsection{Phospholipids}

Phospholipids are a key building block of cellular membranes, including the milk fat globule membrane (MFGM), and are categorized as polar lipids. They are especially concentrated in brain tissue and bone marrow, but also in milk (Rombaut and Dewettinck 2006). The major classes of phospholipid include sphingophospholipids (sphingomyelin, 
SM) and glycerophospholipids (phosphatidylethanolamine (PE), phosphatidylinositol (PI), phosphatidylserine (PS), and phosphatidylcholine (PC)). Ceramides and gangliosides are other types of polar lipids and are distinguished by their inclusion of hexose sugars. PC, PE, and SM are the main phospholipids found in bovine milk (Fox and McSweeney 2006).

Phospholipids are unique in that they are amphiphilic, meaning that they possess both hydrophilic and hydrophobic properties, which are due to the anionic polar phosphate group and fatty acid chains, respectively (Figure 2.1). The structure of glycerophospholipids, such as PC and PE, consists of two fatty acids linked by ester bonds to a glycerol backbone. The subtypes then differ from one another by their respective fatty acids and polar head group (Figure 2.1). In contrast, SM is built upon a sphingoid base (typically sphingosine) that is bonded to a fatty acid chain and phosphocholine (Figure 2.2). In regard to fatty acid composition, SM is heavily saturated (97\%), while among the glycerophospholipids, PC, PS, and PI are the most saturated (52\%, 41\%, and 37\%, respectively) and PE is the least saturated (26\%) (Fox and McSweeney 2006). 

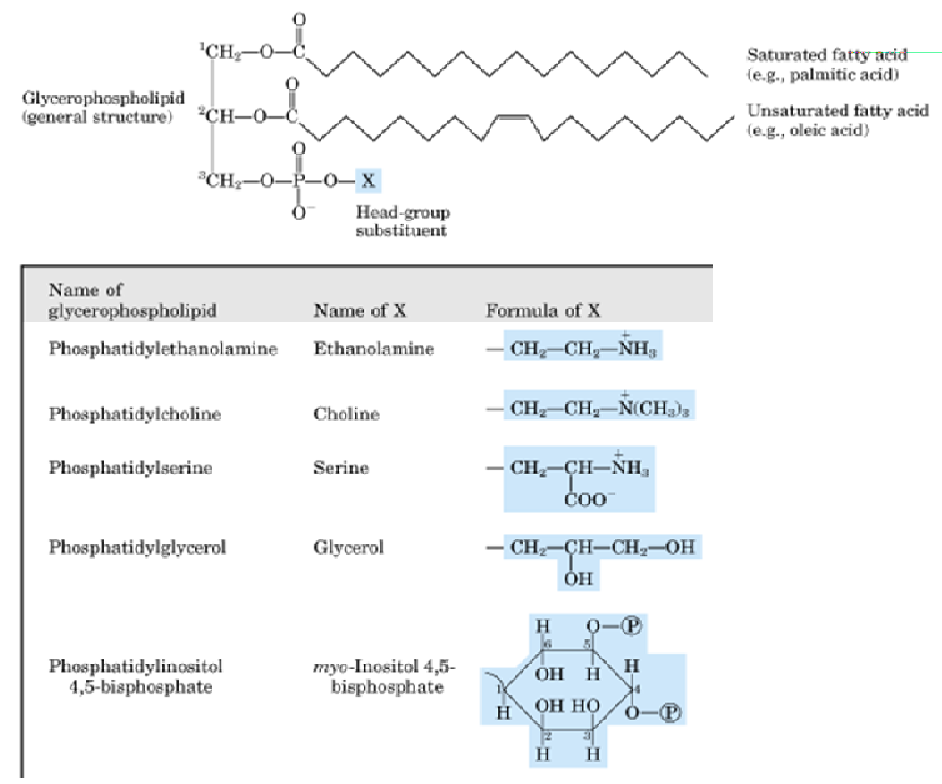

Figure 2.1. General glycerophospholipid structure and subtypes (Nelson and Cox 2000).

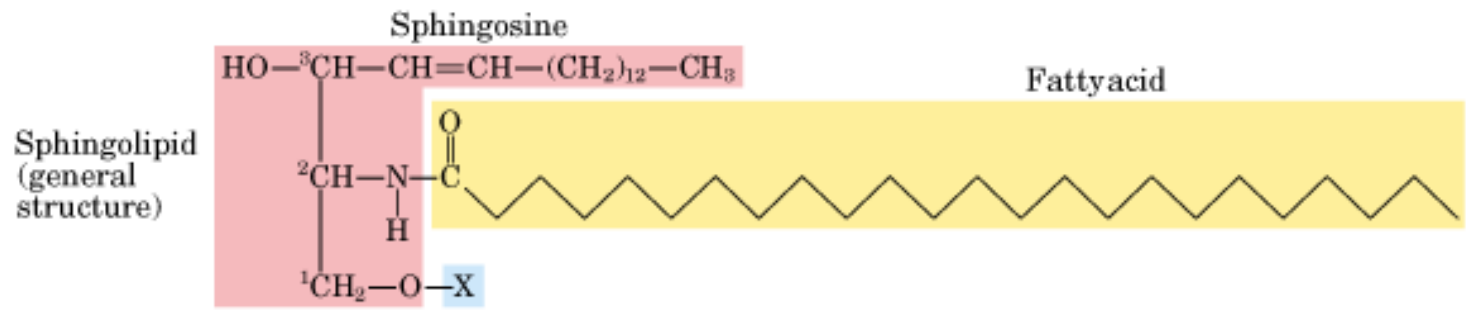

Figure 2.2. General sphingolipid structure. " $\mathrm{X}$ " represents the side group that defines the specific type of sphingolipid (Nelson and Cox 2000).

Phospholipids represent $0.5-1.0 \%$ of total milk fat. The majority (60-65\%) are found in the intact milk fat globule membrane (MFGM), while the rest are found in protein and membrane fragments in solution. Phospholipids account for $15-30 \%$ of the MFGM (Fox and McSweeney 2006). The distribution of some of the major phospholipids in the MFGM is as follows: PC (35\%), PE (30\%), SM (25\%), PI (5\%), and PS (3\%) (Deeth 1997; Danthine et al. 2000). During milk processing, phospholipids are distributed in different ratios to each milk fraction. As a percentage of the total lipid content, the highest ratios of phospholipid are found in buttermilk and skim milk, due to 
the amount of MFGM material in these products. However, butter, cream, and buttermilk contain the greatest percentage of phospholipids in a weight/volume ratio (Fox and McSweeney 1998).

The health benefits of polar lipids and their metabolites are numerous. They include positive effects on the function of the immune system, heart, and brain, as well as anti-cancer mechanisms. Phospholipids have antioxidative, antimicrobial, and antiviral properties, in addition to instrumental roles as secondary messengers for cell signaling, regulation, and growth (Pettus et al. 2004; Fox and McSweeney 2006). Phospholipids can protect against stomach ulcers and adhesion of pathogenic gram-positive bacteria, such as Listeria monocytogenes, particularly by buttermilk-derived phospholipids in the latter case (Fox and McSweeney 2006). Sphingolipids are also noteworthy in the realms of antibacterial, anticancer, and hypocholesterolemic effects. SM holds the potential for significant anti-tumor effects (Rombaut and Dewettinck 2006). This occurs primarily through the ability of SM metabolites (ceramide and sphingosine) to induce cellular growth prohibition, differentiation, and apoptosis. Sphingolipids protect against infection by bacterial toxins and viruses by competitive binding to these invaders before they can bind to epithelial cells (Dewettinck et al. 2008).

In addition to the incredible roles of phospholipids in health promotion, these lipids possess a unique set of nutritional and technological functions. Nutritionally, these include brain and liver cell nourishment and reduction of blood lipid levels. Phosphatidylcholine (PC) also provides choline to the bloodstream, which is essential in the synthesis of acetylcholine, a crucial neurotransmitter for muscle function, memory, and other cognitive processes (Schmitt 2008). Some of the technological functions of 
phospholipids are demonstrated in lecithins, compounds naturally found in plant and animal foods. In lecithins and on their own, phospholipids are largely responsible for emulsification, stabilization, and foaming (Schmitt 2008). In food products, milk fat globule membrane (MFGM) isolates, which include phospholipids, may serve as good emulsifiers or fat replacers. For example, an emulsion mimicking cream can be formed by combining $2 \%$ MFGM material with $25 \%$ milk fat (Kanno 1989). Phospholipids can impart either prooxidant or antioxidant effects to foods, depending on the type, $\mathrm{pH}$, and water concentration. For instance, due to the inclusion of monounsaturated and polyunsaturated fatty acids, phospholipids can bind to metal ions, resulting in lipid oxidation, especially with the presence of heat (Fox and McSweeney 2006). However, the large assortment of phospholipids benefits outweighs the aforementioned negative effects by far. Because of the combined technological and nutritional benefits of phospholipids, they present excellent potential for use in functional foods (Schmitt 2008).

\subsubsection{Caseins and whey proteins}

Caseins and whey proteins are rich sources of bioactive peptides. Bovine milk consists of about $3.5 \%$ protein, of which approximately $80 \%$ is casein and $20 \%$ is whey proteins. Each of these proteins is classified into numerous subtypes, including $\alpha-, \beta-$, and $\kappa$-caseins, and many types of whey proteins. Some of the whey proteins include $\alpha$ lactalbumins and $\beta$-lactoglobulins (18\% and 48\%, respectively), immunoglobulins (12\%), and serum albumin (6\%) (Swaisgood 1993; Tremblay et al. 2003). These bioactives are found in both milk and colostrum, but they are much more concentrated in the latter (Korhonen 2009). Lactalbumins and lactoglobulins are the two major fractions of whey, and can be distinguished by their chemical behavior; the former are soluble in $50 \%$ 
saturated $\left(\mathrm{NH}_{4}\right)_{2} \mathrm{SO}_{4}$ or saturated $\mathrm{MgSO}_{4}$, while the latter come out of solution as salts under these conditions. The immunoglobulins are concentrated mainly in the lactoglobulin fraction, while serum albumins collect with the lactalbumins (Neyestani et al. 2003; Saito 2009).

During cheesemaking, milk proteins are separated into their respective types, with casein comprising the cheese curd, and whey proteins concentrated in the resulting liquid. This liquid, aptly named whey, can then be made into a variety of powder forms to concentrate and preserve the proteins, including whey protein concentrate (WPC) and whey protein isolate (WPI). If the physicochemical properties of whey proteins are well understood, these proteins can be applied in food product innovations due to their functionality in gelation, foaming, emulsification, stabilization, and water-holding (Ko and Kwak 2009). For instance, native $\alpha$-lactalbumin is a good emulsifier, and native $\beta$ lactoglobulin results in exceptional gelation and foaming (Korhonen et al. 1998).

Whey proteins are a high-quality protein due to their overall amino acid composition, and high level (26\%) of branched-chain amino acids (BCAAs). These amino acids, including leucine, isoleucine, and valine, are potent stimulators of protein synthesis and energy production in skeletal muscle tissue, and are only metabolized in the muscle. Leucine has also been found capable of increasing insulin secretion by adjusting the concentration of this hormone in the blood, and is also key in regulating the metabolism of amino acids and proteins (Ko and Kwak 2009). Whey proteins have also been shown beneficial in exercise performance and muscle recovery, satiety and weight control, stress relief, cognitive function, cancer prevention, and wound healing (Korhonen 2009). 
As part of the whole protein molecule the amino acid sequences comprising casein and whey peptides are inactive, but once released they possess significant value. Bioactive peptides are typically released from their precursor proteins by digestive enzyme hydrolysis, proteolysis by fermentative starter cultures or other microbes, or by some combination thereof. The most common of the digestive enzymes involved are pepsin, trypsin, and chymotrypsin. Starter cultures used in yogurt and cheese have been shown to liberate a variety of potent bioactive peptides (Korhonen 2009). Their functions consist of antimicrobial, antihypertensive (ACE-inhibitory), antithrombotic, antioxidative, anticytotoxic, probiotic, binding vitamins and minerals for improved absorption, hypocholesterolemic activity, and immune supportive effects (Ko and Kwak 2009; Park 2009). WPC has exhibited anticarcinogenic effects by providing amino acids that stimulate the production of glutathione, a natural cellular peptide that enhances immune activity (Ko and Kwak 2009).

\subsubsection{Immunoglobulins and colostrum}

Immunoglobulins (Ig) are a highly beneficial fraction of whey proteins. They are most highly concentrated in colostrum (70-80\% of total protein compared to $1-2 \%$ in milk) and carry out the functions of antibodies by providing passive immunity against pathogens (Korhonen et al. 2000). Each class of immunoglobulin shares a similar fundamental Y-shaped structure consisting of four chains, two heavy and two light, which are associated by disulfide bonds. These subtypes and their respective concentrations in milk are shown in Table 2.1 (Larson 1992; Hurley 2003). For comparison, the total concentration of immunoglobulins in colostrum ranges from 0.7 to $10 \mathrm{mg} / \mathrm{ml}$ within a few days of parturition, although initially it is much higher (Saito 
2009). The subtype $\mathrm{IgG}_{1}$ is the most abundant in bovine milk as well as colostrum, where it initially represents over 90\% of immunoglobulins (Hurley 2003).

Table 2.1: Immunoglobulin subtypes and concentrations in milk (Hurley 2003).

\begin{tabular}{|l|l|}
\hline Immunoglobulin class & Concentration in milk $(\mathrm{mg} / \mathrm{ml})$ \\
\hline Total Ig & $0.6-1.0$ \\
\hline $\mathrm{IgG}_{1}$ & 0.59 \\
\hline $\mathrm{IgG}_{2}$ & 0.20 \\
\hline $\mathrm{IgA}$ & 0.10 \\
\hline $\mathrm{IgM}$ & 0.05 \\
\hline
\end{tabular}

The functions of immunoglobulins include prevention of pathogen adhesion to epithelial cells and the prevention of pathogen survival, agglutination of bacteria, and neutralization of toxins and viruses (Korhonen 2009). Immunoglobulin G (IgG) holds the highest concentration of the subtypes in milk, is $150 \mathrm{kDa}$, and is well-studied. Bovine milk IgG activity has been shown to have comparable effects with human milk IgG in promoting immune function (Ko and Kwak 2009). Research about the efficacy of colostral immunoglobulins in disease prevention has shown promising results against infections in humans and animals, including those caused by rotavirus, Escherichia coli, Clostridium difficile, Candida albicans, and Helicobacter pylori (Korhonen 2009). One of the most important activities of milk $\operatorname{IgG}$ is the inhibition of enteropathogenic microbes from adhering to epithelial cells in the intestine (Ko and Kwak 2009). Retention of IgG bioactivity is of concern during digestion. Due to the acid $\mathrm{pH}$ of stomach fluids, immunoglobulin activity is reduced, and once the intestine is reached they are enzymatically dissociated into their main constituents. Fortunately, much of their bioactivity is retained in the upper digestive tract, and some inhibitory activity is still present in the intestine (Mehra et al. 2006). Encapsulation techniques can also improve retention of immunoglobulin bioactivity and survival (Kelly et al. 1997). 
Clinical trials have not shown negative effects from colostrum supplementation, though their regulatory status has not been established in many countries (Mehra et al. 2006).

As previously noted, bovine colostrum is an excellent source of highly beneficial immunoglobulins, especially IgG. Colostrum is a rich, complex source of many other bioactive proteins, as well as lactoferrin and lysozyme, and is produced in mammalian mothers just after birth. This remarkable product has numerous beneficial effects, including contributions to the immune system, growth factors, and tissue repair factors. It is also implicated in anti-viral (polio, influenza A, herpes simplex) and anti-bacterial effects (E. coli, salmonella, streptococcus), as well as wound healing and musculoskeletal repair (Uruakpa et al. 2002).

A number of commercial products exist that exploit the colostrum bioactives, particularly the immunoglobulins. Immunoglobulins are among the most heat-stable whey proteins, though this varies with the subtype (IgG being the most resistant) (Dominguez et al. 2001). Retention of their bioactivity post-processing is of concern, however, due to their potential denaturation and loss of associated beneficial functions. This seems to be dependent on the processing method. For instance, experiments on commercially-processed milk have shown that immunoglobulin concentrations and antigen-binding activities (assessed by ELISA and RID) are preserved with the use of batch pasteurization parameters $\left(63^{\circ} \mathrm{C}\right.$ for $\left.30 \mathrm{~min}\right)$, but significantly reduced $(25-40 \%)$ or completely lost with treatment by HTST $\left(72^{\circ} \mathrm{C}\right.$ for $\left.15 \mathrm{sec}\right)$ and UHT $\left(138^{\circ} \mathrm{C}\right.$ for $\left.4 \mathrm{sec}\right)$ pasteurization processes, respectively (Li-Chan et al. 1995). Other research suggests that immunoglobulin denaturation can be relatively low (1-14\%) in response to lab-scale HTST treatment (determined by RID) (Mainer et al. 1997). $\mathrm{pH}$ also directly impacts the 
survival and activity of immunoglobulins, and significant denaturation (31\%) has been reported when they are solubilized in phosphate buffer and heated at acid pH values (e.g. $\mathrm{pH}$ 4.5). However, this effect may be less severe when in the presence of milk or colostrum, likely due to inherent protection by milk proteins and salts (Dominguez et al. 2001). Chen et al. (2000) found that milk IgG could be significantly stabilized during heat processing when in the presence of $20 \%$ glycerol, $20 \%$ maltose, or $0.2 \%$ glutamic acid. The reasons for this protective effect are not certain, but may be related to increased hydrophobic interactions in the $\operatorname{IgG}$ (Chen et al. 2000). Microencapsulation methods may also improve IgG stability. Chen et al. (1999) found that multiple emulsions, such as water-in-oil-in-water (W/O/W), improved milk IgG stability by 21$56 \%$ against acid ( $\mathrm{pH} 2.0), 33-62 \%$ against alkali ( $\mathrm{pH} 12.0)$, and 35-82\% against various

proteases. A disadvantage of this process, however, was loss of 41-50\% of the IgG used to prepare the multiple emulsion.

\subsubsection{Other milk bioactives}

The activity of milk bioactives is quite impressive. Other noteworthy compounds include lactoferrin, lactoperoxidase, and glycomacropeptide. Lactoferrin is an ironbinding glycoprotein found in milk and colostrum, and is of major importance in conferring anticancer, anti-inflammatory, and extensive antimicrobial effects. It is suspected to be instrumental in innate immune function against pathogens, stimulation of antibody response, prevention of microbial adhesion to epithelial cells, and reduction of destructive attack by molecules such as free radicals (Korhonen 2009). 
Lactoperoxidase is another glycoprotein, and the chief enzyme in milk. It can generate oxidation products of thiocyanate ions that kill or prevent growth of both pathogenic and spoilage bacteria in milk.

Glycomacropeptide is a glycopeptide enzymatically derived from $\kappa$-casein, and is a major peptide found in the whey fraction from cheesemaking. Ample research has shown its value in improving immune responses, inactivating microbial toxins, improving blood pressure, and promoting the growth of bifidobacteria (Korhonen 2009).

\subsubsection{Bioactive delivery systems}

Nutrition has a significant impact on human health. It can either improve health by reducing disease prevalence or by contributing to quality of life, or it can diminish health in the same areas. Due to the wealth of nutrition and health research, as well as the current prevalence of lifestyle-related diseases, many new food products have been created to target human wellness. The main approach to this is the development of functional foods, which have gained considerable consumer interest over the last decade or so. These foods are defined as ones that can attribute specific health benefits, such as reduction of disease risk, above the capabilities of basic nutrients (Korhonen 2002; Park 2009). The trend toward using food as medicine has taken root, and products are now designed with multiple targets, including immune defense, digestive health, bone health, prevention of heart disease, weight management and loss, and physical performance. Commercial manufacture of functional foods requires attention to processing parameters to ensure retention of bioactivity, thus new methods have been developed for these applications. This includes non-thermal processes, supercritical fluid extraction, and membrane separation techniques (Korhonen 2002). 
Milk bioactives are important and growing inclusions of the numerous functional foods in the consumer marketplace. Dairy ingredients hold a significant place in this arena, especially due to the fact that in addition to being valuable carriers of bioactive compounds, dairy products are also good sources of major nutritional proteins. Commercial products already exist that are targeted at improving immune function and hypertension, as well as assisting in weight control and prevention of gastrointestinal infections (Korhonen 2009). In 2008, the Mintel Group reported that functional dairy food product sales increased by over 33\% between 2005 and 2007, to a value of $\$ 2$ billion, or $75 \%$ of overall sales for functional foods. As of 2008 , these sale volumes were expected to continue to increase substantially (Park 2009).

The trend toward high nutrient density foods can be seen by the use of dairy in products such as energy bars, yogurt drinks, and nutritional powders. Certain dairy ingredients prevail in providing concentrated and functional sources of bioactives for application in food products. Some of the best ones include buttermilk powder, colostrum, and whey protein concentrate (WPC) and isolate (WPI). Most of these represent high-nutrient value products that were previously treated as waste by-products from cheese and butter manufacturing. Through innovation, however, waste has become highly profitable. For instance, cheese whey is commonly made into WPC and WPI and exploited in countless food products, including nutrition bars and other sports nutritionrelated and processed foods. Lesser known perhaps, but with high functionality, is buttermilk, the side product of butter manufacture. When spray-dried into powder, buttermilk contains five times the amount of phospholipids as raw milk (on dry basis) (Rombaut et al. 2005), and provides exceptional emulsification properties, and protein 
fortification. Its addition to bakery mixes and baked goods is well-established, but it has great potential to enhance other food products as well (Morin et al. 2007).

Colostrum is an excellent source of a variety of bioactive proteins, immunoglobulins, and other constituents (Uruakpa et al. 2002). It can be pasteurized and either spray-dried or freeze-dried under conditions that retain bioactivity and made into a variety of dry powders. Numerous colostrum-rich nutritional and pharmaceutical products have been commercialized throughout the world, many of which are aimed at prevention or treatment of intestinal infections, and others for boosting the immune system or physical performance. Some examples of these products include GastrogardR ${ }^{\mathrm{TM}}$, an Australian pharmaceutical colostrum concentrate for prevention of rotavirus-induced diarrhea in children, and ImmuNOVA ${ }^{\mathrm{TM}}$, a Finnish drinkable colostrum product used in hospitals and by individuals as a nutrition supplement for intestinal problems or immune support. Some research suggests that powerful synergistic health effects could result from combinations of bovine immunoglobulins, probiotic lactic acid bacteria, lactoferrin, and growth factors (Mehra et al. 2006).

\subsection{Probiotics}

\subsubsection{Definition, background, \& characteristics}

Probiotics are living microorganisms that can greatly benefit human health when consumed in adequate amounts (FAO/WHO 2002). As far back as ancient times, milk products fermented by lactic acid bacteria were prescribed for ailments of the gastrointestinal tract and liver. In the early 1900s, microbiologist and Nobel Prize winner Elie Metchnikoff began to elucidate the mechanisms by which these bacteria confer health benefits, and promoted their ability to increase human longevity (Jelen and Lutz 
1998; Jin Baek and Lee 2009). Fermentation by lactic acid bacteria was believed to result in improved gastrointestinal function and nutrient absorption, as well as stimulation of the immune system and intestinal flora balance (Jin Baek and Lee 2009). More modern identification of lactic acid bacteria has resulted in the widespread production of foods such as yogurt, acidophilus milk, and kefir (Jelen and Lutz 1998).

LAB are gram-positive, coccus- or rod-shaped bacteria that ferment carbohydrates into lactic or acetic acid and carbon dioxide. They are typically facultative anaerobes, meaning that they can produce ATP energy in the presence of oxygen, but given anaerobic conditions they switch to fermentation. Their preferred growth temperature depends on the specific species and subtype, but the range is generally $35-38^{\circ} \mathrm{C}$, with $37^{\circ} \mathrm{C}$ optimal for many. The ideal $\mathrm{pH}$ values for growth are slightly acidic, for example, 5.5-6.0 for Lactobacillus acidophilus. LAB are represented by multiple bacterial genera, including Lactobacillus, Lactococcus, Streptococcus, and Bifidobacterium. Some common probiotic species of lactobacillus are L. acidophilus, L. reuteri, L. helveticus, and L. rhamnosus. Bifidobacteria have similar characteristics to lactobacilli, except that they are irregularly shaped rods and are their growth requirements are more strict. They are classified as obligate anaerobes because they die in the presence of oxygen, which also complicates their viability when added to food and nutritional products (Jin Baek and Lee 2009). Their pH growth range is from 4.5-8.5 (Anal and Singh 2007). Typical probiotic species are B. bifidum, B. infantis, and B. breve. Both genera of bacteria are resistant to bile and are common members of human intestinal microflora (Jin Baek and Lee 2009). 


\subsubsection{Probiotics in the human body}

Lactic acid bacteria (LAB) and bifidobacteria are among the most common types of probiotics, and are found frequently in fermented dairy products, human mucosa, and the natural environment (Jin Baek and Lee 2009). The human gastrointestinal (GI) tract is colonized by a complex community of microflora, including probiotics, and contains hundreds of bacterial species in staggering quantities of $10^{12} / \mathrm{g}$ in the colon, or $60 \%$ of fecal mass (Savage 1977; Simon and Gorbach 1984). The mucosa of the gastrointestinal tract provides an impressive $150-200 \mathrm{~m}^{2}$ to which bacteria can colonize, mainly due to the numerous folds, or villi, of the intestine. This is an incredibly large area compared to the $2 \mathrm{~m}^{2}$ of human skin surface (Waldeck 1990). Moreover, the GI tract is the largest immune organ in the body, and the site of production for $80 \%$ of the body's antibodies (Saavedra 2007). Because this is a major site of immune activity, it is understandable that the colonization of immune-supportive probiotic bacteria would have significant impact on this vital bodily system. However, a number of factors can negatively impact the variety and activity of microflora, including stress, diet, age, disease, and medications, such as antibiotics (Jin Baek and Lee 2009). Thus, consuming viable probiotics in sufficient quantities $\left(10^{6}-10^{7} \mathrm{cfu} / \mathrm{g}\right)$ offers great potential in maintaining and restoring the diversity of gut microflora and their extensive benefits (FAO/WHO 2001).

Probiotic growth and activity can be stimulated in the body by prebiotic substances, such as various oligosaccharides, inulin, and $\beta$-glucan. Prebiotics are indigestible in the stomach and small intestine, and are specifically utilized by certain bacteria in the colon. A growing number of prebiotics are produced commercially, and are derived from plant materials, such as chicory root, beans, and oats (Bomba et al. 
2002; Su et al. 2007). Inulin-type fructans are well-suited to fermentation by bifidobacteria, and can increase microbiota by as numbers as high as $0.5-1.0 \log _{10}$ (Kolida and Gibson 2007). Prebiotics can resolve challenges with probiotic colonization and survival, as well as impart health benefits. These include improved glucose tolerance, regulation of GI transit times, reduction in lipid absorption, and promotion of beneficial short-chain fatty acids (SCFA) by resident microbes (Roberfroid 1996). Due to the prevalence of antibiotic-misuse and bacterial resistance, as well as the demand for probiotic functional foods, research in the areas of probiotics, prebiotics, and combinations thereof has become very important (Jin Baek and Lee 2009).

The health benefits of probiotic bacteria are certainly outstanding. They do seem to be strain-specific rather than genus- or species-specific, and also enhanced by combinations of probiotics (Shah 2007). Nonetheless, health impacts include enhancement of immune system function and intestinal microflora balance, aid in serum cholesterol reduction and lactose metabolism, reduction of adhesion and colonization by pathogenic bacteria, and improvement of nutrient bioavailability. Other functions involve anticarcinogenic effects, antimicrobial activity, and improvement of intestinal inflammatory diseases. Certain species of bifidobacteria may also prevent the development of allergies (Jin Baek and Lee 2009).

During infancy, the predominant gut microflora are significantly impacted by whether breast milk or formula is consumed. Breast-fed babies' feces is mainly composed of beneficial lactobacilli, bifidobacteria, and staphylococci, while formulafeeding results in primarily coliforms, enterococci, and bacteriodes (Walker and Duffy 1998). Studies have shown that the impact of probiotics on infant immune system 
development has lifelong benefits, thus the choice of breast-feeding or probiotic formulas is critical (Ouwehand et al. 2002).

Probiotics play a major role in the prevention of diarrheal-related illnesses, as well as attributing relief to constipation and inflammatory bowel disease. Diarrheal illness is serious, especially in developing countries, where millions of children die each year due to diarrhea caused primarily by the imbalance of beneficial microflora with rotavirus and Clostridium difficile. As previously mentioned, antibiotics also negatively impact microflora, resulting in diarrhea in up to $25 \%$ of patients. In children, treatment with lactic acid bacterial probiotics such as Lactobacillus rhamnosus GG has been effective (Jin Baek and Lee 2009).

One of the means by which probiotic bacteria protect against invading enteropathogens is by inhibiting their growth. Some of their normal metabolic processes produce substances toxic to pathogens, including organic acids (e.g. acetic acid) and bacteriocins (Tamura 1983). The probiotic Lactobacillus reuteri produces an antimicrobial during glycerol metabolism called $\beta$-hydroxypropionaldehyde (Axelsson et al. 1989). This compound, also known as reuterin, is active against a range of bacteria, including strains causing foodborne illness such as Listeria monocytogenes and E. coli O157:H7 (Chung et al. 1989; El-Ziney and Debevere 1998). Probiotic deconjugation of bile salts also assists in inhibiting pathogen growth, as well as in the reduction of serum cholesterol by preventing its absorption (Jin Baek and Lee 2009).

Anticarcinogenic probiotic effects have also been suggested. Clinical trials have been inconclusive, however, probiotics may inhibit abnormal cell proliferation by 
reducing inflammation, improving immune activity, and binding dietary carcinogens (Geier et al. 2006).

Lactose intolerance is another important condition on which probiotics may exert a positive impact. This disorder is attributed to reduction of $\beta$-galactosidase (lactase) enzymes and/or by loss of small intestinal mucosa, both of which result in severe diarrhea, abdominal pain, flatulence, and bloating. $\beta$-galactosidase, which is produced by lactic acid bacteria, provides relief from lactose intolerance by catabolizing lactose into glucose and galactose (Jin Baek and Lee 2009).

Colonization of probiotic bacteria to epithelial cells in the intestine has been demonstrated to prevent the adherence of certain pathogens (Mukai et al. 2004). In one encouraging study, L. reuteri was successfully used to reduce the duration of rotavirusinduced diarrhea (Shornikova et al. 1997). Infants hospitalized for this condition were treated with a placebo or one of two quantities of L. reuteri. After 2 days of treatment, the diarrhea continued in just $48 \%$ of the subjects treated with large dose of L. reuteri $(\mathrm{p}=0.04 ; \mathrm{n}=21)$, compared to $80 \%$ persistence in the placebo group $(\mathrm{n}=25)$. This study exemplifies the potentially powerful benefits of probiotic bacteria in the treatment and prevention of disease.

\subsubsection{Adhesion mechanisms of probiotics}

It is well known that bacteria take up residence in multiple regions of the human body, especially the digestive tract. This includes both pathogenic and nonpathogenic species, such as Escherichia coli and Lactobacillus reuteri, respectively. One of the most important factors in pathogenic infection is the attachment of the offending microorganisms. Once these pathogens adhere to the intestinal epithelial cells, the 
processes of colonization, cellular damage, and disrupted cellular mechanisms can begin (Coconnier et al. 1993). These harmful effects can be prevented, however, by lactic acid bacteria. The mechanisms by which probiotic bacteria protect against pathogenic infections are not fully understood, but may include reduction in $\mathrm{pH}$, production of antimicrobial compounds such as organic acids and bacteriocins, stimulation of the immune system, and competition for binding sites and nutrients (Collins and Gibson 1999). In order for probiotics to exert beneficial effects, however, they must have suitable environmental conditions in the human body as well as the initial means of delivery and growth therein. By examining the means of probiotic binding as well as the components to which they bind, fundamental understanding can be gained for the optimal parameters needed for delivery of these valuable microorganisms.

Specific characteristics of the metabolism and physiology of lactobacilli determine their adaptation to the host intestinal environment and thus their contribution of probiotic benefits (Lebeer et al. 2008). Surface interactions between lactobacilli and intestinal cells occur initially via hydrophobic interactions from afar, and then by specific associations involving complementary binding sites once in close proximity (Deepika and Charalampopoulos 2010). The cell wall structure plays a key role in many of the proposed mechanisms for lactic acid bacterial binding, and includes binding receptor components such as proteins, carbohydrate chains, and enzymes that influence the interaction of the bacteria with its environment. Some of the possible methods of these interactions include hydrophobic or electrostatic interactions, passive forces, lipoteichoic acids in the cell wall, and other structural means such as lectin-coated appendages (Servin and Coconnier 2003). Another very important contributing structural attribute is the 
presence of cell surface proteins such as sortase-dependent proteins (SDPs) and S-layer proteins (Lebeer et al. 2008).

S-layer proteins consist of an outer shell of protein subunits arranged in a paracrystalline structure that covers much of the cell surface. The protein constituents of the S-layer are identical monomolecules that are generally small (40-200 kDa), have a strong tertiary structure, and are typically not glycosylated in lactobacilli (Lebeer et al. 2008; Deepika and Charalampopoulos 2010). S-layer proteins are likely a key mechanism of binding between bacteria and the intestinal mucosal layer (Deepika and Charalampopoulos 2010). They are present in both gram-positive and gram-negative bacteria, thus their contributions to structure and virulence are presumably essential to many bacteria. In fact, pathogen survival may be enhanced by a possible role of the Slayer in subjugating threats of phagocytosis and bactericidal attacks (Sleytr and Beveridge 1999). In some strains of lactobacilli, research has shown that removal of the S-layer greatly hinders bacterial adherence to other substances, which illustrates the importance of the S-layer in this area (Sillanpaa et al. 2000; Roos and Jonsson 2002; Frece et al. 2005). Cell surface hydrophobicity and charge are likely to be highly influential in determining bacterial adhesion to surfaces, and may be imparted by S-layer proteins. For example, in experiments with $L$. acidophilus and L. crispatus (both with natural S-layers), as well as a recombinant strain of $L$. casei (previously without an Slayer), the presence of S-layer proteins was found to significantly increase adhesion to hydrophobic, negatively charged hexadecane. This demonstrates the influential nature of cell surface hydrophobicity in Lactobacillus adhesion (van der Mei et al. 2003). 
Another significant element in the interaction of bacteria with the human intestinal tract is the presence of the glycoproteins called mucins. These are glycosylated cell surface proteins that are a major component of the intestinal mucosal layer protecting epithelial cells, and also provide an important binding medium for bacteria. Multiple strains of Lactobacillus and Bifidobacterium have been found to attach via interactions between carbohydrate moieties and the mucosal surface of the intestine, although the overall adhesion mechanisms are still not definite. Successful colonization of probiotic bacteria via binding to the mucosal layer is important because with increased residence time in an attached state, the bacteria are allowed more opportunity to infer positive health effects on the host (Kirjavainen et al. 1998). The ability of the bacteria to adhere to the intestine may be correlated to its effectiveness in the host. For example, in a study where people were treated with probiotics, their serum antibody titres were directly related to the adherence ability of the bacterial strain used for treatment (O'Halloran et al. 1997).

Lipids represent a significant component of the mucosal layer, some subtypes of which include glycolipids such as glycosphingolipids, neutral lipids, and phospholipids, the latter of which include mainly phosphatidylcholine, phosphatidylethanolamine, and sphingomyelin (Blomberg et al. 1995). Glycosphingolipids also function as specific binding sites for bacteria, viruses, and certain cellular receptors and enzymes, in addition to also having a place in bacterial cell membranes (Huwiler et al. 2000). These details illustrate the important role of lipid subtypes in the achievement of probiotic binding to surfaces. 
Several components of the milk fat globule membrane (MFGM) exhibit an affinity for bacterial cell surfaces, including mucins, phospholipids, proteins, glycophospholipids, and gangliosides (Deepika and Charalampopoulos 2010). While the means of adhesion of bacterial proteins and other cellular components to the intestinal mucosa have been fairly well examined, binding to lipids has been minimally studied. Both sources are embedded with a variety of membrane proteins, glycoproteins, carbohydrates, enzymes, and phospholipids. It is important to note that much research thus far has been on isolated MFGM, which likely limits the findings that could come from studies involving the intact, native membrane (Evers 2004). Nonetheless, because of the similarity in composition between the MFGM and intestinal epithelial cells, it is worth exploring the binding mechanisms of probiotic bacteria to the MFGM. Research in this area may provide insight as to why dairy foods serve as natural carriers of these bacteria, as well as why they may deserve greater merit for this position over other foods (Bachiero et al. 2007).

Phospholipids and sphingolipids, previously identified in this review as part of the intestinal mucosal layer, are a key component of the MFGM. Lipid-binding thus represents a noteworthy area of interest due to the practical application to probiotic bacteria incorporated into food matrices, such as milk and dairy products. Some studies have been completed concerning certain influential binding characteristics of bacteria and lipids. One such of these showed that greater bacterial binding to MFGM components is associated with the cell surface hydrophobicity (Brisson et al. 2010), although this is not always the case (Deepika and Charalampopoulos 2010). In another study measuring the binding affinity of lactic acid bacteria to various dairy lipids, two types of binding were 
found. Lactic acid bacteria exhibited definite binding to triglycerides (non-polar) and strain-specific, but even more significant binding to phospholipids (polar). The results of this study also display some of the influences of food processing on binding affinity, including increased binding in milk powders that have undergone supercritical fluid extraction (Bachiero et al. 2007). Other processing research has revealed that cooling milk results in a $20 \%$ reduction in phospholipids and heating it results in whey protein adsorption, aggregation of minor MFGM proteins, and enzyme denaturation (Ye et al. 2002). The results of the aforementioned studies, combined with future work in the elucidation of specific binding to phospholipids and other MFGM components, serve as practical contributors to the design of probiotic dairy foods with optimal health benefits.

As previously mentioned, it is important to note that experiments studying bacterial adhesion are subject to external factors that affect the physiological state of the bacteria. Many of the aforementioned surface properties of lactobacilli are influenced by the fermentation media, time, and conditions, as well as harvesting procedures, storage conditions, and the mode of delivery to the targeted location (Deepika and Charalampopoulos 2010). For instance, in the area of food structures, the interaction of probiotic bacteria with the food constituents can have an important impact on their viability and delivery to the body. Studies with whey protein products have shown that probiotic Lactobacillus rhamnosus GG exhibits improved survival when bound in a matrix of whey proteins, even in the hydrolyzed and denatured state. This environment proves protective against storage stresses such as heat and acid. Yogurt matrices also provide effective defense against bacterial losses during storage, likely due to the gelled 
network (Doherty et al. 2010). This study provides further reinforcement of the idea that dairy is an excellent natural mode of probiotic transport (Tannock 1999).

\subsubsection{Probiotic adhesion and disease prevention}

Numerous studies have demonstrated the effectiveness of probiotic bacteria in disease prevention. For instance, certain lactic acid bacteria have been shown helpful in

eliminating Staphylococcus aureus, an opportunistic pathogen responsible for a range of minor to severe infections of the skin, intestines, and blood. In one study, S. aureus was displaced from human intestinal tissue samples by $39-44 \%$ when in the presence of Lactobacillus rhamnosus GG, Lactococcus lactis subsp. lactis, and Propionibacterium freudenreichii subsp. shermanii JS. Lactobacillus reuteri ING1 reduced this pathogen's viability by $27 \%$ after 2 hours incubation, likely due to its production of antimicrobial reuterin (Vesterlund et al. 2006). These results show that treatment of infections with particular probiotic bacteria is a promising, natural and effective method. Furthermore, if probiotics could be used in this way instead of antibiotics, the intestinal flora would be augmented instead of destroyed, providing significant health benefits beyond the immediate treatment of infection.

Experiments involving binding between B. bifidum and L. reuteri (Mukai et al. 2004) have shown that protein-comprised entities of bacterial cell surfaces can attach to the carbohydrate portions of glycolipids in the intestinal tract. The affinity displayed by the bacteria for these glycolipids may be significant in establishing their residency in the intestine. Some probiotic bacteria also seem to share a specific carbohydrate binding manner with enteropathogenic bacteria, however the early presence of the probiotic bacteria may hinder colonization and thus infection by the pathogenic ones (Mukai et al. 
2004). For example, in one experiment (Mukai et al. 2002), Lactobacillus reuteri was used in a competitive binding assay with Helicobacter pylori, the bacterium associated with causing stomach ulcers. The two strains of $L$. reuteri in this assay effectively prevented binding of $H$. pylori by binding to the same glycolipid receptors for which they have an affinity. This is an exciting discovery, showing that certain strains of L. reuteri may prevent gastric infections with $H$. pylori.

\subsection{Techniques for analysis of bioactives}

\subsubsection{Bacterial binding}

Due to the abundance of research that has revealed some of the incredible health benefits of probiotic bacteria, it naturally follows that further research would be carried out to elucidate the actual mechanisms of their actions. Results from this could improve understanding of how to process and deliver these bacteria to the body for optimal benefits. Studies involving bacterial binding have been carried out in tissue cultures as well as other non-tissue surfaces. For instance, radioactive labeling of bacteria has been applied in assessing mucin binding. Tagging bacteria in this manner allows visualization

of adhesion to proteins or glycoproteins that are already attached to a surface (Tuomola et al. 2000). Other methods of bacterial labeling include biotinylation with subsequent colorimetric reactions with conjugated molecules such as avidin-HRP (Rojas and Conway 2001). Another possible means of evaluating binding is through Western blotting. This can be accomplished by first separating bacterial cell wall proteins by polyacrylamide gel electrophoresis (PAGE), then electrophoretically transferring them to a membrane such as polyvinylidene difluoride (PVDF). Radiolabeled mucin probes can 
then be incubated with the membrane and their subsequent illumination of specific protein bands can reveal binding affinities (Ryan et al. 2001).

Other techniques to measure bacterial binding include DNA quantification, confocal laser scanning microscopy (CLSM), and optical laser tweezers. For DNA quantification, the following protocol can be used. Bacteria are first allowed to incubate with various dairy products, then separated through a sucrose density gradient (SDG), after which the unbound bacteria layer is recovered and the DNA extracted and quantified. After using spectroscopy to determine the amount of unbound bacteria, a simple calculation can be used to find the remaining quantity of bacteria that theoretically bound to the dairy products. A second approach to evaluating binding is CLSM, which allows direct visualization of this interaction. The bacteria and dairy products are fluorescently labeled with different stains, then incubated together and visualized with confocal microscopy (Figure 2.3). In addition to providing an image of binding, this technique makes it possible to determine the binding location of the bacteria to the dairy product components. A final method utilized by this research group is optical laser tweezers. After incubating certain bacteria and dairy products together, they are visualized under an inverted microscope, upon which they are moved into a special optical trap where the milk fat globule is forced against the bacteria to induce binding. Once this occurs, the binding strength can be measured by a calculation resulting from the amount of force necessary to pull the bound complex apart using laser tweezers (Brisson et al. 2010). The aforementioned methods represent promising and varied approaches of measuring bacterial binding for future research as well. 


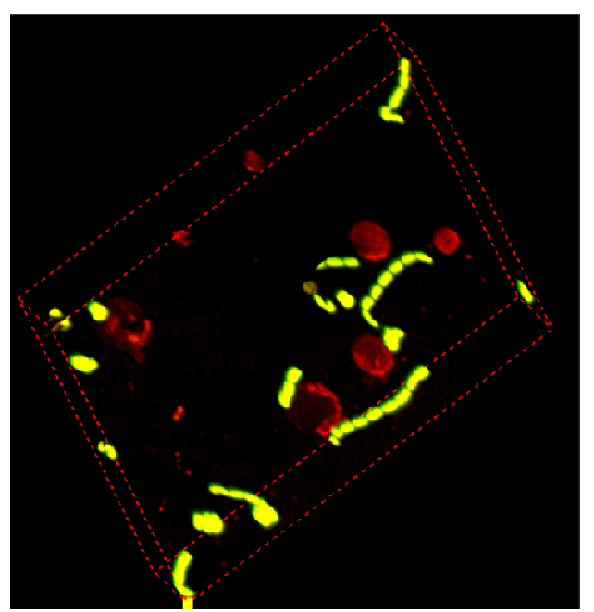

Figure 2.3: Bacterial binding with MFGM. Binding interaction between Lactobacillus acidophilus (NCFM slpA) (stained in green) and milk fat globules (stained in red). Imaging by confocal laser scanning microscopy (Brisson et al. 2010).

Another medium that has been used to evaluate bacterial binding is thin-layer chromatography (TLC). TLC has been used for this purpose by incubating biotinylated lactic acid bacteria with a TLC plate pre-bound with a glycolipid mixture. Upon developing the plate colorimetrically, densitometric analysis was performed to measure the binding specificity of bacteria for various glycolipids (Mukai et al. 2004). A variant of this method is TLC blotting. One research group used this to analyze binding of bacteria to glycosphingolipids. The lipids were first separated by TLC, then transferred to a PVDF membrane, which was allowed to incubate with radioactively-labeled Escherichia coli. Subsequent bioimaging showed binding to specific glycosphingolipids (Taki and Ishikawa 1997). Other researchers have applied TLC-blotting methods to immunological investigations, including quantification of antibody binding to cholesterol (Aniagolu et al. 1995), and binding of certain genes to gangliosides associated with brain tumors (Hamasaki et al. 1999). Disadvantages of TLC that have been reported include sloughing off of silica gel from the plate during treatments. However, advantages of TLC 
include its relative simplicity and short completion time, as well as the ability to easily separate mixtures of lipids and assess binding to each entity.

\subsubsection{Immunoglobulin quantification}

Several methods exist to quantify immunoglobulins (Gapper et al. 2007). Some of the immunochemical techniques include the enzyme-linked immunosorbent assay (ELISA) (Conesa et al. 2005), radial immunodiffusion (RID) (Elizondo-Salazar et al. 2010), and nephelometric immunoassay (Collin et al. 2002). ELISA techniques are extensively used for quantitative or qualitative detection of a variety of antigens. The design of the assay (direct, indirect, sandwich) varies with the order in which the antibodies and antigen are added to the microplate. For example, in the sandwich ELISA, anti-bovine IgG antibodies are bound to the microplate, then overlaid with samples and a secondary conjugated anti-bovine $\mathrm{IgG}$ antibody. The sample $\operatorname{IgG}$ is then detected and quantified by a colorimetric reaction produced by the conjugate and an enzyme (e.g. HRP and OPD, respectively). A standard curve allows interpolation of the sample $\operatorname{IgG}$ concentrations.

Another popular immunochemical technique is RID, a simple but time-consuming assay that entails application of IgG samples to wells of an agarose gel already containing antibodies to IgG. During incubation, the samples penetrate into the gel and form a precipitate with the antibodies that appears as a ring. The ring diameter is then used to calculate the IgG concentration based on results from IgG standards. This method is reported to have poor precision, however (Fleenor and Stott 1981). Nephelometry is a technique that measures the turbidity of the antigen-antibody complex formed in dilute colostrum or milk when anti-IgG1 is introduced to the solution. The increase in light 
scattering produced by this complex is proportional to the original concentration of IgG1 in the sample (Collin et al. 2002). An additional method that is very simplistic is hydrometry, which estimates immunoglobulin concentration by the specific gravity of the colostrum. This physical technique is not very accurate, however, and is generally limited to use in field settings (Fleenor and Stott 1980).

More sophisticated approaches also exist, such as an immunoassay read by direct biosensor surface-plasmon resonance (SPR). The sample containing the desired antigen is allowed to flow over a biosensor surface covered with a covalently attached ligand, such as an antibody specific to IgG. After a specified time period, the sample is removed from the surface. This method works by sensing changes in refractive index due to the binding occurring on the biosensor surface. Advantages of SPR are its high specificity and sensitivity for low concentrations of proteins. The data obtained has been found comparable with RID and nephelometric methods (Gapper et al. 2007).

Separation techniques, including various types of chromatography and electrophoresis, are also applied to the elucidation of immunoglobulin concentration and bioactivity, some of which include affinity chromatography and capillary electrophoresis. The immunochemical approaches, however, were the focus of this review due to the use of ELISA in the research that follows. The above-reviewed methods may be used in experimental research or to satisfy requirements presented by quality control, regulatory compliance, food safety, and clinical or nutritional studies. The selection of technique simply depends on the purpose of the data. SPR and ELISA remain among the most precise and sensitive methods, however, and ELISA the more prevalent of the two (Gapper et al. 2007). 


\subsubsection{HPLC analysis of phospholipids}

Phospholipids can be separated and quantified by a few different methods, including thin-layer chromatography (TLC) and High Pressure Liquid Chromatography (HPLC). TLC is a relatively fast, inexpensive method to separate lipids, though the densitometric quantification thereof is less precise than methods such as HPLC, thus it is mainly used for qualitative analysis. Many HPLC methods have been developed. One of the best thus far for both polar lipid separation and protection of column life is that developed by Rombaut et al. (2005). This protocol uses a silica column with elution buffer containing a gradient of chloroform, methanol, and formic acid-triethylamine at $\mathrm{pH}$ 3. Use of an evaporative light scattering detector (ELSD) with the HPLC system in this method results in excellent separation of polar and non-polar lipids from milk (Figure 2.4) (Rombaut and Dewettinck 2006). Once compared to chromatograms of lipid standards of known concentration, experimental lipid mixtures can be quantified. HPLC lends itself especially well to the production of phospholipid extracts for application in other experiments in order to further explore their nutritional and functional properties. 


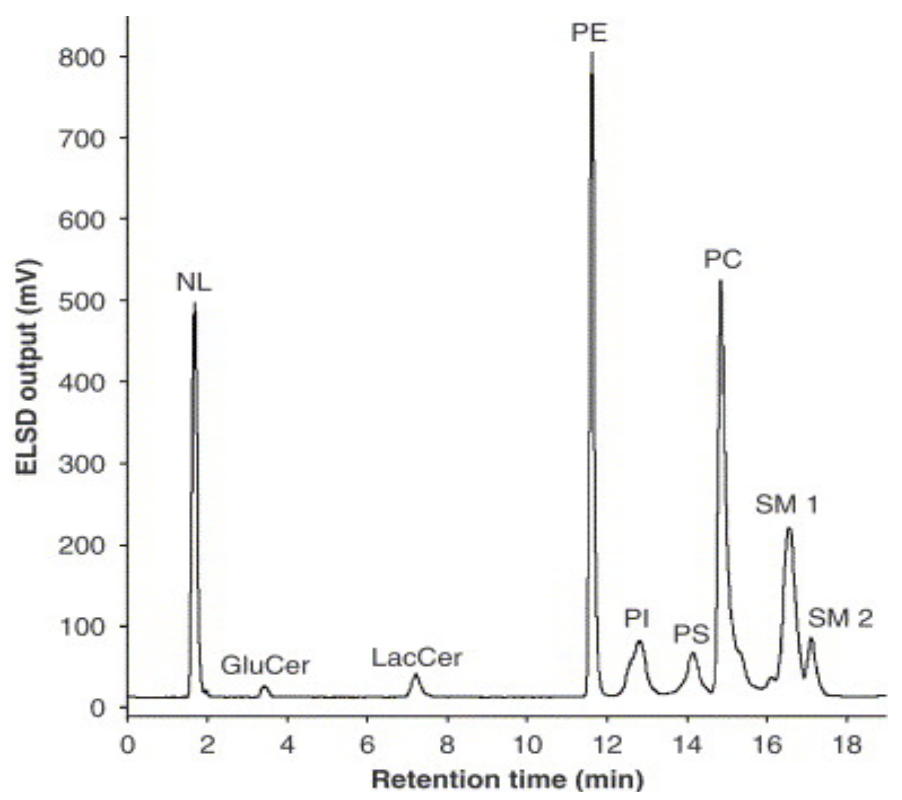

Figure 2.4: HPLC chromatogram of milk phospholipid extract. Shows separation of polar lipids by the method of Rombaut et al. (2005). NL= neutral lipids, GluCer: glucosylceramide; LacCer: lactosylceramide; PE; phosphatidylethanolamine; PI: phosphatidylinositol, PS; phosphatidylserine; PC; phosphatidylcholine and SM: sphingomyelin

\subsection{Justification for this work}

Given the abundance of studies showing the health benefits of probiotic bacteria, as well as the consumer demand for functional foods, it has become necessary to justify these effects with innovative research. Thus far, studies surrounding the topic of probiotic delivery to the human body have been largely insufficient. More definitive studies are needed regarding the interactions of probiotic bacteria with the various components of food matrices, including proteins, lipids, and carbohydrates. These discoveries could provide insight into ways to carry these interrelationships from the food product to the gastrointestinal tract in hopes of exceptional viability and inhabitation.

Due to the many studies that confirm the successful growth of probiotic bacteria in dairy products, it is logical to investigate their specific interactions with the assortment of elements in milk. Understanding the associations of probiotics in their preferred 
environment will likely provide important information that could be applied to the informed development of food delivery systems. This knowledge, coupled with that of colonization mechanisms in the human gastrointestinal tract, could result in great advances in the development of functional food products that would ensure optimal benefits to human health.

In this thesis, some of the highly bioactive components of dairy products were studied to elucidate interactions among them and to apply their dairy ingredient sources to the development of a bioactive-rich food product. Specifically, a novel technique was created that can measure the binding affinity of probiotic lactic acid bacteria for milk phospholipids. Previous research has been completed on the binding of probiotic bacteria to proteins (e.g. mucins), but very little has been conducted with their adhesion to lipids. The lipid-binding method resulting from this work could be used to generate a library of information about the binding capabilities of various probiotic bacteria with lipid sources from food. In addition to the designing the binding method, a dairy-based food product was developed as a means to deliver dairy bioactives such as immunoglobulins, phospholipids, whey proteins, and probiotic lactic acid bacteria. It serves as an illustration of the successful use of these dairy ingredients in creating a high-value product. As previously mentioned, the knowledge gained from bacterial binding studies could promote the development of highly bioactive functional foods, and serve to exploit the inherent health-enhancing properties of both probiotic bacteria and dairy products. 


\subsection{Materials and Methods}

\subsection{Development of a method to measure binding between lactic acid bacteria and}

\section{phospholipids}

\subsubsection{Creation of parent and working stocks of lactic acid bacteria}

Four strains of Lactobacillus were selected to be used in this research based on their probiotic properties (Table 3.1). To create parent and working stocks, frozen cultures from the DPTC library were minimally thawed and $30 \mu 1$ aliquots were inoculated into Man-Rogosa-Sharpe (MRS) broth (cat \#288130, Difco Laboratories, Sparks, MD) enriched with 0.05\% L-cysteine HCl (cat \#BP376-100, Fisher Sci.). Cultures were grown overnight (approx. 18 hours) in an incubator at $37^{\circ} \mathrm{C}$ with $9.0 \%$ $\mathrm{CO}_{2}$ (Isotemp incubator, Fisher Sci.). The next day, a heat-sterilized wire loop was used to streak each culture suspension in duplicate onto MRS $+0.05 \%$ cysteine agar plates, which were grown in an anaerobic chamber (BBL GasPak Plus, cat \#271040, BD, Sparks, MD) for 48 hours at $37^{\circ} \mathrm{C}$. Plates were assessed for purity by the consistency of the colony size, shape, and color. Then one or two colonies were selected, streaked heavily onto two fresh MRS agar plates, and grown at $37^{\circ} \mathrm{C}$ for 48 hours. Two $\mathrm{mL}$ of a sterile solution of $20 \%$ glycerol (cat \#G33-1, Fisher Sci.) in MRS broth $+0.05 \%$ cysteine was added to each plate and gently mixed into a solution with the bacterial colonies using a sterile plastic loop (cat \#22-363-597, Fisher Sci.). The suspension was pipetted into sterile $1.0 \mathrm{~mL}$ cryogenic vials (cat \#5000-0012, Nalge Co., Rochester, NY) and frozen at $-50^{\circ} \mathrm{C}$. One parent vial and two working vials were made for each strain. 
Table 3.1. Lactobacillus species and applications

\begin{tabular}{|l|l|l|}
\hline \multicolumn{1}{|c|}{ Common Name } & \multicolumn{1}{|c|}{ Scientific Name } & \multicolumn{1}{c|}{ Experiment(s) } \\
\hline NCFM & L. acidophilus & $\begin{array}{l}\text { Colorimetric \& fluorescent dots } \\
\text { TLC } \\
\text { Blotted membranes }\end{array}$ \\
\hline SD2112 & L. reuteri & $\begin{array}{l}\text { Colorimetric \& fluorescent dots } \\
\text { TLC } \\
\text { Blotted membranes }\end{array}$ \\
\hline T-1 & L. reuteri & $\begin{array}{l}\text { Fluorescent dots } \\
\text { Blotted membranes }\end{array}$ \\
\hline LC-10 & L. casei & $\begin{array}{l}\text { Colorimetric \& fluorescent dots } \\
\text { TLC }\end{array}$ \\
\hline $1063-\mathrm{S}$ & L. reuteri & $\begin{array}{l}\text { TLC } \\
\text { Blotted membranes }\end{array}$ \\
\hline 700396 & L. acidophilus & Blotted membranes \\
\hline 23272 & L. reuteri & Blotted membranes \\
\hline 33199 & L. gallinarum & Blotted membranes \\
\hline 53103 & L. rhamnosus & Blotted membranes \\
\hline
\end{tabular}

For later use in experiments, $30 \mu 1$ of minimally thawed frozen bacterial working stock was inoculated into $10 \mathrm{~mL}$ of MRS $+0.05 \%$ cysteine broth and allowed to grow overnight (approx. 18 hours) while rotating at $37^{\circ} \mathrm{C}$ and $9.0 \% \mathrm{CO}_{2}$. The next day, $100 \mu \mathrm{l}$ of freshly grown bacterial suspension was inoculated into $10 \mathrm{~mL}$ of new MRS $+0.05 \%$ cysteine broth and grown overnight as before. This subculture was stored at $4{ }^{\circ} \mathrm{C}$ and used as working stock for future research.

The growth of each strain of bacteria was studied during 18 hours to determine the optical density corresponding to mid-log phase, the stage at which the bacteria would be used for experiments. To complete this, $1 \mathrm{~mL}$ of working stock (subcultured twice from frozen stock) was inoculated into $100 \mathrm{~mL}$ of sterile MRS broth and incubated at $37^{\circ} \mathrm{C}$. Every $30-60$ minutes, each $100 \mathrm{~mL}$ flask containing bacteria was swirled gently to mix, then $2 \mathrm{~mL}$ was transferred to a $4.5 \mathrm{~mL}$ cuvette (PMMA, cat \#89047-230, VWR Intl, West Chester, PA), and the optical density was read at $600 \mathrm{~nm}$ using a spectrophotometer (SpectraMax Plus, Molecular Devices, Sunnyvale, CA). Based on this study, to make 
new culture for experiments, $100 \mu \mathrm{l}$ of working stock was added to $10 \mathrm{~mL}$ fresh MRS + $0.05 \%$ cysteine broth and grown at $37^{\circ} \mathrm{C}$ to the same OD at $600 \mathrm{~nm}$, which was approximately 7 hours for mid-log phase.

\subsubsection{Blotted membrane trials}

The first experiments to assess bacterial binding to phospholipids involved blotted membranes. A working stock of each strain of lactic acid bacteria (Table 3.1) was made by inoculating $100 \mu \mathrm{l}$ of DPTC library working stocks (in use by Guillaume Brisson) into $10 \mathrm{~mL}$ fresh MRS $+0.05 \%$ cysteine broth. Bacterial growth phases had not yet been studied, so cultures were grown overnight (about 18 hours) at $37^{\circ} \mathrm{C}$, then stored at $4^{\circ} \mathrm{C}$. For experimentation, cultures were made by inoculating $100 \mu 1$ of the refrigerated working stock into $10 \mathrm{~mL} \mathrm{MRS} \mathrm{broth} \mathrm{and} \mathrm{incubating} \mathrm{at} 37^{\circ} \mathrm{C}$ for about 18 hours. The bacteria were centrifuged at 3200xg for 5 minutes to form pellets (Eppendorf 5810R), then reconstituted in $10 \mathrm{~mL}$ of $1 \mathrm{x}$ phosphate buffered saline (PBS) buffer $\mathrm{pH} 7.2$ (Appendix G), and washed 3 times by centrifugation. Bacteria were diluted to $\mathrm{OD}_{600 \mathrm{~nm}}=$ $1.0 \pm 0.1$, then biotinylated as follows. For each strain dilution, $250 \mu 1$ was transferred into $1.5 \mathrm{~mL}$ eppendorf tubes (cat \#02-406-16, Fisher Sci.), and to each tube $50 \mu 1$ of 10 $\mathrm{mM}$ biotin solution (4.4 $\mathrm{mg}$ in $1 \mathrm{~mL}$ deionized water) (EZ-Link Sulfo-NHS Biotin, cat \#21217, lot \#IH112737, Pierce, Rockford, IL) and $50 \mu$ l of $700 \mathrm{mM} \alpha$-lactose (in deionized water) (cat \#L5-500, Fisher Sci.) was added. Solutions were incubated at room temperature for 1 hour, then centrifuged at 3200x $g$ for 5 minutes. Resuspended pellets were washed twice in 1x PBS pH 7.2 to remove unbound biotin, and centrifuged at 3200x $\mathrm{g}$ for 5 minutes between washes. Washed pellets were resuspended in $1 \mathrm{~mL} \mathrm{PBS.}$ 
Strips of polyvinylidene difluoride (PVDF) $(0.2 \mu \mathrm{m}$ pore, cat \#1620184, lot \#BR8183044, BioRad, Hercules, CA) and nitrocellulose (NC) membranes $(0.45 \mu \mathrm{m}$ pore, cat \#88014, lot \#DD71802, Pierce, Rockford, IL) were cut to $2 \times 8 \mathrm{~cm}$ and soaked in $70 \%$ isopropanol for 30 minutes. They were dried between sheets of filter paper (size \#1, cat \#1001917, Whatman, NJ), then blotted with $3 \mu 1$ of phospholipid standards (PC, PE, PI, PS, SM) (Table 3.2) at $0.4 \mathrm{mg} / \mathrm{ml}$ in 2:1 $\mathrm{CHCl}_{3}: \mathrm{MeOH}$ (cat \#C606-4 \& \#A452-4, Fisher Sci.), and allowed to dry for 20 minutes. Strips were blocked in a solution of 1.5\% porcine gelatin (cat \#G8-500, lot \#954220A, Fisher Sci.) for 20 minutes at room temperature, then washed 3 times in $1 x$ PBS pH 7.2. Each tube of washed, biotinylated bacteria ( $1 \mathrm{~mL}$, from above) was added to $15 \mathrm{~mL}$ of $1 \mathrm{x}$ PBS $\mathrm{pH} 7.2$ in a $50 \mathrm{~mL}$ falcon tube, and to each tube one dried, phospholipid-blotted membrane strip was added. Tubes were incubated overnight (about 18 hours) in an incubator at $37^{\circ} \mathrm{C}$ while gently shaking.

The next day, strips were washed 3 times in 1x PBS pH 7.2, then divided between two small tupperware containers according to the type of bacteria. They were separated in case of cross-contamination from unbound bacteria as well as to ensure that the strip surfaces were fully covered and not prevented from streptavidin attachment due to sticking together. Each tub of two strips was incubated with $15 \mu$ streptavidin-HRP (1mg/mL stock, cat \#31001, lot \#HG105020, Pierce, Rockford, IL) and $30 \mathrm{~mL} 1 \mathrm{x}$ PBS pH 7.2 (1/2000 dilution) for 2 hours at room temperature while gently shaking. Strips were washed 3 times as before, then divided among four small tupperware containers. This allowed the strips to be fully covered by the next treatment, rather than sticking together. A $0.6 \mathrm{mg} / \mathrm{ml}$ color-developing solution was made of $36 \mathrm{mg} \mathrm{3,3'-}$ diaminobenzidine tetrahydrochloride (DAB) (cat \#D5637, lot \#027K37251, Sigma- 
Aldrich), $75 \mu 1$ hydrogen peroxide (30\% w/w, cat \#H1009, Sigma-Aldrich), and $60 \mathrm{~mL}$ 1x PBS pH 7.2, and divided among the strips. While agitating, strips were allowed to react for 5 minutes with the $\mathrm{DAB}$ solution, then rinsed once in DI water and dried between filter paper. The process for this procedure can be seen visually in Figure 3.1. Strips were not quantitatively studied due to lack of proper equipment (e.g. a densitometer). The results were visually inconsistent among trials, and the reproducibility of the method seemed low.

Similar trials to the above were also done with fluorescent streptavidin $(1 \mathrm{mg} / \mathrm{mL}$ stock, AlexaFluor488, cat \#S11249, lot \#449352, Invitrogen) in substitution for HRPconjugated streptavidin. This protocol used the same 1/2000 dilution of streptavidin in PBS, but once added to the strips, they were protected from light by aluminum foil, and analysis was attempted using a GelDoc (BioRad, Hercules, CA), although not the ideal piece of equipment (e.g. densitometer). However, quantitative analysis was still inconsistent among trials and questionable, and visual results were inconsistent. 
A

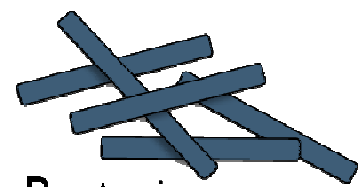

Bacteria

Grown $37^{\circ} \mathrm{C}$, overnight

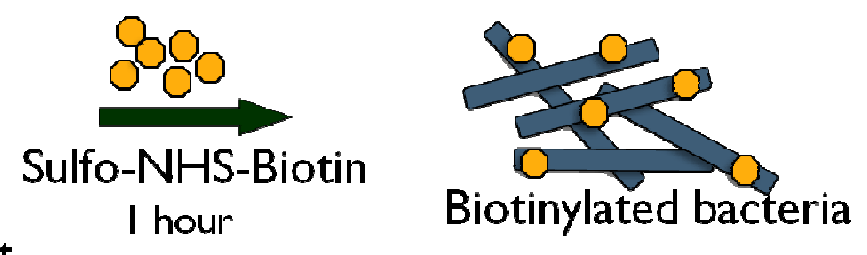

Washed in PBS

B

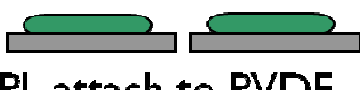

PL attach to PVDF membrane; blocking in $1.5 \%$ gelatin

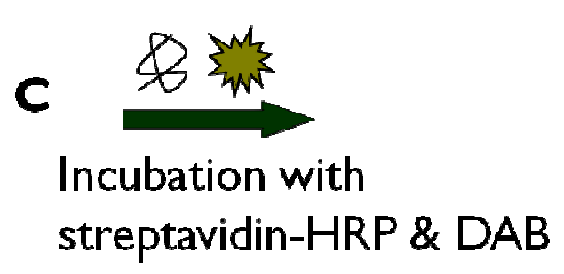

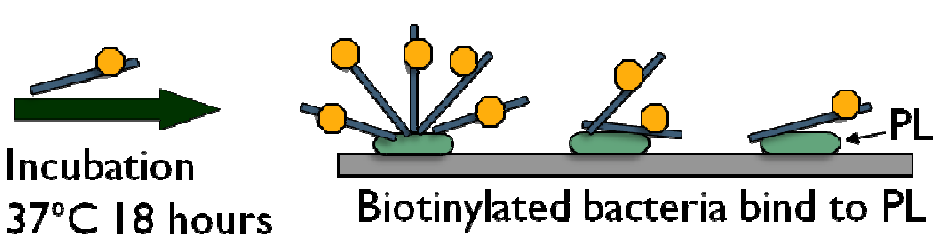

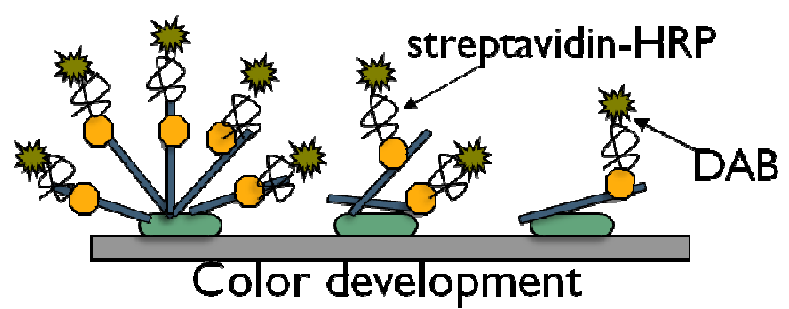

Figure 3.1. Illustration of blotted membrane method. Summary of method that shows (A) preparation of biotinylated bacteria, (B) attachment of the bacteria to the phospholipid-coated PVDF membrane, and (C) color development to reveal binding.

Table 3.2. Phospholipid types and applications

\begin{tabular}{|l|l|l|l|}
\hline Phospholipid name & Source & Company & Experiment(s) \\
\hline Phosphatidylcholine (PC) & Egg yolk & Sigma (P3556) & All \\
\hline Phosphatidylethanolamine (PE) & Egg yolk & Sigma (P7943) & $\begin{array}{l}\text { Blotted membranes } \\
\text { Colorimetric dots } \\
\text { TLC }\end{array}$ \\
\hline Phosphatidylinositol (PI) & Bovine brain & Sigma (P9763) & $\begin{array}{l}\text { Blotted membranes } \\
\text { Colorimetric dots } \\
\text { TLC }\end{array}$ \\
\hline Phosphatidylserine (PS) & Bovine brain & Sigma (P7769) & $\begin{array}{l}\text { Blotted membranes } \\
\text { Colorimetric dots } \\
\text { TLC }\end{array}$ \\
\hline Sphingomyelin (SM) & Bovine brain & Sigma (S7004) & All \\
\hline $\begin{array}{l}\text { Phospholipid concentrate 700 } \\
\text { Cyper FP11 (PL mix) }\end{array}$ & Milk extract & $\begin{array}{l}\text { Fonterra Ltd. } \\
\text { Edgecumbe } \\
\text { (reg \#4182) }\end{array}$ & $\begin{array}{l}\text { Colorimetric dots } \\
\text { Fluorescent dots }\end{array}$ \\
\hline
\end{tabular}




\subsubsection{Thin-layer chromatography (TLC) trials}

This method was adapted from thesis experiments by Dee Bachiero (Bachiero et al. 2007), and based on her results, seemed to be a promising alternative to the blotted membrane method. The procedure can be visualized in Figure 3.2. A glass thin-layer chromatography tank (Kontes Glass Co., NJ) was lined with filter paper (size \#1, cat \#1001917, Whatman, NJ) around the sides, and a mixture of solvents was added to the tank (65:25:4 mL chloroform:methanol:water; cat \#C606-4, cat \# A45204, Fisher Sci.). The solvents were allowed to travel up the filter paper for 20 minutes. Meanwhile $12 \mu 1$ of each phospholipid standard (each at equimolar concentrations of $5 \times 10^{-9} \mathrm{M}$ ) (Table 3.2) was applied with a capillary tube equidistantly along a line $3 \mathrm{~cm}$ from the bottom of a

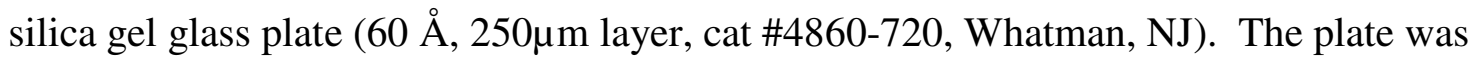
allowed to dry for 10 minutes, placed in the tank, and allowed to sit until the solvents traveled to $1 \mathrm{~cm}$ from the top of the plate. The plate was removed from the tank and allowed to dry in a vacuum oven at $80^{\circ} \mathrm{C}$ for 10 minutes. The method used to prepare the plates for bacterial binding was adapted from Mukai (2004). To fix lipids to the plate, it was dipped in hexane (cat \#H302, Fisher Sci.) for 1 minute, and then a polymer coating for 1 minute. The coating solution was made by preparing a $10 \%(\mathrm{w} / \mathrm{v})$ solution of poly(isobutyl methacrylate) (PIBM, cat \#181544, Sigma-Aldrich) in chloroform, then diluting this $1 / 100$ in hexane for a $1 \mathrm{mg} / \mathrm{ml}$ stock, which was diluted 1/10 with hexane just before use. The plate was blocked in 1\% fish gelatin (cat \#G7041, Sigma-Aldrich) in PBS for 2 hours, washed 3 times in PBS, then incubated overnight with $2 \mathrm{~mL}$ biotinylated bacteria $\left(\right.$ at $\left.\mathrm{OD}_{600 \mathrm{~nm}}=2.0\right)($ Table 3.1$)$ in fresh $1 \%$ fish gelatin in PBS 
(bacterial preparation same as in blotted membrane trials). The plate was incubated overnight (approximately 18 hours) at $37^{\circ} \mathrm{C}$ and $9 \% \mathrm{CO}_{2}$.

The next day, the plate was incubated with a 1/2000 dilution of neutravidin-HRP (1 mg/ml stock, cat \#31001, lot \#HG105020, Pierce, Rockford, IL) in PBS for 2 hours, then washed and developed with DAB. DAB developer was made as in blotted membrane trials, using $36 \mathrm{mg}$ DAB, $75 \mu 130 \%$ hydrogen peroxide, and $60 \mathrm{~mL}$ 1x PBS $\mathrm{pH}$ 7.2. The plate was allowed to react for 5 minutes with the DAB solution, then washed once in PBS and allowed to dry overnight. The dried plate was analyzed with the GelDoc. However, the method was not conducive to good reproducibility (e.g. silica sloughed off of random parts of the plates), and its ability to measure binding differences did not meet the desired consistency and seemed questionable.

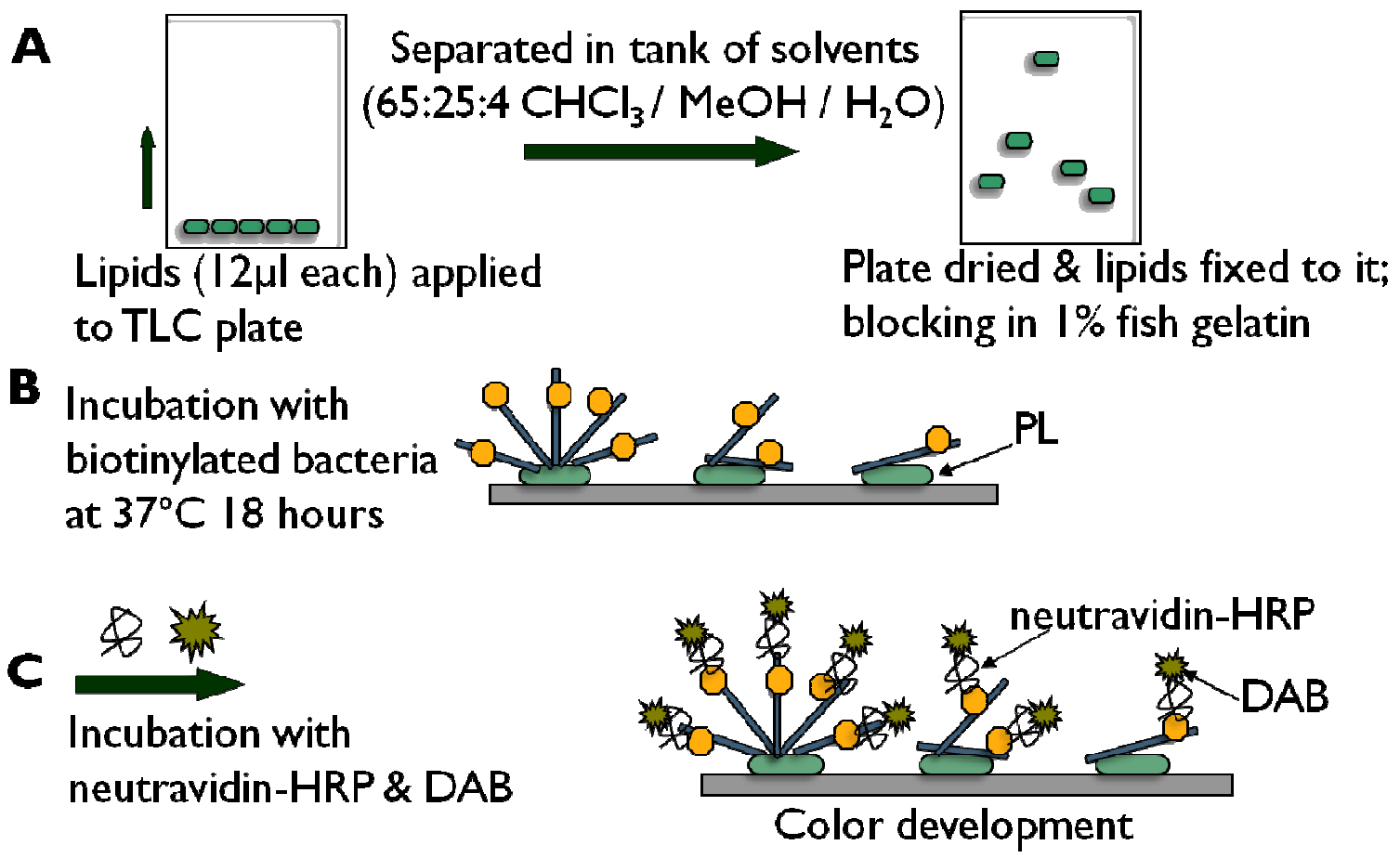

Figure 3.2. Illustration of TLC method. Summary of method that shows (A) lipid separation on TLC plate, (B) attachment of biotinylated bacteria to the phospholipidcoated TLC plate, and (C) color development to show binding. 


\subsubsection{HPLC analysis of phospholipids}

For subsequent binding trials, a phospholipid mixture (PL mix) derived from milk was used (Table 3.2). Analysis of the PL mix was carried out to verify its composition. The phospholipid separation was performed by high performance liquid chromatography (HPLC; Hitachi HPLC System D-7000) combined with a charged aerosol detector (CAD) (Dionex) according to the methodology described by Rombaut et al. (2005). Nitrogen was used as a carrier gas at a backpressure of 2.4 bar. A $150 \mathrm{~mm}$ x $3.0 \mathrm{~mm}$ Prevail $^{\mathrm{TM}}$ silica column with a $3 \mu \mathrm{m}$ particle diameter (cat \#99341, Grace Davison) was used. A precolumn with the same packing, a length of $7.5 \mathrm{~mm}$, a $3.0 \mathrm{~mm}$ internal diameter, and 5 $\mu \mathrm{m}$ particle diameter was also used (cat \#99354, Grace Davison). The samples and the column were equilibrated at $40^{\circ} \mathrm{C}$, and the flow was maintained at $0.5 \mathrm{~mL} / \mathrm{min}$. The injections consisted of volume was $20 \mu \mathrm{l}$ and the injection loop was rinsed with chloroform/methanol $(2: 1 \mathrm{v} / \mathrm{v})$ between injections. The phospholipid standards analyzed were phosphatidylcholine, phosphatidylethanolamine, phosphatidylinositol, phosphatidylserine, and sphingomyelin (Table 3.2) (Sigma-Aldrich). The PL mix sample was diluted to $0.75 \mathrm{mg} / \mathrm{ml}$ in $2: 1$ chloroform/methanol. The phospholipid elution was performed with a linear gradient and 87.5: 12: $0.5(\mathrm{v} / \mathrm{v} / \mathrm{v})$ chloroform/methanol/triethylamine(TEA) buffer $(\mathrm{pH} 3.0,1 \mathrm{M}$ formic acid) at $\mathrm{t}=0$ minutes (ACS grade TEA, all others HPLC grade, Fisher Sci.). At $t=16$ minutes, the mobile phase was $100 \%$ eluent B (28: 60: 12, v/v/v). The mobile phase was brought back to $100 \%$ eluent $\mathrm{A}$ at $\mathrm{t}=17$ minutes, and the column was equilibrated until the next injection at 28 minutes. Samples and standards were run in triplicate, and the collected data was analyzed using PowerChrom (eDAQ) and Excel 2007. 


\subsubsection{Colorimetric dot trials}

After concluding that TLC was not a reliable method for assessing bacterial binding, a modification of the blotted membrane trials was made utilizing dots. A summary of the method is illustrated in Figure 3.3. A standard hole punch was used to create equally sized circles of polyvinylidene difluoride membrane (PVDF) $(0.2 \mu \mathrm{m}$ pore, cat \#1620184, lot \#BR8183044, BioRad, Hercules, CA) as a medium for binding. Dots were placed in $0.6 \mathrm{~mL}$ eppendorf tubes, and to each tube $100 \mu \mathrm{l}$ of phospholipid standards or phospholipid mix at $2.5 \mathrm{mg} / \mathrm{ml}$ was added and allowed to incubate for 45 minutes. Samples included PC, PE, PI, PS, SM, and PL mix (Table 3.2), and the diluent, 2:1 chloroform:methanol, was used as a control. Various levels of phospholipid were evaluated, ranging from 0.15 to $2.5 \mathrm{mg} / \mathrm{ml}$, and $2.5 \mathrm{mg} / \mathrm{ml}$ produced the most even color on the circles. Phospholipids were removed by pipeting, then dots were vacufuged for 10 minutes. After initial trials showing high background color on control dots, a blocking step was added consisting of submersion of each dot in $100 \mu 11 \%$ fish gelatin in PBS for 1 hour. Dots were then washed 3 times in $100 \mu$ PBS. Lactic acid bacteria (Table 3.1) were washed and biotinylated by the same method as in blotted membrane trials, and $100 \mu \mathrm{l}$ was added to each tube $\left(\mathrm{OD}_{600 \mathrm{~nm}}=2.0\right)$. Dots were incubated overnight (approximately 18 hours) at $37^{\circ} \mathrm{C}$.

The next day, dots were washed 3 times in PBS, then incubated for 1 hour with $100 \mu 1$ of $1 / 2000$ neutravidin-HRP ( $1 \mathrm{mg} / \mathrm{ml}$ stock) in PBS. The dots were washed 3 times in PBS, and then DAB color-developing solution was added and allowed to incubate for 15 minutes. DAB developer $(0.6 \mathrm{mg} / \mathrm{ml})$ was made as in blotted membrane trials, but using $8 \mathrm{mg} \mathrm{DAB}, 17 \mu 130 \%$ hydrogen peroxide, and $11 \mathrm{~mL} 1 \mathrm{x}$ PBS pH 7.2. 
After incubation, the dots were rinsed with PBS, then dried between filter paper and affixed to fresh filter paper with clear tape. Similar to the blotted membrane method, quantitative analysis was not performed because a densitometer was not available, and the results were visually inconsistent anyway, so the method was abandoned.

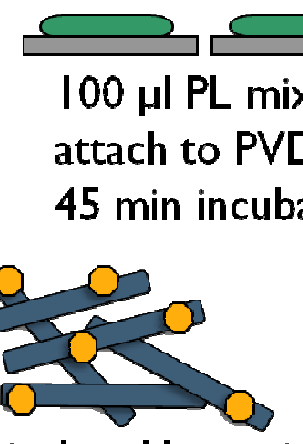

Biotinylated bacteria

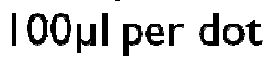

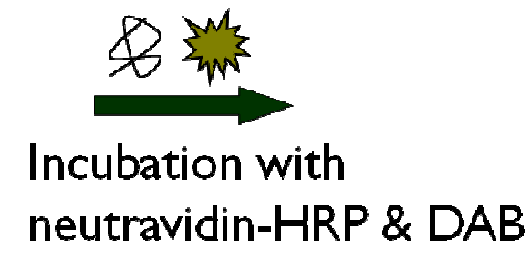

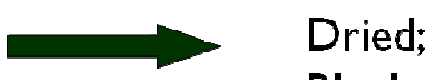

Blocked in $1 \%$ fish gelatin I hour
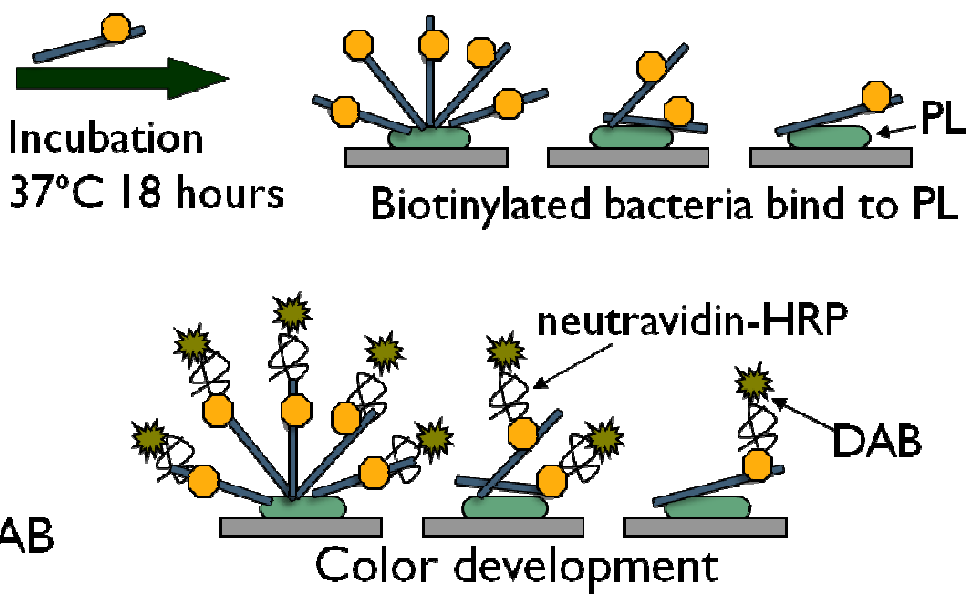

Figure 3.3. Illustration of colorimetric dot method. Summary showing (A) preparation of phospholipid-coated PVDF dots, attachment of biotinylated bacteria to the phospholipid-coated dots, and (C) color development to show binding. 


\subsubsection{Fluorescent dot trials}

Upon the conclusion that a colorimetric method was not feasible for assessing bacterial binding, a modified method using fluorescence was created (also illustrated in Figure 3.4). Dots of Immobilon PVDF transfer membrane $(0.45 \mu \mathrm{m}$ pore, cat \#IPVH00010, lot \#K7PN6216A, Millipore, Bedford, MA) were again made with a standard hole punch, then placed in $0.6 \mathrm{~mL}$ eppendorf tubes. To each tube, $100 \mu \mathrm{l}$ of phospholipid (PL) standards (PC \& SM) and a PL mixture (from milk), all at $12 \mathrm{mg} / \mathrm{ml}$, was added (Table 3.2). $\mathrm{CHCl}_{3} / \mathrm{MeOH}(2: 1)$ was included as a negative control, and canola oil (also at $12 \mathrm{mg} / \mathrm{ml}$ dissolved in the control solvents) was added to compare binding to triglycerides. Preliminary trials included testing a range of ten PL concentrations from $0.75 \mathrm{mg} / \mathrm{ml}$ to $12 \mathrm{mg} / \mathrm{ml}$, and $12 \mathrm{mg} / \mathrm{ml}$ resulted in the most complete coverage of the membrane. Dots were incubated for 10 minutes, then lipids were removed by pipetting and the tubes were vacufuged for 10 minutes to dry (Eppendorf vacufuge). Lactic acid bacteria (Table 3.1) were grown at $37^{\circ} \mathrm{C}$ (with rotation) to their respective optical densities $(600 \mathrm{~nm})$ for mid-log phase (approximately 7 hours) (LC10: 1.463, NCFM: 0.975, SD2112: 1.696, T-1: 1.743) (Appendix A). They were then washed in $0.05 \mathrm{M}$ Tris $\mathrm{pH} 7.2$ and diluted to $\mathrm{OD}_{600 \mathrm{~nm}}=1.0$. One $\mathrm{mL}$ of each strain was incubated for 5 minutes with $1 \mu$ acridine orange (stock at $10 \mathrm{mg} / \mathrm{mL}$, cat \#A8097, lot \#117K1207, Sigma-Aldrich) while protected from light. Bacteria were centrifuged at 960x $g$ for 6 minutes to pellet, and then the pellets were reconstituted and washed twice in $1 \mathrm{~mL} 0.05 \mathrm{M}$ Tris $\mathrm{pH}$ 7.2. To each dry PL dot, $100 \mu \mathrm{l}$ of prepared bacteria was added and dots were allowed to incubate for 20 minutes in the dark. Initial experiments included comparison of binding with four levels of bacteria, consisting of 
dilutions of $25 \%, 50 \%$, and $75 \%$ of the final one used. The highest dilution resulted in the most even binding, thus was used for future experiments. To assess non-specific fluorescing of the stained bacteria and each of the lipids and control, dots were also made after incubation solely with each of these. After exposure to the fluorescent bacteria, dots were rinsed in $0.05 \mathrm{M}$ Tris $\mathrm{pH} 7.2$, dried between filter paper, then affixed with clear tape to a glass plate and covered with foil. Each combination of PL and bacterial strain was tested in duplicate and repeated for four trials. The fluorescence was analyzed with the Typhoon Trio $^{+}$variable mode imager (serial \#98115, Amersham Biosciences).

The Typhoon was allowed to warm up for 5 minutes, and the following scanning parameters were selected: fluorescence acquisition mode, 526 SP Fluorescein Cy2 AlexaFluor488 emission filter, 200 PMT, blue 488 laser, normal sensitivity, 100 pixels, platen focal plane, and ImageQuant analysis. The glass plate with dots attached was placed face down on the scanner. Once scanning was complete, the file was saved in ImageQuant (Amersham Biosciences), and then FluorSep (Amersham Biosciences) was used to produce images showing the fluorescence. The scan was then analyzed by ImageQuant TL (v. 2005) and the array analysis feature was used to measure the fluorescence intensity of circles (size 15 units radius) within each dot. Raw data was then exported to Excel 2007 (Microsoft) for graphing and analyzed statistically in Minitab 16 by Analysis of Variance General Linear Model and Tukey's test. 
A

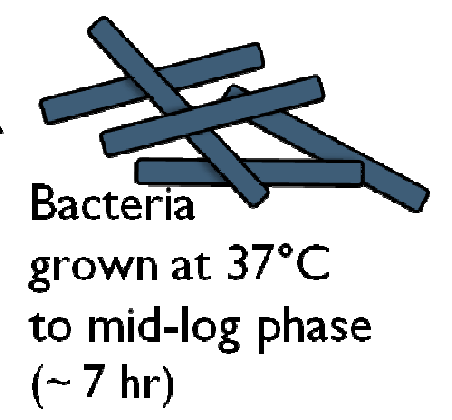

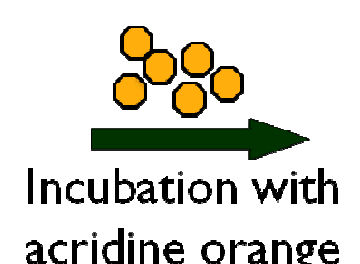

acridine orange

(5 min)

B

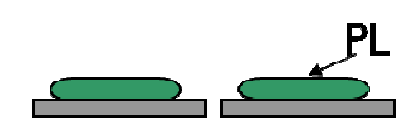

PL attach to PVDF (10 min); then dried

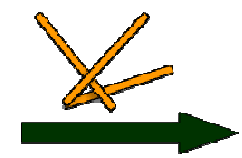

Incubation with stained bacteria (20 min)

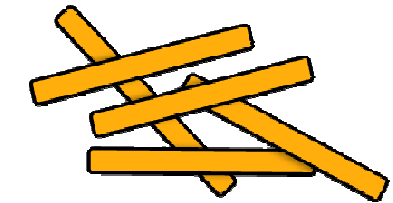

Stained bacteria

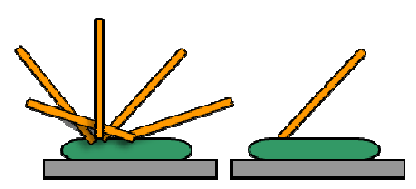

Binding of bacteria to $\mathrm{PL}$

Figure 3.4. Illustration of fluorescent dot method. Summary of method showing (A) preparation of fluorescently-stained bacteria, and (B) attachment of the bacteria to the phospholipid-coated PVDF dots.

\subsection{Development and analysis of a dairy-based, bioactive-rich gel}

\subsubsection{Formulation}

A dairy-based gel was formulated as an additional experiment to demonstrate the successful application of dairy ingredients in creating a highly nutritious food product. Included in this formulation were ingredients containing some of the aforementioned bioactives found in dairy products, such as phospholipids, immunoglobulins, and probiotic bacteria. Other highly nutritious dairy ingredients were also integrated, including whey proteins. The formulation was as follows: whey protein isolate (WPI), water, buttermilk powder (BMP), raw colostrum, sugar, agave nectar, modified food starch, and lactic acid bacteria (Table 3.3). To create the gel, the WPI was dissolved in water by allowing it to stir on a hot plate at $60^{\circ} \mathrm{C}$ for 1 hour. The BMP was dissolved in the raw colostrum by the same method. The colostrum/BMP and the remaining ingredients, except WPI, were boiled for 1 minute, and then the solubilized WPI was 
added. Once the mixture had cooled, the bacteria were added, and the gel was stored in a

$50 \mathrm{~mL}$ falcon tube at $4^{\circ} \mathrm{C}$. Nutritional analysis was done with Genesis R\&D software

(ESHA Research), and is shown in Figure 4.13.

Table 3.3. Dairy-based gel formulation.

\begin{tabular}{|l|l|l|}
\hline Ingredient & Source & Quantity \\
\hline Colostrum - Super Lite & Organic Pastures Dairy Co. LLC (Fresno, CA) & $250 \mathrm{~g}$ \\
\hline Buttermilk Powder (UF/DF) & DPTC produced (2008) & $25 \mathrm{~g}$ \\
\hline $\begin{array}{l}\text { Whey Protein Isolate (WPI), } \\
\text { BiPro, 98\% }\end{array}$ & Davisco Foods Intl (Eden Prairie, MN) & $15 \mathrm{~g}$ \\
\hline Sucrose & C\&H - Domino Foods (Yonkers, NY) & $15 \mathrm{~g}$ \\
\hline Agave nectar & Madhava Honey Co. (Lyons, CO) & $15 \mathrm{~g}$ \\
\hline Water (tap) & - & $100 \mathrm{~g}$ \\
\hline Salt & Morton (Chicago, IL) & $0.4 \mathrm{~g}$ \\
\hline $\begin{array}{l}\text { MaxiGel Modified Food Starch } \\
445\end{array}$ & Tate \& Lyle (Decatur, IL) & $6 \mathrm{~g}$ \\
\hline $\begin{array}{l}\text { Lactic acid bacteria- L. reuteri } \\
\text { (SD2112) \& L. acidophilus } \\
\text { (NCFM) (pellets from 10 mL } \\
\text { tubes) }\end{array}$ & DPTC library & $2 \mathrm{pellets}$ \\
\hline
\end{tabular}




\subsubsection{Analysis by ELISA}

A sandwich ELISA design was used to compare the quantity of immunoglobulin $\mathrm{G}(\mathrm{IgG})$ in commercial whole milk, commercial colostrum, and the aforementioned dairy-based gel. A 96-well clear polystyrene plate (cat \#125-65-501, Fisher Sci.) was coated with $100 \mu \mathrm{l}$ primary antibody (anti-bovine IgG, whole molecule, polyclonal, produced in rabbit, cat \#B5645, lot \#096K4772, Sigma-Aldrich) at 2/1000 in 0.1M carbonate-bicarbonate $\mathrm{pH} 9.6$ (Appendix G) and incubated for 1 hour. For the remaining washing and dilutions, 1x TBS-Tween-20 pH 8.0 was used (Appendix G). The plate was washed and samples were added in triplicate with milk at 2/10,000, and colostrum and gel at 2/100,000. Lyophilized bovine IgG standard was reconstituted in 1x PBS pH 7.2 (cat \#I5506, lot \#058K7675, Sigma-Aldrich) and added in duplicate at dilutions of 0, 7.8, $15.6,31.25,62.5,125$, and $250 \mathrm{ng} / \mathrm{mL}$ to construct a standard curve. The plate was incubated for 1 hour, then washed, and secondary antibody (anti-bovine IgG, HRP conjugate, whole molecule, polyclonal, cat \#A7414, lot \#28H9245, Sigma-Aldrich) was added at a dilution of 5/10,000. The plate was incubated for 1 hour, washed, and $100 \mu 1$ o-phenylenediamine dihydrochloride (OPD) solution (cat \#P6787, Sigma-Aldrich) was added to each well. OPD solution was prepared by dissolving $4 \mathrm{mg}$ OPD in $10 \mathrm{~mL}$ 0.05M citrate-phosphate pH 5.0 (Appendix G) and $10 \mu 130 \%$ hydrogen peroxide. The plate was incubated for 20 minutes, then $50 \mu \mathrm{l}$ of $2 \mathrm{M} \mathrm{H}_{2} \mathrm{SO}_{4}$ (cat \# A300S-212, Fisher Sci.) was added to wells to stop the reaction. After 5 minutes, the plate was read at 492nm, using a spectrophotometer and SoftMax Pro (Molecular Devices), then data was analyzed using Excel 2007 (Microsoft) and Minitab 16. 


\subsection{Results}

\subsection{Bacterial binding with phospholipids}

\subsubsection{Bacterial growth studies}

There were four strains of Lactobacillus used in the final binding experiments, including two types of L. reuteri (SD2112 and T-1), L. acidophilus (NCFM), and L. casei (LC-10) (Table 3.1). As previously mentioned, upon assuring purity by streak plate morphology and preparing frozen stock, each strain was subcultured and its growth was evaluated to determine the optical densities relating to mid-log phase. Throughout the growth study, absorbance readings were taken with a spectrophotometer at $600 \mathrm{~nm}$ every 30-60 minutes during a period of 18 hours, at which point a graphical representation showed that the bacteria had entered stationary phase of growth (Appendix A). The resulting optical densities were plotted with time (Figure 4.1).

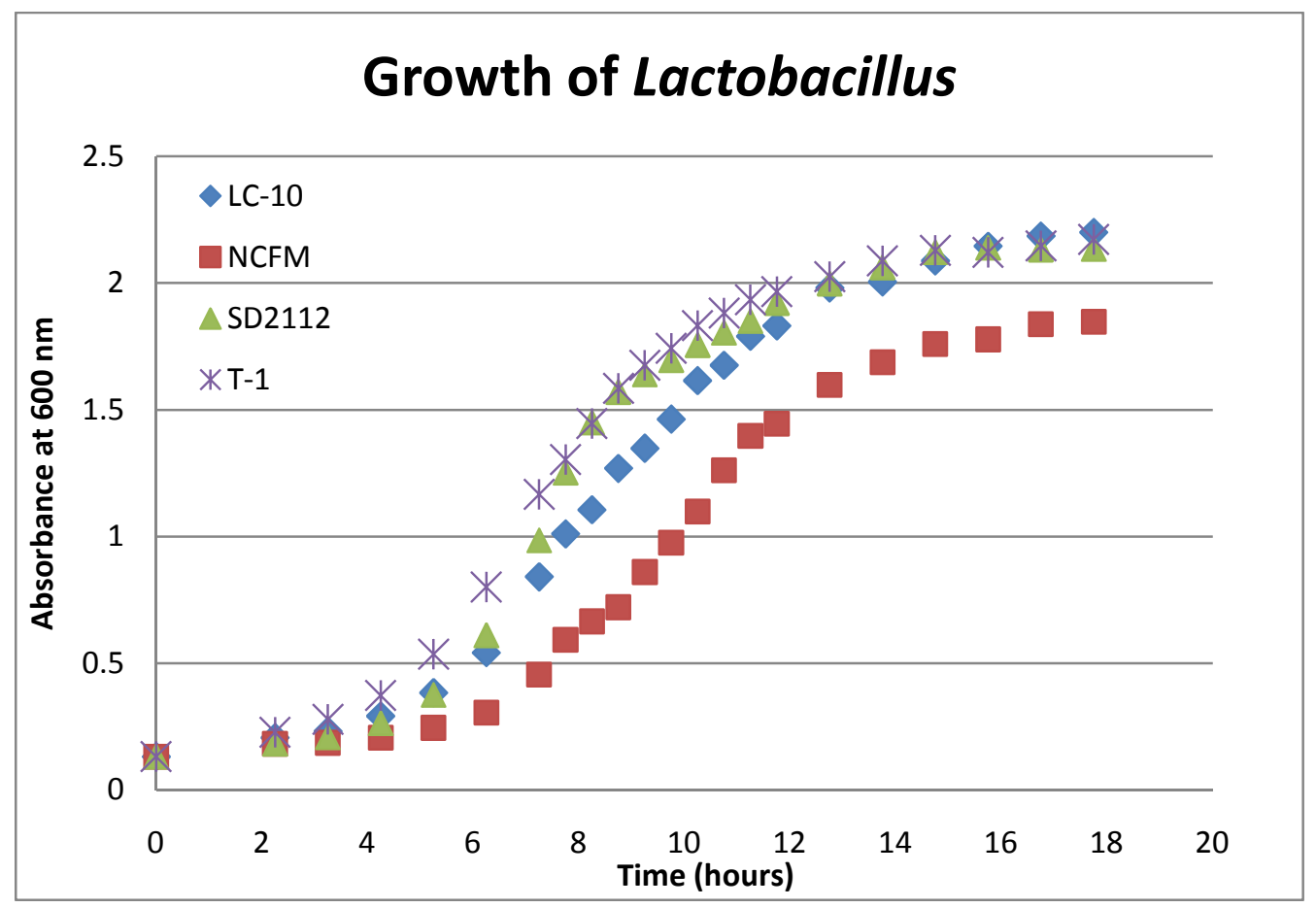

Figure 4.1. Lactobacillus growth over 18 hours. Initial inoculum 1/100 in MRS broth. Incubated at $37^{\circ} \mathrm{C}$ for 18 hours. Identities of bacteria in Table 3.1 . 


\subsubsection{Blotted membrane trials}

The blotted membrane trials were the initial attempt at measuring binding between Lactobacillus strains and phospholipids. These colorimetric assays were not evaluated quantitatively due to lack of proper equipment (e.g. densitometer). The results were also found to be visually inconsistent among trials, and the method seemed minimally reproducible. Photos were taken of the developed strips (Figure 4.2).

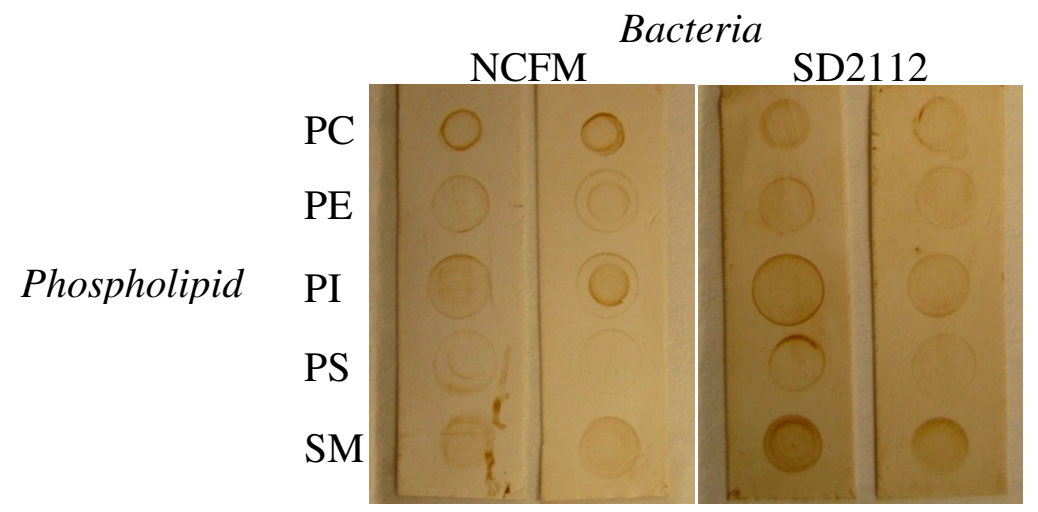

Figure 4.2. Colorimetric blotted membranes to assess bacterial binding. Spots represent different phospholipids, and strips represent different bacteria (in duplicate; both defined in Tables $3.1 \& 3.2$ ).

Trials with fluorescent streptavidin were also attempted as a potential method with less background than the colorimetric experiments, but they were abandoned due to inconsistent and questionable results among trials. Images were obtained with the GelDoc (BioRad, Hercules, CA) (Figure 4.3).

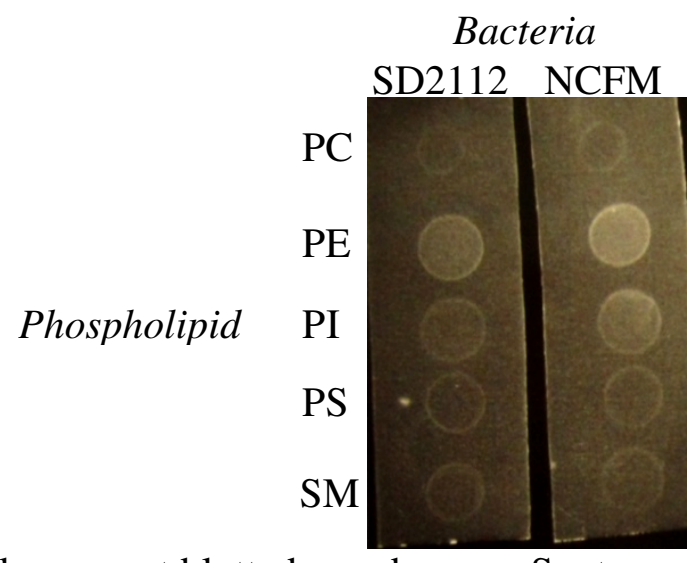

Figure 4.3. Fluorescent blotted membranes. Spots represent different phospholipids, and strips represent different bacteria (both defined in Tables $3.1 \&$ 3.2). 


\subsubsection{TLC trials}

After the blotted membranes were discontinued, another attempt to assess bacterial binding to phospholipids was made using thin-layer chromatography (TLC) plates as a medium. Similar to the colorimetric membranes, the TLC plates were blotted with phospholipid standards, incubated with biotinylated lactic acid bacteria, and developed using neutravidin and DAB. Images were obtained using the GelDoc (BioRad) (Figure 4.4).

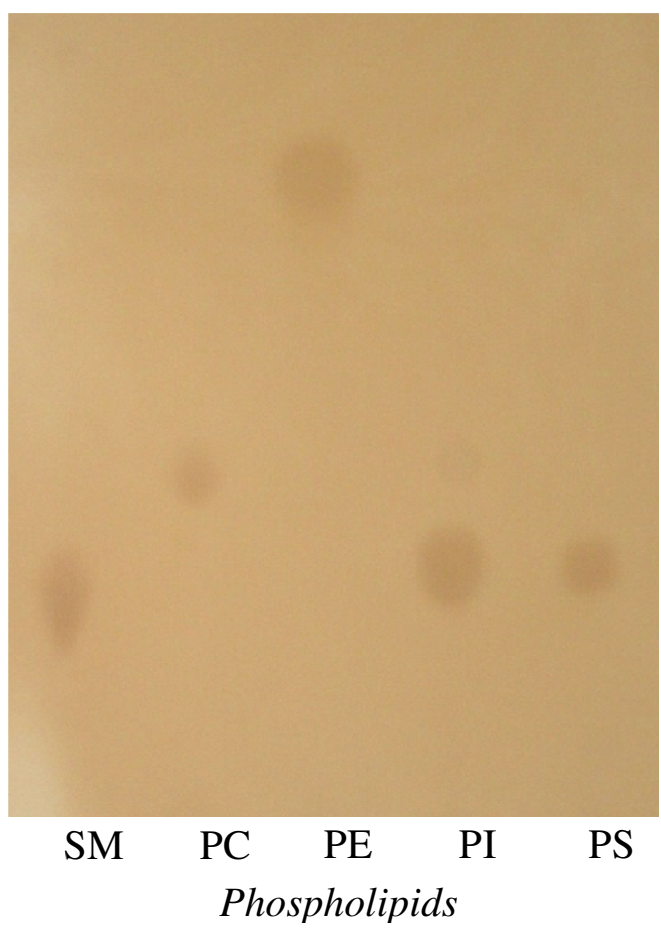

Figure 4.4. TLC binding assay. Spots represent binding of biotinylated bacteria (NCFM in this experiment) to different phospholipid standards (defined in Tables $3.1 \&$ 3.2). 


\subsubsection{Colorimetric dot trials}

After previous unsuccessful methods to measure bacterial binding, a modified approach to blotted membranes was attempted. PVDF membrane was made into dots, which were allowed to bind with triglycerides and phospholipids, and then blocked with $1 \%$ fish gelatin. Again, they were incubated with biotinylated lactic acid bacteria and developed using neutravidin and DAB. These colorimetric assays were not evaluated quantitatively due to lack of proper equipment (e.g. densitometer).

The results were visually inconsistent among trials, and the reliability of the method seemed poor. The method was discarded after this experiment, due to the discovery that biotinylated bacteria bound to the membrane by themselves (visually) equally well as when phospholipids were present, making the PL results false positives. Photos were taken of the developed dots (Figure 4.5).

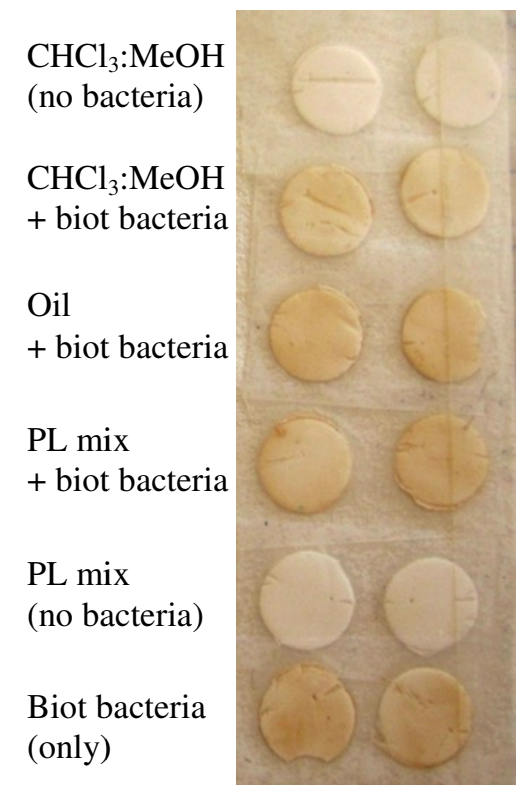

Figure 4.5. Colorimetric dot assay. Controls included the solvents used to dilute the lipids $\left(\mathrm{CHCl}_{3}: \mathrm{MeOH}\right)$ and canola oil. Dots were produced in duplicate, with and without addition of biotinylated lactic acid bacteria (both defined in Tables $3.1 \& 3.2$ ). Oil and PL mix were at $2.5 \mathrm{mg} / \mathrm{ml}$ in 2:1 $\mathrm{CHCl}_{3}: \mathrm{MeOH}$. SD2112 (L. reuteri) was used in this case. 


\subsubsection{Fluorescent dot trials}

The method that finally produced successful results involved fluorescence. Due to the apparent non-specific binding of biotinylated bacteria to the PVDF membrane in the previous method, a more simplistic approach was taken. Bacteria were stained with acridine orange, a fluorescent dye, and allowed to bind to dots of membrane already incubated with phospholipids. A Typhoon image scanner was used to analyze the fluorescence (raw data in Appendix B). To assess non-specific fluorescing of stained bacteria and each of the lipids and control, dots were also made after incubation solely with each of these. After exposure to the fluorescent bacteria, non-specific fluorescence values were comparable amongst dots of $\mathrm{CHCl}_{3}: \mathrm{MeOH}$, PL only, and bacteria only.

The results were statistically consistent among trials $(\mathrm{p}<0.05)$, and the reliability of the method was good. In contrast to the previous colorimetric assay, the fluorescently stained bacteria exhibited very little non-specific binding to the membrane. Images of the resulting dots were obtained with the Typhoon scanner and FluorSep program (Figure 4.6). Not shown are the dots from assessment of non-specific fluorescing of the bacteria and lipids. These dots appeared black, thus none to very little non-specific fluorescence was present. 


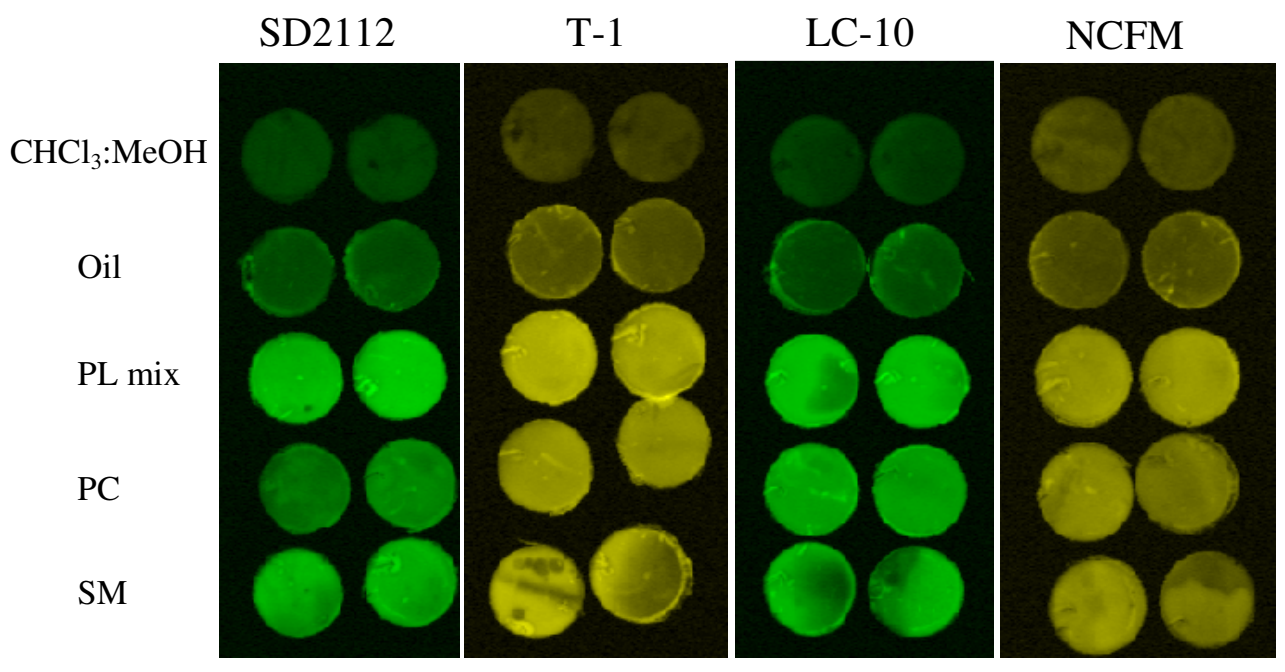

Figure 4.6. Fluorescent dot assay. Controls included the solvents used to dilute the lipids $\left(\mathrm{CHCl}_{3}: \mathrm{MeOH}\right)$ and canola oil. Dots were produced in duplicate, all with addition of fluorescently-stained lactic acid bacteria (defined in Table 3.1). All lipid concentrations were $12 \mathrm{mg} / \mathrm{ml}$ in 2:1 $\mathrm{CHCl}_{3}: \mathrm{MeOH}$ (defined in Table 3.2). Colors shown are arbitrary. 


\subsubsection{Fluorescent dot trial statistical analysis}

The data resulting from the fluorescence trials (Appendix B) was statistically analyzed using Minitab 16 (Appendix E). ANOVA and Tukey's test were used to determine the presence of binding differences among the lipid types and bacterial strains.

Significant differences in binding were found amongst all phospholipids and oil $(\mathrm{p}<0.05)$.

L. acidophilus (NCFM) was found to have significantly different binding than L. casei

(LC-10) and L. reuteri (SD2112) (p<0.05) (Figure 4.7; Table 4.1). From inspection of the residual plots, the data closely follow a normal distribution pattern (Figure 4.8).

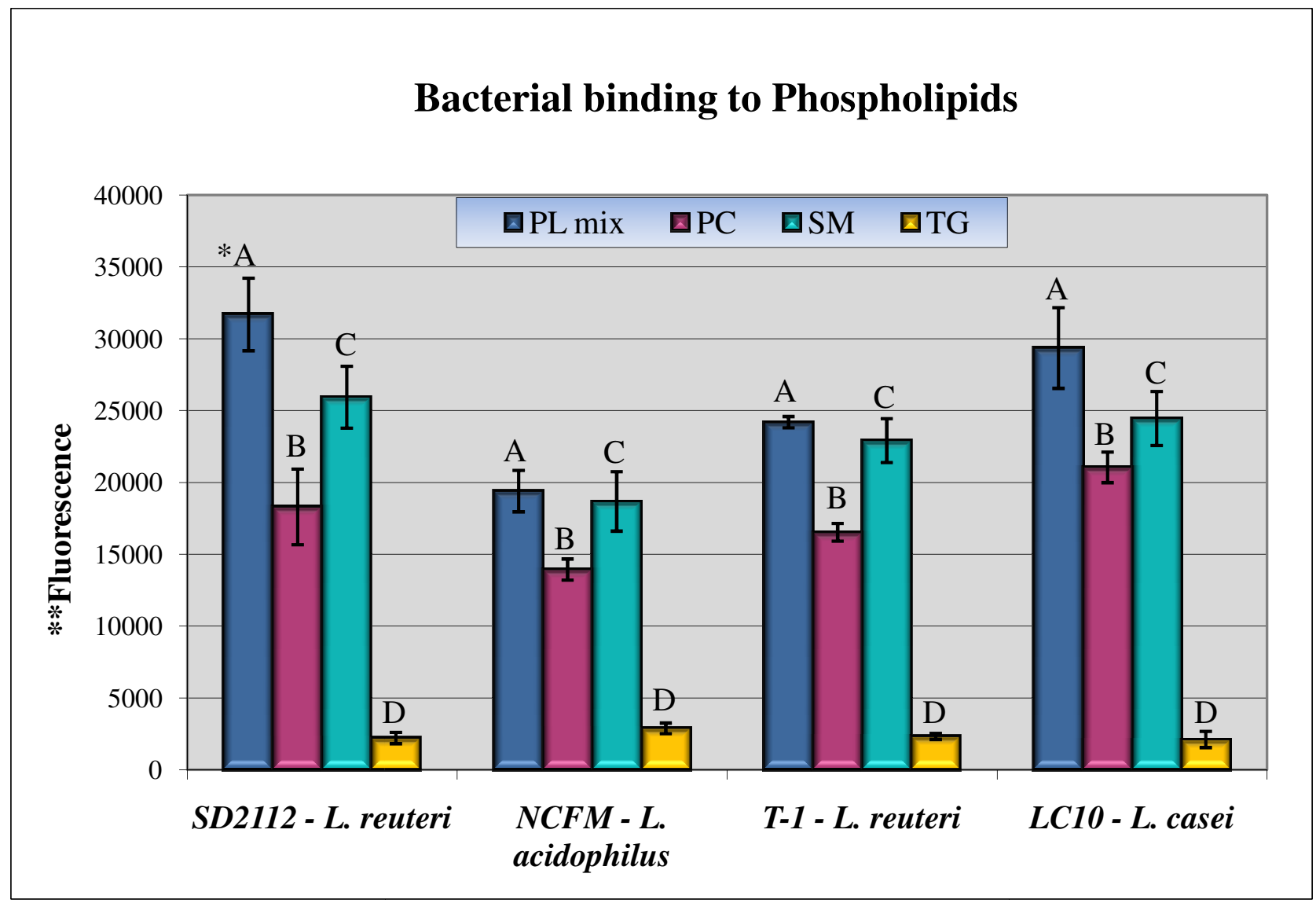

Figure 4.7. Comparison of bacterial binding to lipids. Binding to each lipid (PL's and oil) is significantly different from the others $(\mathrm{p}<0.05)$. * Different letters $(\mathrm{A}, \mathrm{B}, \mathrm{C}, \mathrm{D})$ represent statistically significant differences in lipid binding within each bacterial species (Tukey's test $(\mathrm{p}<0.05)$ ). Binding by NCFM is significantly different from LC10 and SD2112. Error bars represent standard errors of the means. **Fluorescence values after subtraction of background (control). Lipid identities: PL mix: milk PL extract; PC: phosphatidylcholine; SM: sphingomyelin; TG: triglycerides (canola oil). 
Table 4.1. Fluorescent dots analyzed by Tukey's test for comparison. Entities with the same letter in the same column are not significantly different from each other $(\mathrm{p}<0.05)$. Lipids and bacteria are compared separately.

\begin{tabular}{|l|l|}
\hline Lipids & Bacteria \\
\hline PL mix - A & SD2112 - A \\
\hline PC - B & LC10 - A \\
\hline SM - C & T-1 - A, B \\
\hline Oil - D & NCFM - B \\
\hline
\end{tabular}

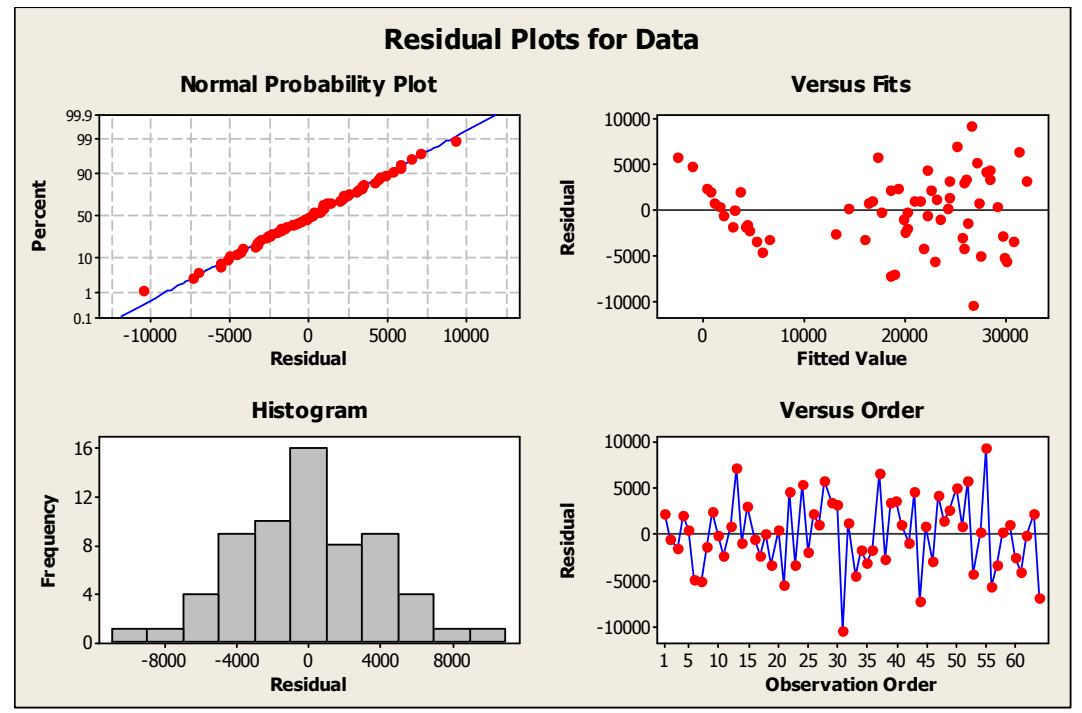

Figure 4.8. Fluorescent dot residual plots. This shows the distribution of binding data accompanying statistical analysis by Minitab 16. 


\subsection{HPLC analysis of phospholipids}

A milk-derived extract of phospholipids (Table 3.2) was used in multiple binding trial experiments alongside individual phospholipid standards. To assess its composition, high pressure liquid chromatography (HPLC) was used to separate the lipids. The chromatogram is shown in Figure 4.9. From the resulting data (Appendix C), the concentrations of each phospholipid in the phospholipid extract were calculated by interpolation from existing equations made from the analysis of phospholipid standards (Table 4.2).

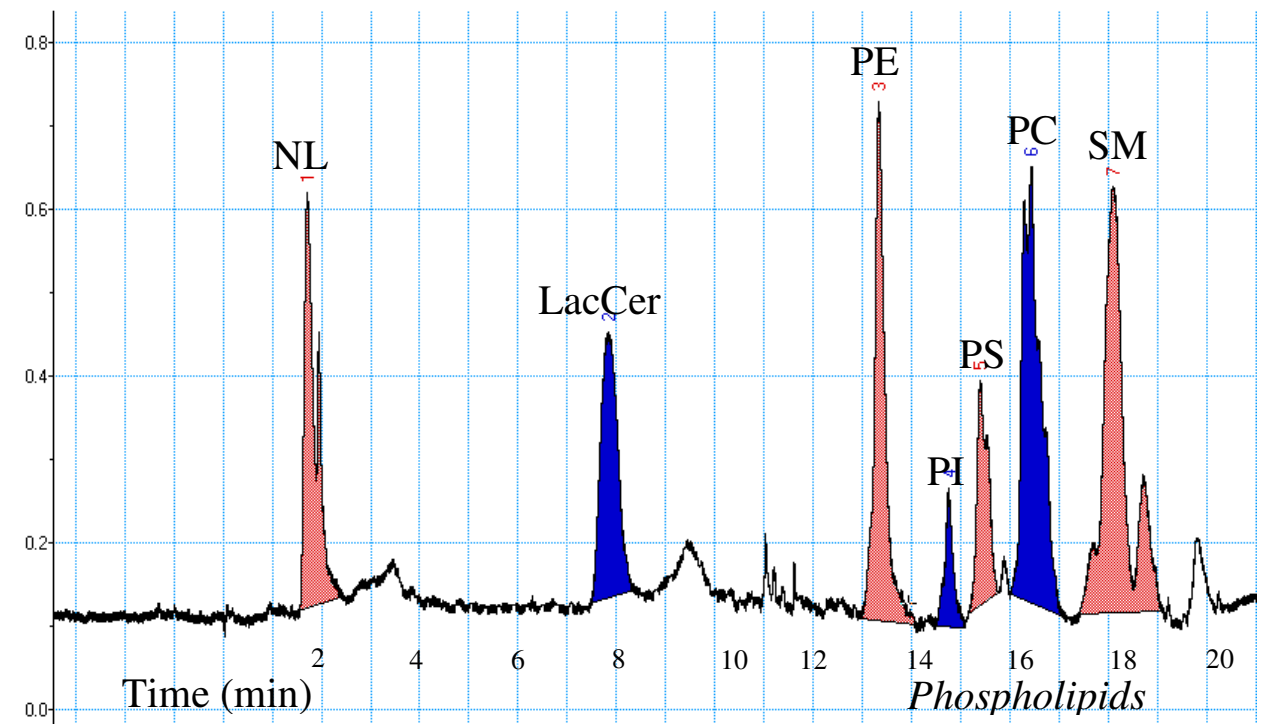

Figure 4.9. Chromatogram from HPLC analysis of PL mixture. NL = neutral lipids; LacCer $=$ lactosylceramide; phospholipids $=$ see table 4.2 below .

Table 4.2. Phospholipid concentrations in milk PL extract. Upon analysis by HPLC, the percent composition of the phospholipid portion of the extract was calculated.

\begin{tabular}{|l|r|}
\hline Phospholipid & $\begin{array}{l}\text { \% of total PL mix } \\
\text { (by mass) }\end{array}$ \\
\hline Phosphatidylcholine (PC) & $19.2 \%$ \\
\hline Phosphatidylethanolamine (PE) & $18.6 \%$ \\
\hline Phosphatidylinositol (PI) & $1.05 \%$ \\
\hline Phosphatidylserine (PS) & $4.87 \%$ \\
\hline Sphingomyelin (SM) & $23.8 \%$ \\
\hline
\end{tabular}




\subsection{Dairy-based, bioactive-rich gel}

\subsubsection{ELISA analysis of immunoglobulins}

Upon creation of the colostrum-rich energy gel, the content of immunoglobulins was of interest. An enzyme-linked immunosorbent assay (ELISA) protocol was developed to accomplish this. A sandwich design was chosen and used to quantify immunoglobulin $\mathrm{G}(\operatorname{IgG})$ in commercial whole milk and colostrum in addition to the aforementioned dairy-based gel. After completion of the assay (Figure 4.11), the absorbance data (Appendix D) were collected using the spectrophotometer and SoftMax Pro, and analyzed using Excel 2007 (Microsoft). A standard curve (quadratic regression) was constructed from the absorbance values of the bovine $\operatorname{IgG}$ standard and used to determine the IgG concentration of each dairy sample (Figure 4.10; Table 4.3). To verify consistency among trials, data (Appendix D) was analyzed using Minitab 16 (Appendix F). A residual plot expressing the normalcy of the data follows (Figure 4.12).

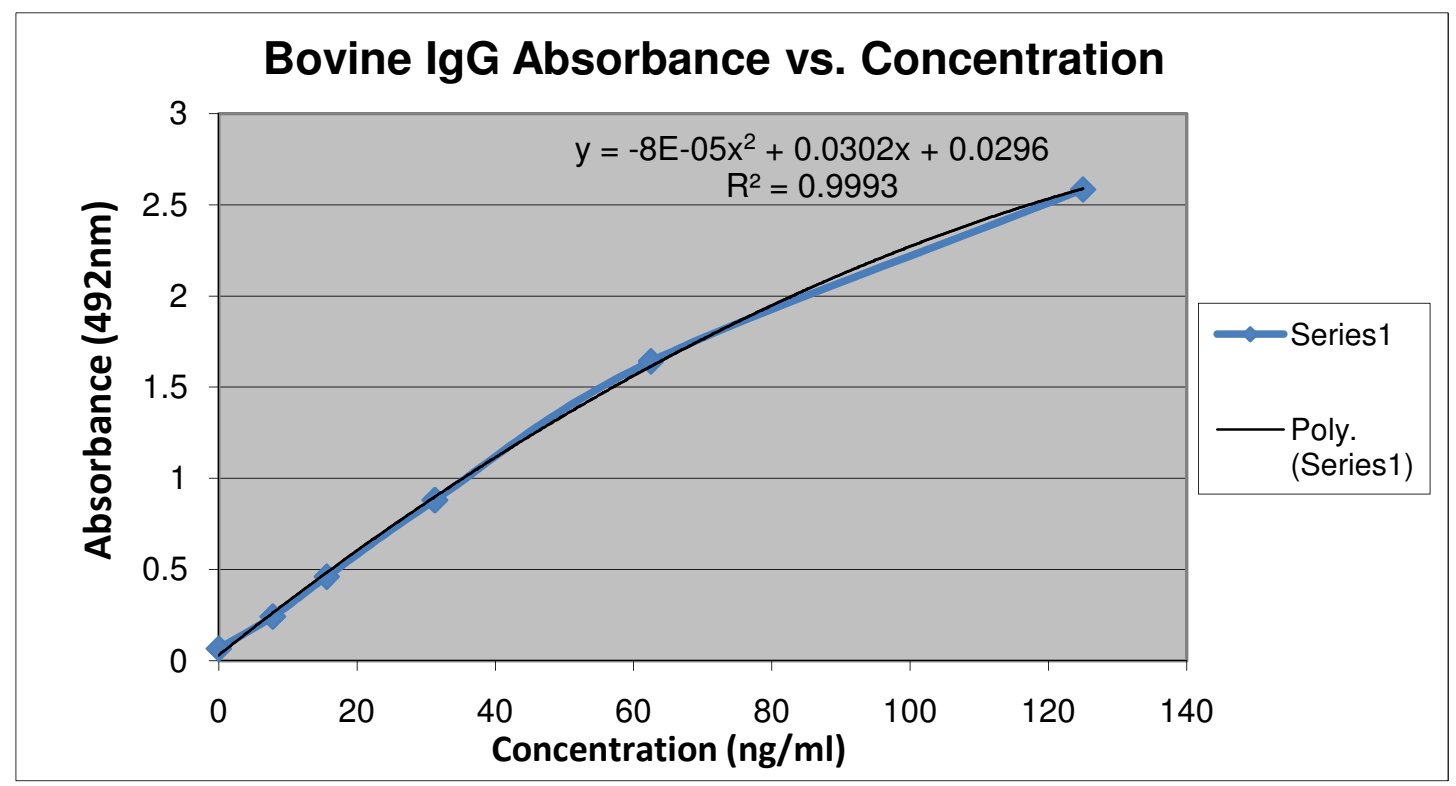

Figure 4.10. Standard curve resulting from ELISA analysis of bovine IgG. Quadratic regression curve fitted to absorbance values $(492 \mathrm{~nm})$ plotted against concentration. 
Table 4.3. Immunoglobulin G (IgG) concentrations of ELISA samples. Based on the quadratic regression curve from the bovine IgG standards, IgG concentrations were calculated from the average respective absorbance values of the milk, colostrum, and gel samples. Literature values for milk and colostrum are also shown for comparison (Hurley 2003; Saito 2009).

\begin{tabular}{|l|l|l|}
\hline \multicolumn{3}{|c|}{ IgG concentrations } \\
\hline Sample & $\begin{array}{l}\text { Bovine IgG }(\mathrm{mg} / \mathrm{ml}) \\
\text { (calculated) }\end{array}$ & $\begin{array}{l}\text { Bovine } \mathrm{IgG}(\mathrm{mg} / \mathrm{ml}) \\
\text { (values expected from literature) }\end{array}$ \\
\hline Milk & 1.50 & 0.79 \\
\hline Colostrum & 6.41 & $0.7-10$ (a few days post-parturition) \\
\hline Gel & 11.7 & - \\
\hline
\end{tabular}

\section{$\begin{array}{lllllll}1 & 2 & 3 & 4 & 5 & 6 & 7\end{array}$}

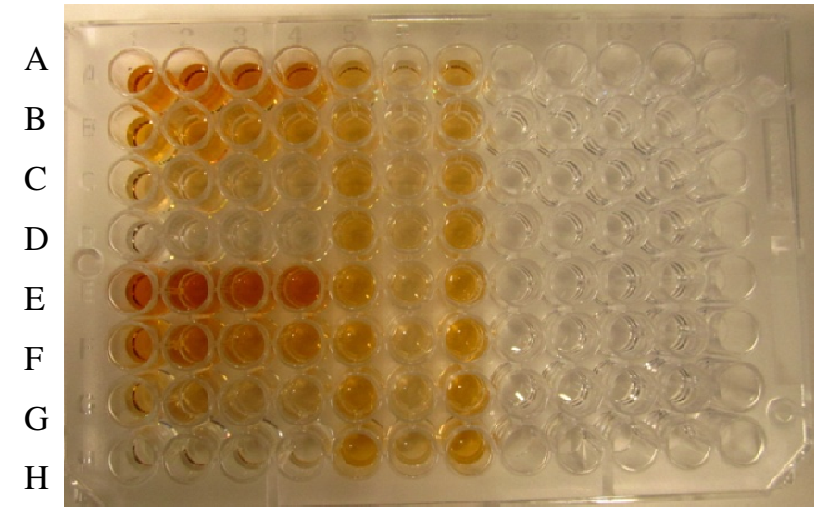

Figure 4.11. ELISA plate after colorimetric development with OPD. Wells in the area of columns 1-4 and rows A-D represent bovine IgG standards (increasing from left to right and top to bottom) (these are replicated in rows E-H, same columns). The contents of columns 5-7 are as follows: milk in 5, colostrum in 6, gel in 7. Remaining wells are blank.

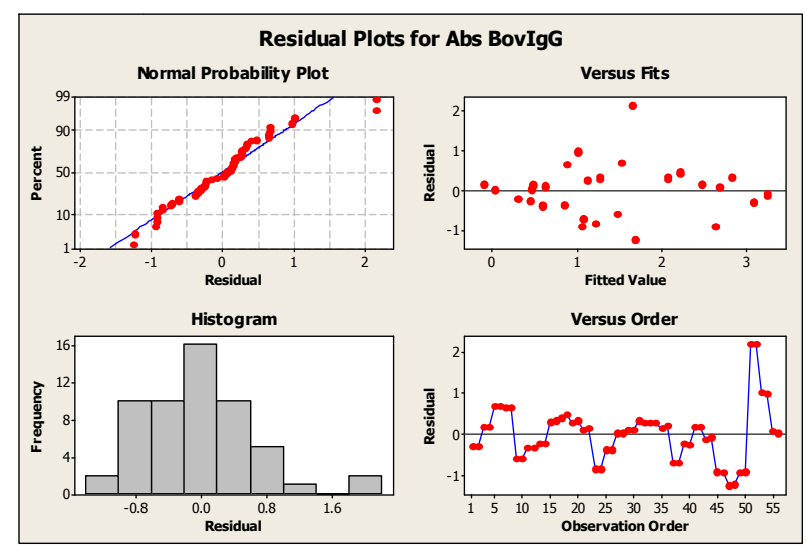

Figure 4.12. Residual plots resulting from ELISA analysis of bovine IgG standards. This shows the distribution of bovine IgG absorbance data used to construct the standard curve. This accompanied statistical analysis by Minitab 16. 


\subsubsection{Nutritional analysis of gel}

The ingredients for the dairy-based gel were added to the database in Genesis

R\&D software, and the formulation was used to calculate the basic nutrition facts for a 100 gram serving of the final energy gel. It should be noted that upon heat processing of the gel, the mass of water lost as steam was calculated by subtracting the final weight of the product obtained from the initial weight of all the ingredients. The formulation entered into Genesis reflects the water loss. The finished gel is shown in figure 4.3.2.2.

\begin{tabular}{|c|c|c|c|}
\hline \multicolumn{4}{|c|}{$\begin{array}{l}\text { Nutritor } \\
\text { Serving Size }(100 \mathrm{~g}) \\
\text { Servings Per Container }\end{array}$} \\
\hline \multirow{2}{*}{ Calories 140} & \multicolumn{3}{|c|}{ Calories from Fat 40} \\
\hline & \multicolumn{3}{|c|}{ \% Daily Value } \\
\hline \multicolumn{3}{|l|}{ Total Fat 4g } & $6 \%$ \\
\hline \multicolumn{2}{|c|}{ Saturated Fat 2g } & & $10 \%$ \\
\hline \multicolumn{4}{|c|}{ Trans Fat Og } \\
\hline \multicolumn{2}{|c|}{ Cholesterol 10mg } & & $3 \%$ \\
\hline \multicolumn{2}{|c|}{ Sodium 60mg } & & $3 \%$ \\
\hline \multicolumn{2}{|c|}{ Total Carbohydrate $18 \mathrm{~g}$} & & $6 \%$ \\
\hline \multicolumn{2}{|c|}{ Dietary Fiber 1g } & & $4 \%$ \\
\hline \multicolumn{4}{|l|}{ Sugars $15 \mathrm{~g}$} \\
\hline \multicolumn{4}{|l|}{ Protein 12g } \\
\hline \multicolumn{4}{|l|}{ Vitamin A 2\% } \\
\hline \multicolumn{4}{|c|}{ Calcium 8\% } \\
\hline \multicolumn{4}{|c|}{$\begin{array}{l}\text { *Percent Daily Values are based on a } 2,000 \text { calorie diet. } \\
\text { Your daily values may be higher or lower depending on } \\
\text { your calorie needs: } \\
\text { Calories } 2,000\end{array}$} \\
\hline $\begin{array}{l}\text { Total Fat } \\
\text { Saturated Fat } \\
\text { Cholesterol } \\
\text { Sodium } \\
\text { Total Carbohydrate } \\
\text { Dietary Fiber } \\
\end{array}$ & $\begin{array}{l}\text { Less Than } \\
\text { Less Than } \\
\text { Less Than } \\
\text { Less Than }\end{array}$ & $\begin{array}{l}65 \mathrm{~g} \\
20 \mathrm{~g} \\
300 \mathrm{mg} \\
2,400 \mathrm{mg} \\
300 \mathrm{~g} \\
25 \mathrm{~g} \\
\end{array}$ & $\begin{array}{l}, 00 \mathrm{~g} \\
25 \mathrm{~g} \\
300 \mathrm{mg} \\
2,400 \mathrm{mg} \\
375 \mathrm{~g} \\
30 \mathrm{~g} \\
\end{array}$ \\
\hline $\begin{array}{c}\text { Calories per gram: } \\
\text { Fat } 9 \cdot \text { c }\end{array}$ & Carbohydrat & & \\
\hline
\end{tabular}

Figure 4.13. Nutrition analysis of gel by Genesis. Based on 100g serving.

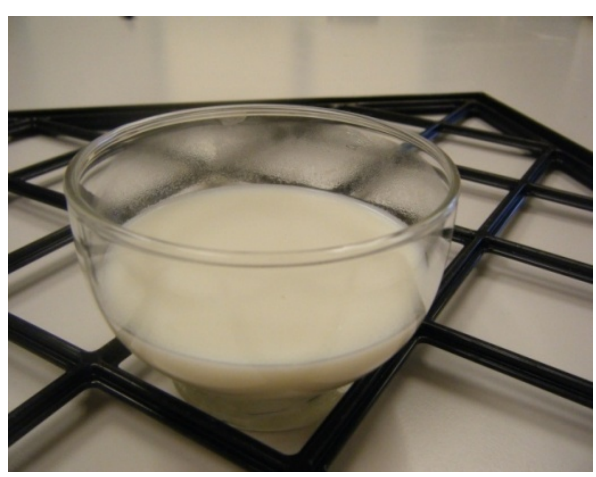

Figure 4.14. Finished colostrum-based gel ready for packaging. 


\subsection{Discussion}

\subsection{Bacterial binding with phospholipids}

\subsubsection{Selection and growth of probiotics}

The purpose of studying the binding of lactic acid bacteria to phospholipids was to demonstrate both the presence of this interaction and to determine variations among Lactobacillus species and strains. Lactobacillus reuteri, Lactobacillus acidophilus, and Lactobacillus casei were all selected due to their established identities as probiotics in human health and in food applications. These bacteria were subjected to API (Analytical Profile Index, Biomérieux) analysis by previous researchers in our lab to affirm their identities. In this research, their purity was affirmed by inspection of colony morphology and gram stains, and frozen and working stocks were maintained. A growth study of each species was completed in order to find the length of time needed for each to proliferate to mid-log phase. This stage of growth was selected as a means to support

consistency in the physiological state of each bacterial strain when used for binding. This is also a phase in which bacteria are highly metabolically active (e.g. enzyme activity and gene synthesis), thus it serves to mimic their dynamic in the intestine. This state should induce bacterial receptivity to binding to surfaces for colonization, such as mucins or phospholipids, again making it ideal for the purposes of these experiments.

\subsubsection{Binding assays}

The initial experiments performed to evaluate the binding interactions between lactic acid bacteria and phospholipids were not the most reproducible or reliable, but they served as necessary building-blocks to achieve the final method. The principle behind all of the assays was to first allow a fixed concentration of phospholipids to attach to a 
surface (e.g. PVDF membrane or TLC plate), and then expose them to equal quantities of chemically-labeled bacteria. Labeling was a key component in producing distinct colorimetric or fluorescent results to indicate that binding had occurred. These results then served as a measure of binding presence and frequency.

\subsubsection{Blotted membrane and TLC trials}

PVDF membrane was an indispensable tool in many of the methods attempted. In the blotted membrane trials, phospholipid standards were blotted in circles and biotinylated bacteria were allowed to incubate with the entire membrane. One problem encountered was difficulty in applying the lipids to an even area on the membrane, but with the use of a plastic template this was improved. Visually, the results from both colorimetric and fluorescent assays seemed promising because it was clear that binding was indeed occurring, however, they also appeared inconsistent and the necessary analytical equipment (e.g. densitometer) was unavailable to assess the true precision of this method. Thin-layer chromatography (TLC) also appeared to be a feasible method, again based on the principle that biotinylated bacteria would attach to phospholipid standards separated on a TLC plate. Unfortunately, a couple of factors hindered the ultimate use of this technique; namely, lack of consistency (visually) among trials, sloughing of silica from the plates, and lack of proper equipment to assess binding.

\subsubsection{Colorimetric dot trials}

A variation on the initial blotting method was initiated with the use of holepunched dots of PVDF membrane. Also at this time, a phospholipid mixture was obtained and analyzed to verify its composition by HPLC, which showed results following a similar compositional pattern as that of other HPLC analyses of milk 
phospholipid composition (Rombaut et al. 2005). The calculated proportions of each phospholipid did not all precisely match those in the literature, however due to being from a unique extract concentrate (as opposed to milk), some variation seems reasonable. Also, due to the limited number of trials $(n=3)$, additional analysis might produce results more consistent with those in the literature. This mixture was used for all subsequent trials, having the advantage of providing a natural source of phospholipids extracted from milk. Individual dots were incubated with the phospholipid standards, as well as the milk phospholipid extract, allowing more uniform distribution of the solvent and also providing a definite area on which to quantitatively measure binding. At the outset, a similar system to the blotted membranes was employed, in that it involved the sequence of phospholipid binding, blocking with fish gelatin, and incubation with biotinylated bacteria, followed by the attachment of neutravidin-HRP and colorimetric development. An additional note about the blocking step is that fish gelatin was used due to studies that have shown superior blocking activity compared to porcine gelatin, bovine serum albumin, and casein in ELISA and Western blot applications (Vogt et al. 1987; Lee et al. 1994). Despite the theoretical success of this method's organization, however, eventually the creation of certain controls led to the discovery of false positive results. Color development was present to a similar visual extent in both blocked and unblocked PVDF dots that were not coated in phospholipids, but that were incubated in the presence of biotinylated bacteria. The bacteria also exhibited affinity for dots only submersed in the control solvents, chloroform and methanol. Thus it was surmised that by this assay, the bacteria also had confounding binding affinity for both the PVDF and fish gelatin 
proteins. Due to the lack of success at fixing this challenge, the mode of bacterial labeling was modified, and also simplified.

\subsubsection{Fluorescent dot trials}

Fluorescent labeling of the bacteria proved to be the most successful means to assess binding. In summary, all of the previous approaches showed that bacteria can indeed adhere to phospholipids attached to a membrane or surface, thus these same principles were carried forward in a manner that would prove reliable and quantifiable. In this last method, bacteria were simply stained with acridine orange and allowed to incubate with phospholipid-coated dots of PVDF. Acridine orange stained the proteins of the bacteria, and provided a more direct means to report their presence than the use of biotinylation. The buffer formulation was modified from PBS to Tris once this experiment began in order to eliminate the potential for nonspecific binding of bacteria to the phosphate in PBS (since they have shown affinity for phospholipids in other research). Another modification from previous methods was the use of bacterial dilutions at $\mathrm{OD}_{600 \mathrm{~nm}}=1.0$ instead of 2.0 , in order to reduce potential variability in bacterial concentration due to spectrophotometric limitations. Immediately upon completion of the experimental protocol, binding affinity was measured by fluorescence readings obtained from the Typhoon imaging scanner. Fluorescence measurements for each bacterial species and the corresponding phospholipids and controls were then analyzed by Excel and Minitab for graphical and statistical comparisons. The use of fluorescence to label the bacteria was advantageous in terms of its simplicity and production of results relatively quickly. Disadvantages could potentially include induction of variation due to pipetting such a small volume of dye, as well as the possibility of not having well- 
calibrated this volume so as not to oversaturate the bacteria. Also, it is conceivable that different bacteria may uptake the dye to different extents, depending on their cellular structure and reaction to growth conditions, which could drastically alter the representation of actual binding occurring. Nonetheless, this proved to be the most reliable means of measuring binding in this series of experiments.

For statistical analysis of the results, a General Linear Model (GLM) was used with fluorescence data as the response, and bacterial type, lipid, and trial as the model factors (Appendix E). Tukey's pairwise comparisons were made with the bacteria and lipids. The results of the ANOVA and Tukey tests show that each of the four bacterial species exhibited minimal binding to the negative control $\left(2: 1 \mathrm{CHCl}_{3}: \mathrm{MeOH}\right)$ and significantly less affinity for the positive control (canola oil triglycerides) than for all of the phospholipids included in the assay $(\mathrm{p}<0.05)$. Certain phospholipids were preferred over others as shown by the significant differences in binding affinity to each $(\mathrm{p}<0.05)$. NCFM displayed significantly different binding than SD2112 and LC-10, but not T-1, and showed a tendency toward less $(\mathrm{p}<0.05)$. There was no significant difference due to trial ( $\mathrm{p}>0.05)$, which is also shown by the size of the error bars for the standard errors of the means (Figure 4.7). Thus, in these experiments, binding events depended largely on the specific phospholipid or mixture thereof and somewhat on the bacterial strain. From these findings, the questions arise as to why the bacteria preferentially bound to phospholipids instead of triglycerides and why they showed different affinities for each one. 


\subsubsection{Interpretation of fluorescent binding results}

First, the very principles by which binding likely occurs must be reviewed. Lactic acid bacteria are believed to attach to other molecules or surfaces primarily through interactions with their capsule, the region surrounding the cell wall. Most notably for this discussion, in lactic acid bacteria this structural component may include anionic teichoic or lipoteichoic acids, but especially the S-layer proteins. Bacterial attachment to phospholipids must involve the properties of the polar head group, given that this is the main distinction between these lipids and others with lower binding, such as triglycerides. To illustrate this, the arrangement of PL in the milk fat globule membrane (or any other cellular membrane for that matter) is such that the polar head groups face outward, and the nonpolar, hydrophobic FA chains face inward. Since bacterial binding has been demonstrated with intact milk fat globules, it is logical to reason that the bacteria bind to the polar head group of the PL. However, observations by other researchers that the more hydrophobic bacterial strains exhibit greater binding frequency complicate this conjecture. These issues will be evaluated in the discussion that follows.

While S-layer proteins are typically acidic (pI 4-6) in most bacteria, in lactic acid bacteria they are usually highly basic $(\mathrm{pI}>9.4)$ due to the greater proportion of positively charged amino acid residues. These cationic residues (e.g. lysine and arginine) have been suggested to interact with lipid head groups possessing an anionic charge (Smit et al. 2001). In our experiments, the bacteria were diluted in Tris buffer at $\mathrm{pH} 7.2$, which is very likely below the $\mathrm{pI}$ of their S-layer proteins, meaning that they would have a net positive charge under the conditions provided for binding. Therefore, we can also propose that binding may be occurring between these positively charged amino acid 
residues and any negatively charged portions of the phospholipid, including the phosphate group itself and the polar head group. This could be occurring in the case of phosphatidylserine (PS) and phosphatidylinositol (PI) since both of these contain anionic polar head groups (Nelson and Cox 2000). It can also be postulated from this that more binding interactions occur with increasing cationic properties imparted by a greater number of S-layer proteins.

Thus, another explanation for the variance in binding affinity among strains of lactic acid bacteria may be differing proportions of S-layer proteins- the quantity has been shown to vary among strains and may directly impact binding. Since the absence of S-layer proteins significantly hinders adhesive properties of lactic acid bacteria, their interactions with binding surfaces and molecules such as phospholipids are certainly worth exploring (Sillanpaa et al. 2000; Roos and Jonsson 2002; Frece et al. 2005). The hydrophobicity imparted by S-layer proteins may explain why the more hydrophobic bacterial strains sometimes have greater binding affinity. In binding experiments with environmental conditions of varying ionic strength, it has also been proposed that some lactobacilli without S-layers may have adaptable mechanisms to change their surface hydrophobicity, thus adapting to conditions in order to promote surface adhesion (Vadillo-Rodriguez et al. 2004). This may explain binding events that occur with neutrally charged lipids, such as triglycerides. Although S-layer proteins were not analyzed in our experiments, further study may show correlations in binding strength with S-layer protein proportions and cell surface hydrophobicity.

Specifically examining the results of our research, a notable occurrence was the drastically lower binding exhibited by the bacteria for triglycerides than for all of the 
phospholipids. Previous research has found that binding to triglycerides is rather nonspecific compared to phospholipid binding, meaning that its occurrence is in more direct correlation with the concentration of lipid present. In contrast, this publication also showed that bacterial binding affinity to phospholipids was specific to the strain rather than simply increasing with the concentration of lipid presented (Bachiero et al. 2007). The results of our experiments are compatible with these findings in that bacterial binding to equal concentrations of phospholipids and triglycerides was vastly different. Thus, hypothetically, if the concentration of triglyceride had been increased in these experiments, greater binding may have occurred. This illustrates the exceptional properties possessed by phospholipids. Also, the reasons for the preferential binding to phospholipids may be due to the presence of PL on cell surfaces. Binding is a surface to surface interaction, thus it is logical that PL would be natural recipients of binding. In contrast, triglycerides are not present on cell surfaces due to their hydrophobicity and structure, thus binding preference for them would theoretically be low, which is again clearly revealed in the results of these experiments.

From our observations, it appears that providing a mixture of phospholipids to lactic acid bacteria is more advantageous to binding than providing isolated phospholipids. It seems logical that the mixture would receive greater binding than its counterparts due to the possible synergy among phospholipids, as well as being a source of the complete range of milk lipids that the bacteria might coexist with had they been in this type of natural environment. It must be noted that this mixture does contain some non-polar lipids in addition to phospholipids, which may also account for some of the elevated binding affinity shown in this study. Nonetheless, these results support the 
notion that dairy products can provide excellent delivery of probiotics. Given that it contains preferred molecules on which to adhere, the dairy system components theoretically result in better probiotic colonization in the product, as well as transportation of a higher proportion of viable microorganisms to the host.

The phospholipid standards phosphatidylcholine (PC) (from egg yolk) and sphingomyelin (SM) (from bovine brain) used in these studies were also shown to have significant binding with the bacteria. Being from non-milk sources, these results show that bacteria may adhere to any individual phospholipids, and also may help indicate the location of binding. PC and SM have similar structural characteristics, and also share a net neutral charge on their polar head group (both contain identically structured phosphatidylcholine and phosphocholine, respectively), although this group contains positively charged amino acid residues. Given that these polar lipids share the same polar head group, the question arises as to why binding data would significantly differ. It may be that with more trials, this difference would become insignificant, but it is also possible that this variation is due to the dissimilarities of their structural backbones, glycerol and sphingosine. The specific reasons behind this are not definitely known. Previously it was noted that binding may occur between positively charged amino acid residues of S-layer proteins and negatively charged portions of the polar lipid heads. If that same principle did not apply in the case of PC and SM (only containing the anionic phosphate group), it may be that binding can also occur between the positively charged polar head and any anionic amino acid residues of the S-layer proteins, although present in lower proportions than the cationic ones (Nelson and Cox 2000). However, the best explanation for the binding preference to $\mathrm{SM}$ as opposed to $\mathrm{PC}$ is the glycosylated nature 
of SM, which is aptly classified as a glycolipid. Glycolipids, which also include the mucins of the intestinal lining, are common cell-surface receptors, while phospholipids are situated in the cell membrane bilayer. Thus, structurally it is logical that binding would naturally occur more frequently to SM than PC due to its structure and location.

Given the complexity of biological systems such those studied here, it seems logical that there is actually an interplay of factors that result in binding interactions between lactic acid bacteria and phospholipids. These may include the aforementioned structural properties of lactic acid bacteria, as well as the aspects of environmental conditions, which are likely to be crucial. As demonstrated by these experiments, however, dairy systems can provide components essential to ensuring better probiotic colonization in the product, as well as deliverance of an increased number of functional microorganisms to the gastrointestinal tract. As of now, there is no definitive explanation for why and how these associations occur, however, this study and others have at least shown their existence. Also, due to the relatively limited direct research performed thus far on these microscale interactions, the work we have done will perhaps inspire further curiosity to explore and elucidate the details within.

\subsection{Formulation and analysis of a dairy-based, bioactive-rich gel}

The dairy-based gel was created to demonstrate the successful application of ingredients with high bioactivity in a form with the potential for use as a nutritional supplement in the realms of sports nutrition or clinical applications. Some of the major, bioactive-rich dairy ingredients—namely colostrum, buttermilk powder, and whey protein isolate-were indeed effectively integrated into a gel-like food product containing bioactives such as immunoglobulins, phospholipids, and whey proteins, as well as 
probiotic bacteria. Colostrum was used as a rich source of all milk bioactives, including immunoglobulins, whey proteins and peptides, lactoferrin, and probiotic lactic acid bacteria. Buttermilk powder was also used a high-quality source of whey proteins and phospholipids, and whey protein isolate for its concentrated contribution of whey protein. L. acidophilus and L. reuteri were included due to their well-known exploitation as probiotics in dairy foods.

As reviewed in the literature, the heat treatment used (boiling for 1 minute) does pose a concern in the denaturation of the immunoglobulins, however the parameters used are at least not as extreme as UHT treatment $\left(138^{\circ} \mathrm{C}\right.$ for $\left.4 \mathrm{sec}\right)$. Nevertheless, if this product were commercially processed and packaged, it would be more feasible to pasteurize the product at lower temperatures, such as those between batch pasteurization and HTST parameters $\left(63^{\circ} \mathrm{C}\right.$ for $30 \mathrm{~min}$ and $72^{\circ} \mathrm{C}$ for $15 \mathrm{sec}$, respectively). This would minimize the immunoglobulin denaturation, and perhaps that of the other whey proteins as well (Li-Chan et al. 1995). Also, the presence of the other ingredients in the formulation, such as sugars and milk proteins, may actually have a protective effect on the integrity of the immunoglobulin structure, though this was not explored in this study (Chen et al. 2000; Dominguez et al. 2001). Microencapsulation is also an option for preserving their native structure (Chen et al. 1999).

Nutritional analysis by Genesis R\&D software revealed a gel composition of $12 \%$ protein, with just 140 kilocalories per 100 gram serving. Depending on the ultimate application, the formulation could be adjusted to augment the protein or kilocalorie composition. 
Sensory analysis of this gel was not performed due to time constraints and microbial concerns due to the method of processing, however, this would be a worthy addition to the future development of the product.

\subsubsection{ELISA analysis of immunoglobulins}

Upon designing the dairy-based gel, the concentration of immunoglobulins within was of interest, thus an immunoassay was used to reveal this. An enzyme-linked immunosorbent assay (ELISA) was chosen for this purpose due to its relative simplicity, precision, sensitivity, and the availability of the necessary laboratory materials. A sandwich design was developed using empirically-derived concentrations of anti-bovine primary and secondary antibodies made in rabbit. During the development of the assay, a few different blocking agents were evaluated, specifically porcine gelatin, fish skin gelatin, bovine serum albumin, and finally the TBS buffer with Tween-20 that was also used for washing. The latter proved the simplest and most effective, and did not present problems with removal from the wells, thus its use was continued. A lyophilized bovine immunoglobulin $\mathrm{G}$ (IgG) standard was employed alongside dilutions of commercial whole milk and colostrum, as well as the dairy-based gel formulation. A standard quadratic regression curve $\left(\mathrm{R}^{2}=0.999\right)$ was successfully constructed from the absorbance values produced by the bovine IgG standard, with no significant differences among trials (p>0.05) (Appendix F).

The regression equation was used to estimate the $\operatorname{IgG}$ concentration in each of the dairy samples included (from the respective averages of the data), of which the milk and colostrum values $(1.50$ and $6.41 \mathrm{mg} / \mathrm{ml}$, respectively) were found to be near those expected by the literature. However, the concentration calculated for milk is a bit higher 
than the literature value, which may be due to the wide natural variations possible in milk, or to imperfections in pipetting or in sample concentrations. Since the standard curve was successfully constructed and used to determine this value, variation from the literature value did not likely stem from poor concentrations of detection antibodies, although that is a possibility. At first glance, the colostrum value is within range; however this value is actually somewhat low compared to samples obtained soon after parturition. Early colostrum can contain IgG levels anywhere from $32-212 \mathrm{mg} / \mathrm{ml}$, but this value drops drastically $(0.7-10 \mathrm{mg} / \mathrm{ml})$ within a few days post-parturition (Hurley 2003; Saito 2009). However, due to the commercial nature of this colostrum, this value seems reasonable given that it is not very feasible to produce large volumes of early colostrum. The IgG value estimated in the gel $(11.7 \mathrm{mg} / \mathrm{ml})$ also seems reasonable given that it is a more concentrated source of colostrum.

Despite the apparent accuracy of these results, it is possible that there is a portion of inherent false positive data. This would be due to the use of a secondary antibody developed to be sensitive to the whole molecule of $\mathrm{IgG}$, which shares characteristics with other classes of immunoglobulins, to which it could theoretically bind. The primary antibody was also developed with the whole $\operatorname{IgG}$ molecule, again presenting the risk of cross-reactions, but theoretically the vast majority of sample immunoglobulins that bound should have been IgG, and also supporting this is the minimal concentration of non-IgG antibodies in milk $(0.15 \mathrm{mg} / \mathrm{ml} \mathrm{IgM}$ and $\mathrm{IgA} ; 0.79 \mathrm{mg} / \mathrm{ml} \mathrm{IgG)} \mathrm{(Hurley} \mathrm{2003).} \mathrm{If}$ antibodies developed for specific fragments of $\operatorname{IgG}$ had been used, such as the Fc portion, the assay would have been more reliable to be detecting $\mathrm{IgG}$, but the signal strength may have also been diminished (PierceBiotechnology 2007). 
Statistical analysis of these results showed that the absorbance values for the bovine $\operatorname{IgG}$ used to construct the standard curve were not significantly different among trials ( $\mathrm{p}>0.05$ ) (Appendix F). This indicates good consistency, thus a strong curve on which to interpolate the sample data. However, analysis of the absorbance data for the milk, colostrum, and gel samples showed inconsistency among trials, specifically that they were all respectively statistically significantly different among trials $(\mathrm{p}<0.05)$. Tukey's pairwise comparison tests showed that for milk, the sample values were different in all trials, although for the colostrum and gel the values were not different from each other in two of the four trials. Although these inconsistencies exist statistically, the actual calculated values being found different do not generally cover a wide range. For instance, the means compared for gel are 0.5, 0.6, 0.8, and 0.8 (Appendix F). Due to the small sample size $(n=16)$ and limited number of trials $(n=4)$, these unfavorable statistical results would likely be improved if a larger data set were obtained (Appendix D).

Due to the nature of the sandwich ELISA method, there are many steps at which inaccuracies may be introduced. It is probable that a great deal of error was introduced by pipetting variances such as those induced by small air bubbles or inconsistently calibrated pipets. Other modes of error may include flaws in the microplates, inconsistent spectrophotometer readings, imperfect plate washing, or even fluctuations in environmental conditions that could affect antibody binding. Again, perhaps with a greater number of trial replicates, the strength of the data could be improved despite the inherent sources of error in this method.

The results of the ELISA analyses illustrate the changing concentrations of immunoglobulins between colostrum and milk production. These experiments also 
reveal a mode in which these valuable bioactive molecules can be concentrated and delivered in a fashion that, when compared to liquid colostrum, is potentially more agreeable to consumers as well as more shelf-stable. Given the promise of these results, more research should be done on developing a successful method to manufacture a colostrum-based gel on a large scale. 


\subsection{Conclusions}

Milk, colostrum, and other dairy ingredients offer valuable and unique sources of bioactive compounds. These components present a rich array of potential health benefits, including immune system modulation, anti-hypertensive effects, antibacterial effects, anticancer effects, and more. Dairy ingredients are well-studied and have immense potential for use in functional food applications due to their availability, functional attributes, and the demand for health benefits. Large-scale manufacture is already in place for the major milk proteins as well as some of the minor protein and lipid components. Food products developed using these remarkable ingredients could prove of great benefit to the immunocompromised, the elderly, and infants, as well as in athletic performance and prevention of disease (Korhonen 2009).

The results of this thesis show the feasibility of creating a technique to measure probiotic binding with phospholipids, as well as demonstrating their selective binding nature. In particular, it was shown that L. reuteri, L. casei, and L. acidophilus were all effective at phospholipid binding. It seems conceivable that this method could be applied to studies of probiotic interactions with other dairy components, such as minor proteins. The elucidation of the specific interactions of probiotics with dairy product constituents (e.g. phospholipids) improves the understanding of their preferred environment and could result in the development of more efficacious ways to transport them in a viable form to the human body. In addition, this research displays the effective application of dairy ingredients in a bioactive-rich food product. Analysis by ELISA showed that at least one category of bioactives, the immunoglobulins, could be delivered by this matrix in a more concentrated form. With additional analysis methods, it is reasonable to expect similar 
effects with other classes of bioactives. Indeed, these results, as well as the probiotic interactions illuminated by the experiments of this thesis, offer a modest contribution to the future development of innovative modes of bioactive delivery and the continued benefit of these amazing compounds to human health. 


\subsection{Future Research}

- Perform more extensive studies of the binding of probiotic bacteria to phospholipids extracted from various dairy products.

- Explore the specific types of S-layer proteins that correlate well with bacterial binding to phospholipids, and produce recombinant probiotic bacteria containing these to optimize lipid binding in food product applications.

- Confocal microscopy to visualize interactions between probiotic bacteria and phospholipids from an actual food product.

- Study the production and cost feasibility of larger-scale manufacture of colostrumbased foods, as well as the effects of processing parameters (e.g. heating) on the retention of immunoglobulin function. Also investigate the effects of formulation, manufacturing, and packaging on the prevention of microbial spoilage and the viability of immunoglobulins and probiotics.

- Cell culture studies to elucidate the impact of the colostrum gel on some aspects of immune function.

- Explore the practicality of the application of the more minor milk bioactives in products for the consumer market. Also market their extensive health potential. 


\subsection{References}

Anal, A. K. and H. Singh (2007). "Recent advances in microencapsulation of probiotics for industral applications and targeted delivery." Trends in Food Science \& Technology 18: 240-251.

Aniagolu, J., G. M. Swartz, et al. (1995). "Analysis of anitcholesterol antibodies using hydrophobic membranes." Journal of Immunological Methods 182: 85-92.

Axelsson, L. T., T. C. Chung, et al. (1989). "Production of a broad spectrum antimicrobial substance by Lactobacillus reuteri." Microbial Ecology in Health and Disease 2: 131-136.

Bachiero, D., S. Uson, et al. (2007). Lipid Binding Characterization of Lactic Acid Bacteria in Dairy Products. Proceedings of the Annual American Society for Microbiology. Washington, DC.

Blomberg, L., L. Gustafsson, et al. (1995). "Growth of Escherichia coli K88 in piglet ileal mucus: protein expression as an indicator of type of metabolism." J. Bacteriol. 177(23): 6695-6703.

Bomba, A., R. Nemcova, et al. (2002). "The possibilities of potentiating the efficacy of probiotics." Trends in Food Science \& Technology 13: 121-126.

Brisson, G., H. F. Payken, et al. (2010). "Characterization of Lactobacillus reuteri interaction with milk fat globule components in dairy products." Journal of Agricultural and Food Chemistry 58: 5612-5619.

Chen, C. C., Y. Y. Tu, et al. (1999). "Efficiency and protective effect of encapsulation of milk immunoglobulin G in multiple emulsion." Journal of Agricultural and Food Chemistry 47: 407-410.

Chen, C. C., Y. Y. Tu, et al. (2000). "Thermal Stability of Bovine Milk Immunoglobulin $\mathrm{G}(\mathrm{IgG})$ and the Effect of Added Thermal Protectants on the Stability." Journal of Food Science 65(2): 188-193.

Chung, T. C., L. T. Axelsson, et al. (1989). "In-vitro studies on reuterin synthesis by Lactobacillus reuteri." Microbial Ecology in Health and Disease 2: 137-144.

Coconnier, M.-H., M.-F. Bernet, et al. (1993). "Inhibition of adhesion of enteroinvasive pathogens to human intestinal Caco-2 cells by Lactobacillus acidophilus strain LB decreases bacterial invasion." FEMS Microbiology Letters 110: 299-306.

Collin, R., C. Prosser, et al. (2002). "Development and validation of a nephelometric immunoassay for IgG1 in milk." Journal of Dairy Research 69(1): 27-35. 
Collins, M. D. and G. R. Gibson (1999). "Probiotics, prebiotics, and synbiotics: approaches for modulating the microbial ecology of the gut." American Journal of Clinical Nutrition 69: 1052S-1057S.

Conesa, C., M. Lavilla, et al. (2005). "Determination of IgG levels in bovine bulk milk samples from different regions of Spain." European Food Research and Technology 220(2): 222-225.

Danthine, S., C. Blecker, et al. (2000). "Progress in milk fat globule membrane research: A review." Le Lait 80(2): 209-222.

Deepika, G. and D. Charalampopoulos (2010). "Surface and Adhesion Properties of Lactobacilli." Advances in Applied Microbiology 70: 127-145.

Deeth, H. C. (1997). "The role of phospholipids in the stability of milk fat globules." Australian Journal of Dairy Technology 52: 44-46.

Dewettinck, K., R. Rombaut, et al. (2008). "Nutritional and technological aspects of milk fat globule membrane material." International Dairy Journal 18(5): 436-457.

Doherty, S. B., V. L. Gee, et al. (2010). "Efficacy of whey protein gel networks as potential viability-enhancing scaffolds for cell immobilization of Lactobacillus rhamnosus GG." Journal of Microbiological Methods 80(3): 231-241.

Dominguez, E., M. Dolores Perez, et al. (2001). "Effect of pH on antigen-binding activity of $\operatorname{IgG}$ from bovine colostrum upon heating." Journal of Dairy Research 68(03): 511-518.

El-Ziney, M. G. and J. M. Debevere (1998). "The effect of reuterin on Listeria monocytogenes and Escherichia coli $\mathrm{O} 157: \mathrm{H7}$ in milk and cottage cheese." Journal of Food Protection 61: 1275-1280.

Elizondo-Salazar, J. A., B. M. Jayarao, et al. (2010). "Effect of heat treatment of bovine colostrum on bacterial counts, viscosity, and immunoglobulin G concentration." Journal of dairy science 93(3): 961-967.

Evers, J. M. (2004). "The milkfat globule membrane-compositional and structural changes post secretion by the mammary secretory cell." International Dairy Journal 14: 661-674.

FAO/WHO. (2001). "Health and Nutritional Properties of Probiotics in Food including Powder Milk with Live Lactic Acid Bacteria." Retrieved January 27, 2011.

FAO/WHO. (2002). "Guidelines for the evaluation of probiotics in food." Retrieved January 26, 2011, from http://www.who.int/foodsafety/fs_management/en/probiotic_guidelines.pdf. 
Fleenor, W. A. and G. H. Stott (1980). "Hydrometer Test for Estimation of Immunoglobulin Concentration in Bovine Colostrum." Journal of Dairy Science 63: 973-977.

Fleenor, W. A. and G. H. Stott (1981). "Single Radial Immunodiffusion Analysis for Quantitation of Colostral Immunoglobulin Concentration1." Journal of dairy science 64(5): 740-747.

Fox, P. F. and P. L. H. McSweeney (1998). Dairy Chemistry and Biochemistry. London, Blackie Academic \& Professional.

Fox, P. F. and P. McSweeney (2006). Advanced Dairy Chemistry, Volume 2 - Lipids (3rd Edition), Springer - Verlag. 2.

Frece, J., B. Kos, et al. (2005). "Importance of S-layer proteins in probiotic activity of Lactobacillus acidophilus M92." Journal of Applied Microbiology 98: 285-292.

Gapper, L. W., D. E. J. Copestake, et al. (2007). "Analysis of bovine immunoglobulin G in milk, colostrum and dietary supplements: a review." Analytical and Bioanalytical Chemistry 389: 93-109.

Geier, M. S., R. N. Butler, et al. (2006). "Probiotics, Prebiotics, and Synbiotics: A role in chemoprevention for colorectal." Cancer Biological Therapy 5: 1265-1269.

Hamasaki, H., M. Aoyagi, et al. (1999). "GT1b in human metastatic brain tumors: GT1b as a brain metastasis-associated ganglioside." Biochimica et Biophysica Acta 1437: 93-99.

Hurley, W. L. (2003). Immunoglobulins in Mammary Secretions. Advanced Milk Chemistry. P. F. F. a. P. L. H. McSweeney. Gaithersburg, MD, Aspen Publications. 1: 421-447.

Huwiler, A., T. Kolter, et al. (2000). "Physiology and pathophysiology of sphingolipid metabolism and signaling." Biochimica et Biophysica Acta (BBA) - Molecular and Cell Biology of Lipids 1485(2-3): 63-99.

Jelen, P. and S. Lutz, Eds. (1998). Functional Milk and Dairy Products. Functional Foods: Biochemical and Processing Aspects. Lancaster, PA, Technomic Publishing Company.

Jin Baek, Y. and B. H. Lee (2009). Probiotics and Prebiotics as Bioactive Components in Dairy Products, Wiley-Blackwell.

Kanno, C. (1989). "Emulsifying properties of bovine milk fat globule membrane in milk fat emulsion: conditions for the reconstitution of milk fat globules." Journal of Food Science: 54 (6) 1534-1539 54(6): 1534-1539. 
Keenan, T. W., I. H. Mather, et al., Eds. (1988). Physical equlibria: Lipid phase. Fundamentals of dairy chemistry. New York, Aspen Publishers.

Kelly, C. P., S. Chetman, et al. (1997). "Survival of anti-Clostridium difficile bovine immunoglobulin concentrate in the human gastrointestinal tract." Antimicrobial Agents and Chemotherapy 41: 236-241.

Kirjavainen, P. V., A. C. Ouwehand, et al. (1998). "The ability of probiotic bacteria to bind to human intestinal mucus." FEMS Microbiology Letters 167: 185-189.

Ko, S. and H.-S. Kwak (2009). Bioactive Components in Whey Products, WileyBlackwell.

Kolida, S. and G. R. Gibson (2007). "Prebiotic capacity of inulin-type fructans." Journal of Nutrition 137(11): S2503-S2506.

Korhonen, H., A. Pihlanto-Leppäla, et al. (1998). "Impact of processing on bioactive proteins and peptides." Trends in Food Science \& Technology 9(8-9): 307-319.

Korhonen, H., P. Marnila, et al. (2000). "Bovine milk antibodies for health." British Journal of Nutrition 84(SupplementS1): 135-146.

Korhonen, H. (2002). "Technology options for new nutritional concepts." International Journal of Dairy Technology 55(2): 79-88.

Korhonen, H. J. (2009). Bioactive Components in Bovine Milk, Wiley-Blackwell.

Larson, B. L., Ed. (1992). Immunoglobulins of the mammary secretions. Advanced Dairy Chemistry. London, Elsevier.

Lebeer, S., J. Vanderleyden, et al. (2008). "Genes and Molecules of Lactobacilli Supporting Probiotic Action." Microbiology and Molecular Biology Reviews 72(4): 728-764.

Lee, S.-L., J. Stevens, et al. (1994). A liquid gelatin blocking reagent for Western blotting with chemiluminescent detection. Biotechniques. Natick, MA, Eaton Pub. Co. 17: 60-62.

Li-Chan, E., A. Kummer, et al. (1995). "Stability of bovine immunoglobulins to thermal treatment and processing." Food Research International 28: 9-16.

Mainer, G., L. Sanchez, et al. (1997). "Kinetic and thermodynamic parameters for heat denaturation of bovine milk IgG, IgA and IgM." Journal of Food Science 62: 131137.

Mehra, R., P. Marnila, et al. (2006). "Milk immunoglobulins for health promotion." International Dairy Journal 16(11): 1262-1271. 
Morin, P., M. Britten, et al. (2007). "Microfiltration of Buttermilk and Washed Cream Buttermilk for Concentration of Milk Fat Globule Membrane Components." Journal of dairy science 90(5): 2132-2140.

Mukai, T., T. Asasaka, et al. (2002). "Inhibition of binding of Helicobacter pylori to the glycolipid receptors by probiotic Lactobacillus reuteri." FEMS Immunology \& Medical Microbiology 32(2): 105-110.

Mukai, T., S. Kaneko, et al. (2004). "Binding of Bifidobacterium bifidum and Lactobacillus reuteri to the carbohydrate moieties of intestinal glycolipids recognized by peanut agglutinin." International Journal of Food Microbiology 90(3): 357-362.

Nelson, D. L. and M. M. Cox (2000). Lehninger Principles of Biochemistry. Figure 1110, W.H. Freeman.

Neyestani, T. R., M. Djalali, et al. (2003). "Isolation of [alpha]-lactalbumin, [beta]lactoglobulin, and bovine serum albumin from cow's milk using gel filtration and anion-exchange chromatography including evaluation of their antigenicity." Protein Expression and Purification 29(2): 202-208.

O'Halloran, S., M. Feeney, et al. (1997). Adhesion of potential probiotic bacteria to human epithelial cell lines. Functional Foods: Designer Foods for the Future. Cork, Ireland.

Ouwehand, A. C., S. Salminen, et al. (2002). "Probiotics and overview of beneficial effects." Antonie van Leeuwenhoek 82: 279-289.

Park, Y. W. (2009). Overview of Bioactive Components in Milk and Dairy Products, Wiley-Blackwell.

Pettus, B. J., C. E. Chalfant, et al. (2004). "Sphingolipids in inflammation: Roles and implications." Current Molecular Medicine(4): 405-418.

PierceBiotechnology (2007). Choosing a secondary antibody: A guide to fragment specificity, Thermo Fisher Scientific.

Roberfroid, M. B. (1996). "Functional effects of food components and the gastrointestinal system: chicory fructooligosaccharides." Nutrition Reviews 54: S38-S42.

Rojas, M. and P. L. Conway (2001). "A dot-blot assay for adhesive components relative to probiotics." Methods in Enzymology 336: 389-402.

Rombaut, R., J. V. Camp, et al. (2005). "Analysis of Phospho- and Sphingolipids in Dairy Products by a New HPLC Method." Journal of dairy science 88(2): 482488. 
Rombaut, R. and K. Dewettinck (2006). "Properties, analysis, and purification of milk polar lipids." International Dairy Journal(16): 1362-1373.

Roos, S. and H. Jonsson (2002). "A high molecular mass cell surface protein from Lactobacillus reuteri 1063 adheres to mucus components." Microbiology 148: 433-442.

Ryan, P. A., V. Pancholi, et al. (2001). "Group A Streptococci Bind to Mucin and Human Pharyngeal Cells through Sialic Acid-Containing Receptors." Infect. Immun. 69(12): 7402-7412.

Saavedra, J. M. (2007). "Use of probiotics in pediatrics, rationale, mechanisms of action, and practical aspects." Nutrition in Clinical Practice 22: 351-365.

Saito, T. (2009). Potential for Improving Health: Immunomodulation by Dairy Ingredients, Wiley-Blackwell.

Savage, D. C. (1977). "Microbial ecology of the gastrointestinal tract." $\underline{\text { Annual Reviews }}$ of Microbiology 31: 107-133.

Schmitt, H. (2008). Lecithin \& phospholipids- healthy and natural powerful nutrients. Wellness Foods Europe. Hamburg, Germany, Dr. Claus-Jörg Harnisch and Benno Keller: 24-29.

Servin, A. L. and M.-H. Coconnier (2003). "Adhesion of probiotic strains to the intestinal mucosa and interaction with pathogens." Best Practice \& Researchc Clinical Gastroenterology 17(5): 741-754.

Shah, N. P. (2007). "Functional cultures and health benefits." International Dairy Journal 17: $1262-1277$.

Shornikova, A. V., I. A. Casas, et al. (1997). "Bacteriotherapy with Lactobacillus reuteri in rotavirus gastroenteritis." Pediatric Infectious Disease Journal 16(12): 11031107.

Sillanpaa, J., B. Martínez, et al. (2000). "Characterization of the collagen-binding S-layer protein CbsA of Lactobacillus crispatus." Journal of Bacteriology 182(22): 64406450 .

Simon, G. L. and S. L. Gorbach (1984). "Intestinal flora in health and disease." Gastroenterology 86: 174-193.

Sleytr, U. B. and T. J. Beveridge (1999). "Bacterial S-layers." Trends in Microbiology 7(6): 253-260.

Smit, E., F. Oling, et al. (2001). "The S-layer Protein of Lactobacillus acidophilus ATCC 4356: Identification and Characterization of Domains Responsible for S-protein Assembly and Cell Wall Binding." Journal of Molecular Biology 305: 245-257. 
Su, P., A. Henriksson, et al. (2007). "Selected prebiotics support the growth of probiotic monocultures in vitro." Anaerobe 13: 134-149.

Swaisgood, H. E., Ed. (1993). Chemistry of the caseins. Advanced Dairy Chemistry. London, Elsevier Applied Science.

Taki, T. and D. Ishikawa (1997). "Review: TLC Blotting: Application to Microscale Analysis of Lipids and as a New Approach to Lipid-Protein Interaction." Analytical Biochemistry 251: 135-143.

Tamura, Z. (1983). "Nutrition of Bifidobacteria." Bif. Microflora 2: 3-16.

Tannock, G., Ed. (1999). A fresh look at the intestinal microflora. Probiotics: A Critical Review. Wymondham, UK, Horizon Scientific Press.

Tremblay, L., M. F. Laporte, et al., Eds. (2003). Quantitation of proteins in milk and milk products. Advanced Dairy Chemistry. London, Elsevier Applied Science.

Tuomola, E. M., A. C. Ouwehand, et al. (2000). "Chemical, physical and enzymatic pretreatments of probiotic lactobacilli alter their adhesion to human intestinal mucus glycoproteins." International Journal of Food Microbiology 60(1): 75-81.

Uruakpa, F. O., M. A. H. Ismond, et al. (2002). "Colostrum and its benefits: a review." Nutrition Research 22: 755-767.

Vadillo-Rodriguez, V., H. J. Busscher, et al. (2004). "Dynamic Cell Surface Hydrophobicity of Lactobacillus Strains with and without Surface Layer Proteins." J. Bacteriol. 186(19): 6647-6650.

van der Mei, H. C., B. van de Belt-Gritter, et al. (2003). "Cell surface hydrophobicity is conveyed by S-layer proteins--a study in recombinant lactobacilli." Colloids and Surfaces B: Biointerfaces 28: 127-134.

Vesterlund, S., M. Karp, et al. (2006). "Staphylococcus aureus adheres to human intestinal mucus but can be displaced by certain lactic acid bacteria." Microbiology 152: 1819-1826.

Vogt, R. V. J., D. L. Phillips, et al. (1987). "Quantitative differences among various proteins as blocking agents for ELISA microtiter plates." Journal of Immunological Methods 101(1): 43-50.

Waldeck, F., Ed. (1990). Funktionen des Magen-Darm-Kanals. Physiologie des Menschen. Berlin, Springer Verlag.

Walker, W. A. and L. C. Duffy (1998). "Diet and bacterial colonization: Role of probiotics and prebiotics." Journal of Nutritional Biochemistry 9: 668-677. 
Ye, A., H. Singh, et al. (2002). "Characterization of protein components of natural and heat-treated milk fat globule membranes." International Dairy Journal 12(4): 393402. 


\section{APPENDICES}

Appendix A: Growth study of lactic acid bacteria

\begin{tabular}{|r|r|r|r|r|}
\hline & \multicolumn{4}{|c|}{ Abs 600nm of bacteria } \\
\hline \multicolumn{1}{l|}{ lour } & \multicolumn{1}{|c|}{ LC-10 } & NCFM & \multicolumn{1}{l|}{ SD2112 } & \multicolumn{1}{l|}{-1 } \\
\hline 0 & 0.131 & 0.131 & 0.131 & 0.131 \\
\hline 2.25 & 0.206 & 0.182 & 0.182 & 0.228 \\
\hline 3.25 & 0.231 & 0.186 & 0.207 & 0.278 \\
\hline 4.25 & 0.291 & 0.206 & 0.263 & 0.372 \\
\hline 5.25 & 0.383 & 0.245 & 0.375 & 0.535 \\
\hline 6.25 & 0.541 & 0.305 & 0.61 & 0.801 \\
\hline 7.25 & 0.841 & 0.455 & 0.985 & 1.167 \\
\hline 7.75 & 1.01 & 0.592 & 1.252 & 1.303 \\
\hline 8.25 & 1.105 & 0.665 & 1.45 & 1.446 \\
\hline 8.75 & 1.269 & 0.721 & 1.571 & 1.585 \\
\hline 9.25 & 1.348 & 0.86 & 1.64 & 1.675 \\
\hline 9.75 & 1.463 & 0.975 & 1.696 & 1.743 \\
\hline 10.25 & 1.615 & 1.098 & 1.756 & 1.832 \\
\hline 10.75 & 1.676 & 1.261 & 1.805 & 1.882 \\
\hline 11.25 & 1.79 & 1.397 & 1.851 & 1.935 \\
\hline 11.75 & 1.831 & 1.445 & 1.922 & 1.966 \\
\hline 12.75 & 1.981 & 1.598 & 1.999 & 2.026 \\
\hline 13.75 & 2.005 & 1.688 & 2.063 & 2.088 \\
\hline 14.75 & 2.088 & 1.759 & 2.123 & 2.129 \\
\hline 15.75 & 2.146 & 1.778 & 2.14 & 2.121 \\
\hline 16.75 & 2.186 & 1.838 & 2.133 & 2.147 \\
\hline 17.75 & 2.2 & 1.847 & 2.135 & 2.173 \\
\hline
\end{tabular}


Appendix B: Raw data for fluorescent dots

\begin{tabular}{|c|c|c|c|c|c|}
\hline & \multicolumn{5}{|c|}{ Sample coating on dots } \\
\hline Bacteria ID & $\begin{array}{c}\text { Control }(2: 1 \\
\left.\mathrm{CHCl}_{3}: \mathrm{MeOH}\right)\end{array}$ & $\begin{array}{c}\text { Triglycerides } \\
\text { (canola oil) }\end{array}$ & PL standard & $\begin{array}{c}P C \\
\text { standard }\end{array}$ & $\begin{array}{c}\text { SM } \\
\text { standard }\end{array}$ \\
\hline \multirow{4}{*}{$\begin{array}{l}\text { SD2112- } \\
\text { L. reuteri }\end{array}$} & 3879 & 1334 & 37850 & 22472 & 28082 \\
\hline & 2680 & 2972 & 21636 & 12802 & 17699 \\
\hline & 3349 & 3383 & 35355 & 26649 & 32176 \\
\hline & 4629 & 1204 & 31950 & 11279 & 25779 \\
\hline \multirow{4}{*}{$\begin{array}{l}\text { NCFM - L. } \\
\text { acidophilus }\end{array}$} & 6807 & 2972 & 21636 & 12802 & 17699 \\
\hline & 5309 & 3716 & 24531 & 14702 & 20221 \\
\hline & 3324 & 1983 & 35913 & 17712 & 24789 \\
\hline & 5623 & 49 & 17346 & 10565 & 12020 \\
\hline \multirow{4}{*}{$\begin{array}{l}\text { LC10-L. } \\
\text { casei }\end{array}$} & 6807 & 1334 & 24549 & 18245 & 29513 \\
\hline & 5055 & 2530 & 32977 & 20919 & 27660 \\
\hline & 4411 & 3383 & 27419 & 21903 & 16290 \\
\hline & 3433 & 1204 & 32490 & 23156 & 24357 \\
\hline \multirow{4}{*}{$\begin{array}{l}\mathrm{T}-1-L . \\
\text { reuteri }\end{array}$} & 4864 & 2180 & 24857 & 13945 & 18682 \\
\hline & 6574 & 1538 & 22536 & 17426 & 22556 \\
\hline & 4752 & 2836 & 24632 & 17529 & 28897 \\
\hline & 4037 & 2772 & 24755 & 17245 & 21543 \\
\hline
\end{tabular}




\section{Appendix C: HPLC analysis of milk-derived phospholipid extract}

Data from HPLC analysis of phospholipid extract

\begin{tabular}{|r|r|r|r|r|r|r|r|r|r|r|r|}
\hline Run1 & tR min & \multicolumn{1}{|c|}{ tS min } & tE min & H(V) & Hnorm & A(V.s.) & Anorm & W0.1 & Asym & Effic & Res \\
\hline 1 & 1.69 & 1.5 & 2.16 & 0.51 & 17.16 & 7.47 & 12.51 & 0.46 & 3.08 & 247 & \\
\hline 2 & 7.59 & 7.21 & 8.14 & 0.33 & 11.31 & 8.08 & 13.53 & 0.64 & 1.24 & 2555 & 11.42 \\
\hline 3 & 13.19 & 12.82 & 13.89 & 0.65 & 22.12 & 9.14 & 15.31 & 0.47 & 1.18 & 14724 & 10.82 \\
\hline 4 & 14.68 & 14.42 & 14.95 & 0.16 & 5.44 & 1.72 & 2.89 & 0.36 & 1 & 30866 & 3.88 \\
\hline 5 & 15.31 & 15.13 & 15.71 & 0.25 & 8.4 & 4.06 & 6.79 & 0.46 & 2.17 & 20322 & 1.66 \\
\hline 6 & 16.41 & 15.98 & 17.05 & 0.53 & 17.84 & 13.38 & 22.4 & 0.71 & 1.43 & 9823 & 2.01 \\
\hline 7 & 18.11 & 17.43 & 19.11 & 0.52 & 17.71 & 15.88 & 26.58 & 0.86 & 0.59 & 8136 & 2.32 \\
\hline Run2 & tR min & tS min & tE min & H(V) & Hnorm & A(V.s.) & Anorm & W0.1 & Asym & Effic & Res \\
\hline 1 & 1.72 & 1.52 & 2.54 & 0.52 & 17.82 & 8.5 & 13.99 & 0.5 & 2.58 & 221 & \\
\hline 2 & 7.64 & 7.26 & 8.23 & 0.32 & 10.82 & 7.72 & 12.7 & 0.64 & 1.37 & 2622 & 11.18 \\
\hline 3 & 13.26 & 12.91 & 13.8 & 0.63 & 21.53 & 8.9 & 14.64 & 0.46 & 1.22 & 15170 & 10.94 \\
\hline 4 & 14.72 & 14.48 & 14.96 & 0.16 & 5.54 & 1.69 & 2.78 & 0.38 & 1.02 & 28324 & 3.76 \\
\hline 5 & 15.38 & 15.11 & 15.8 & 0.26 & 8.74 & 4.42 & 7.27 & 0.48 & 2.16 & 19189 & 1.66 \\
\hline 6 & 16.44 & 16.01 & 17.14 & 0.52 & 17.76 & 13.24 & 21.78 & 0.72 & 1.72 & 9729 & 1.91 \\
\hline 7 & 18.15 & 17.36 & 19.26 & 0.52 & 17.79 & 16.32 & 26.84 & 0.86 & 0.56 & 8123 & 2.33 \\
\hline Run3 & tR min & tS min & tE min & $\mathbf{H ( V )}$ & Hnorm & A(V.s.) & Anorm & W0.1 & Asym & Effic & Res \\
\hline 1 & 1.71 & 1.54 & 2.46 & 0.5 & 17.17 & 8.17 & 13.47 & 0.51 & 3.39 & 209 & \\
\hline 2 & 7.83 & 7.45 & 8.4 & 0.32 & 10.96 & 7.66 & 12.63 & 0.66 & 1.43 & 2561 & 11.21 \\
\hline 3 & 13.34 & 12.98 & 14.09 & 0.62 & 21.39 & 9.41 & 15.53 & 0.49 & 1.19 & 13485 & 10.2 \\
\hline 4 & 14.76 & 14.49 & 15.09 & 0.17 & 5.68 & 1.99 & 3.29 & 0.45 & 1.11 & 19626 & 3.24 \\
\hline 5 & 15.4 & 15.16 & 15.78 & 0.27 & 9.29 & 4.19 & 6.92 & 0.43 & 2.01 & 23620 & 1.56 \\
\hline 6 & 16.43 & 16.03 & 17.05 & 0.52 & 17.97 & 13.42 & 22.14 & 0.73 & 1.69 & 9274 & 1.9 \\
\hline 7 & 18.09 & 17.4 & 19.09 & 0.51 & 17.55 & 15.77 & 26.02 & 0.85 & 0.69 & 8360 & 2.25 \\
\hline
\end{tabular}




\section{Appendix D: Raw data for ELISA analysis}

\begin{tabular}{|c|c|c|c|c|c|c|c|c|c|}
\hline \multicolumn{10}{|c|}{ ELISA absorbance values $(492 \mathrm{~nm})$} \\
\hline 250 & 125 & 62.5 & 31.2 & 15.6 & 7.81 & 0 & $\begin{array}{l}\text { Milk } \\
(\text { diluted } \\
\left.2 \times 10^{-4}\right)\end{array}$ & $\begin{array}{l}\text { Colostrum } \\
(\text { diluted } \\
\left.2 \times 10^{-5}\right)\end{array}$ & $\begin{array}{l}\text { Gel } \\
(\text { diluted } \\
2 \times 10^{-5}\end{array}$ \\
\hline 2.780 & 2.647 & 2.197 & 1.525 & 0.867 & 0.488 & 0.059 & 0.849 & 0.469 & 0.816 \\
\hline 2.780 & 2.647 & 2.197 & 1.525 & 0.867 & 0.488 & 0.059 & 0.861 & 0.344 & 0.794 \\
\hline 3.136 & 2.617 & 1.523 & 0.723 & 0.360 & 0.199 & 0.069 & 0.849 & 0.469 & 0.816 \\
\hline 3.156 & 2.690 & 1.599 & 0.758 & 0.377 & 0.203 & 0.051 & 0.861 & 0.344 & 0.794 \\
\hline 2.787 & 2.403 & 1.366 & 0.620 & 0.365 & 0.183 & 0.043 & 0.843 & 0.321 & 0.610 \\
\hline 2.759 & 2.335 & 1.374 & 0.657 & 0.347 & 0.167 & 0.043 & 0.835 & 0.309 & 0.621 \\
\hline 3.109 & 2.643 & 1.722 & 0.908 & 0.444 & 0.222 & 0.116 & 0.825 & 0.319 & 0.609 \\
\hline 3.179 & 2.751 & 1.710 & 0.970 & 0.462 & 0.231 & 0.122 & 0.821 & 0.370 & 0.596 \\
\hline & & & & & & & 0.504 & 0.117 & 0.449 \\
\hline & & & & & & & 0.494 & 0.114 & 0.468 \\
\hline & & & & & & & 0.504 & 0.147 & 0.496 \\
\hline & & & & & & & 0.493 & 0.137 & 0.505 \\
\hline & & & & & & & 1.122 & 0.545 & 0.781 \\
\hline & & & & & & & 1.102 & 0.555 & 0.706 \\
\hline & & & & & & & 1.094 & 0.566 & 0.748 \\
\hline & & & & & & & 1.096 & 0.627 & 0.785 \\
\hline
\end{tabular}




\section{Appendix E: Statistical Analysis by Minitab 16 - Fluorescent dots}

\section{Fluorescent dot trials for bacterial binding to phospholipids}

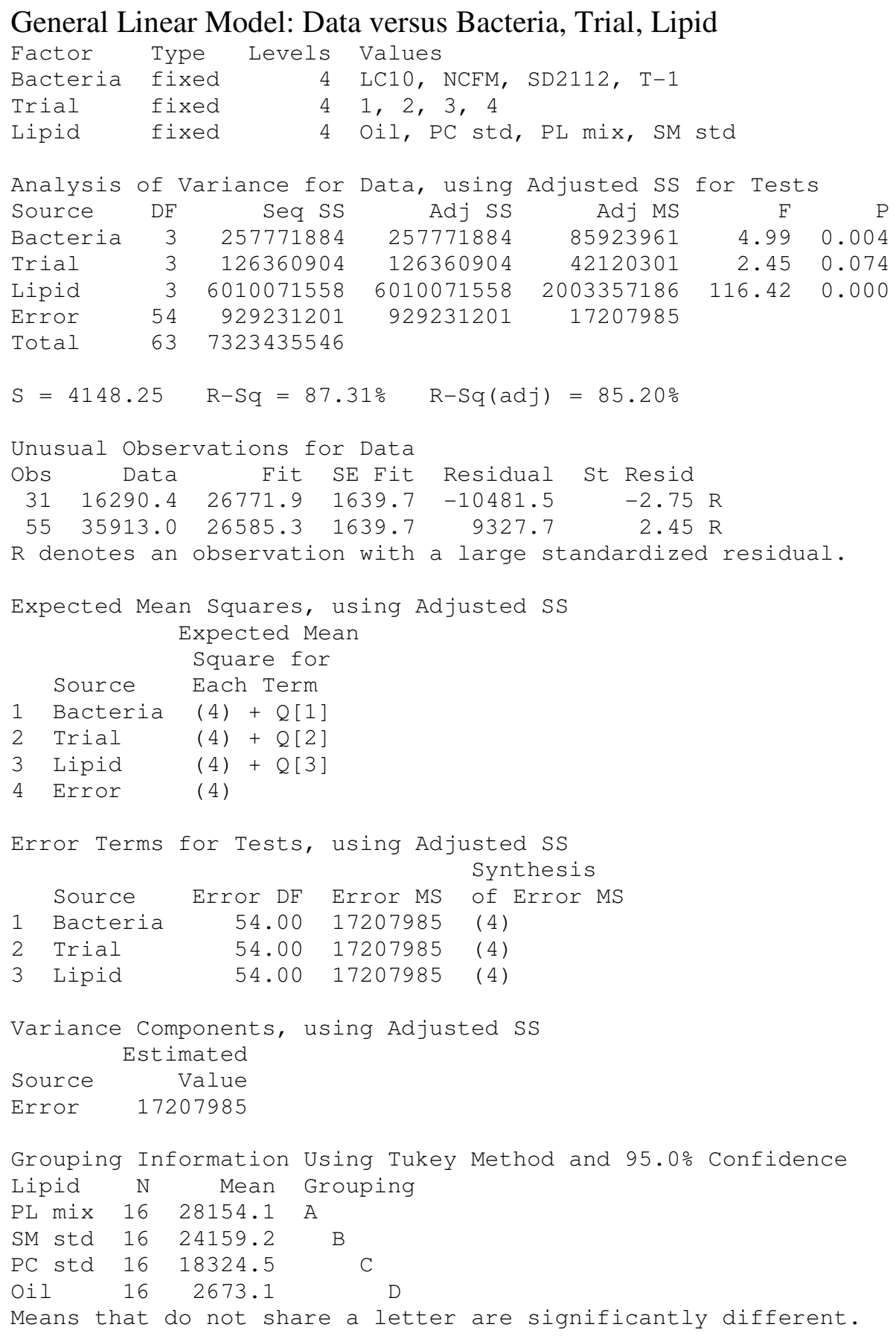


Tukey 95.0\% Simultaneous Confidence Intervals

Response Variable Data

All Pairwise Comparisons among Levels of Lipid

Lipid = Oil subtracted from:

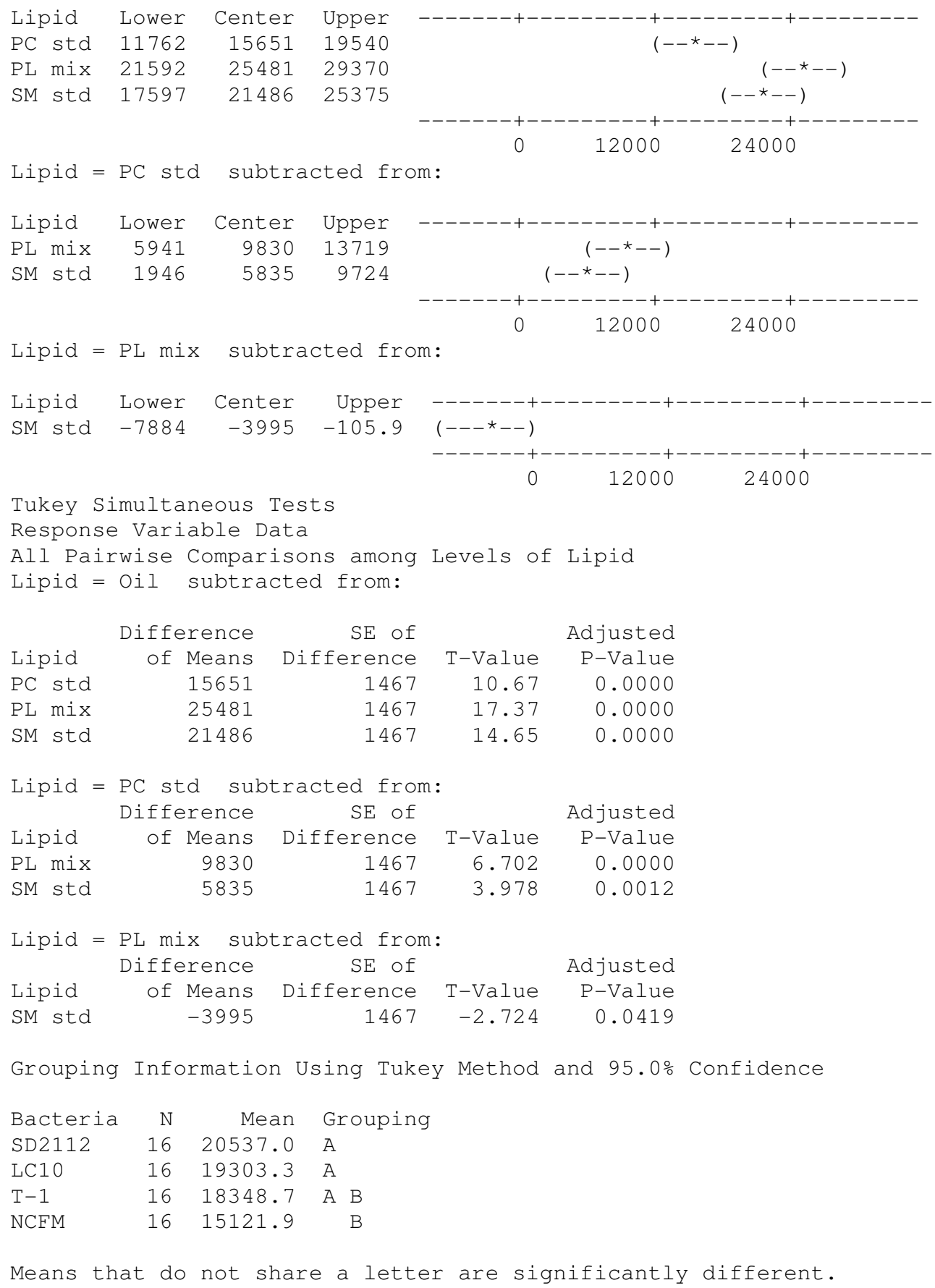


Tukey 95.0\% Simultaneous Confidence Intervals

Response Variable Data

All Pairwise Comparisons among Levels of Bacteria

Bacteria $=$ LC10 subtracted from:

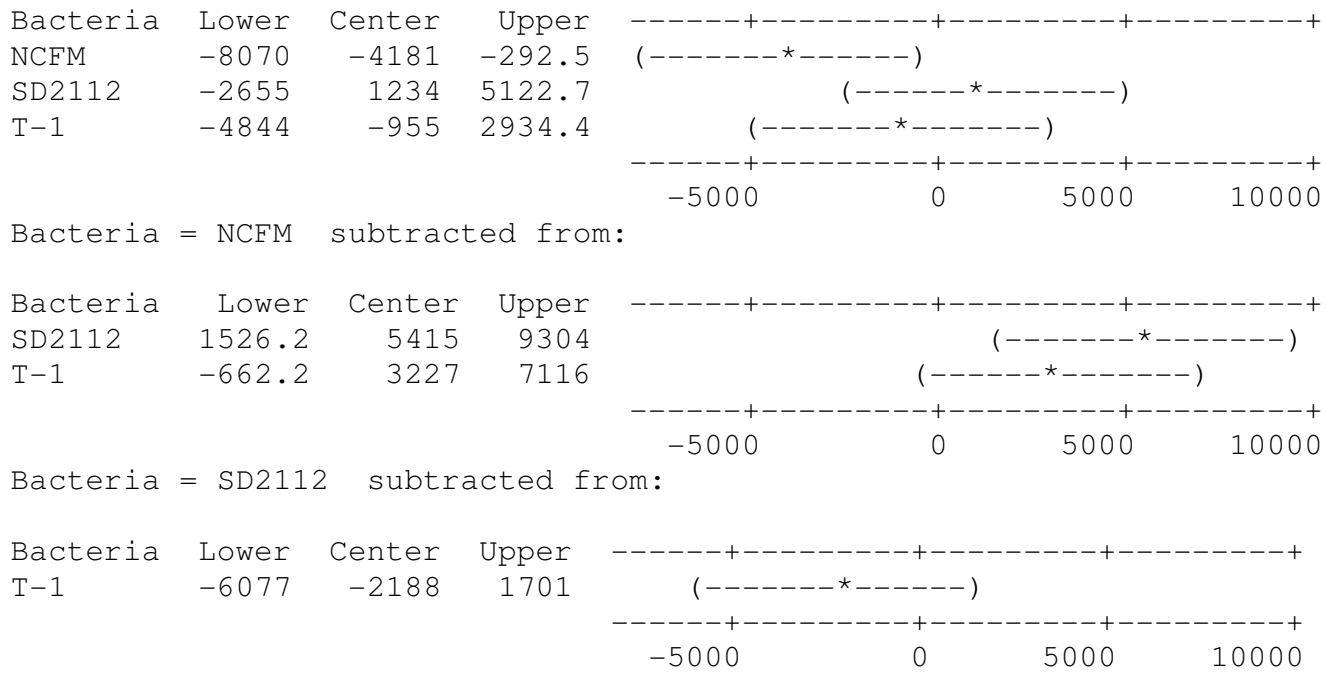

Tukey Simultaneous Tests

Response Variable Data

All Pairwise Comparisons among Levels of Bacteria

Bacteria = LC10 subtracted from:

$\begin{array}{lrrrr} & \begin{array}{r}\text { Difference } \\ \text { of Means }\end{array} & \begin{array}{r}\text { SE of } \\ \text { Difference }\end{array} & \text { T-Value } & \text { Adjusted } \\ \text { P-Value } \\ \text { NCFM } & -4181 & 1467 & -2.851 & 0.0304 \\ \text { SD2112 } & 1234 & 1467 & 0.841 & 0.8346 \\ \text { T-1 } & -955 & 1467 & -0.651 & 0.9148\end{array}$

Bacteria = NCFM subtracted from:

$\begin{array}{lrrrr} & \text { Difference } & \text { SE of } & \text { Adjusted } \\ \text { Bacteria } & \text { of Means } & \text { Difference } & \text { T-Value } & \text { P-Value } \\ \text { SD2112 } & 5415 & 1467 & 3.692 & 0.0028 \\ \text { T-1 } & 3227 & 1467 & 2.200 & 0.1362\end{array}$

Bacteria $=$ SD2112 subtracted from:

$\begin{array}{rrrr}\text { Difference } & \text { SE of } & \text { Adjusted } \\ \text { of Means } & \text { Difference } & \text { T-Value } & \text { P-Value } \\ -2188 & 1467 & -1.492 & 0.4493\end{array}$




\section{Appendix F: Statistical Analysis by Minitab 16 - ELISA analysis}

\section{Evaluation of bovine IgG standard curve}

General Linear Model: Abs BovIgG versus Trial, BovIgG conc

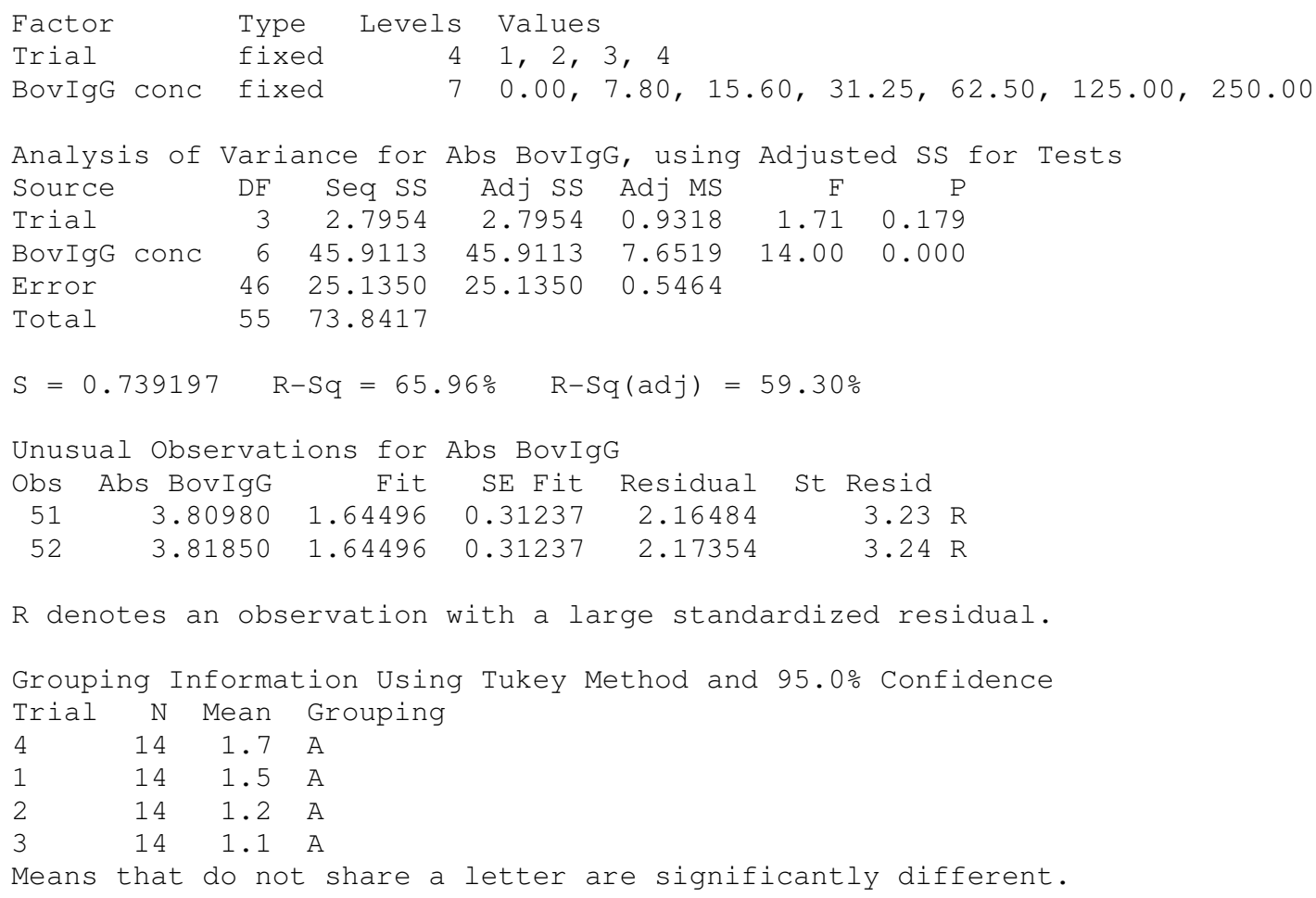




\section{Evaluation of ELISA samples}

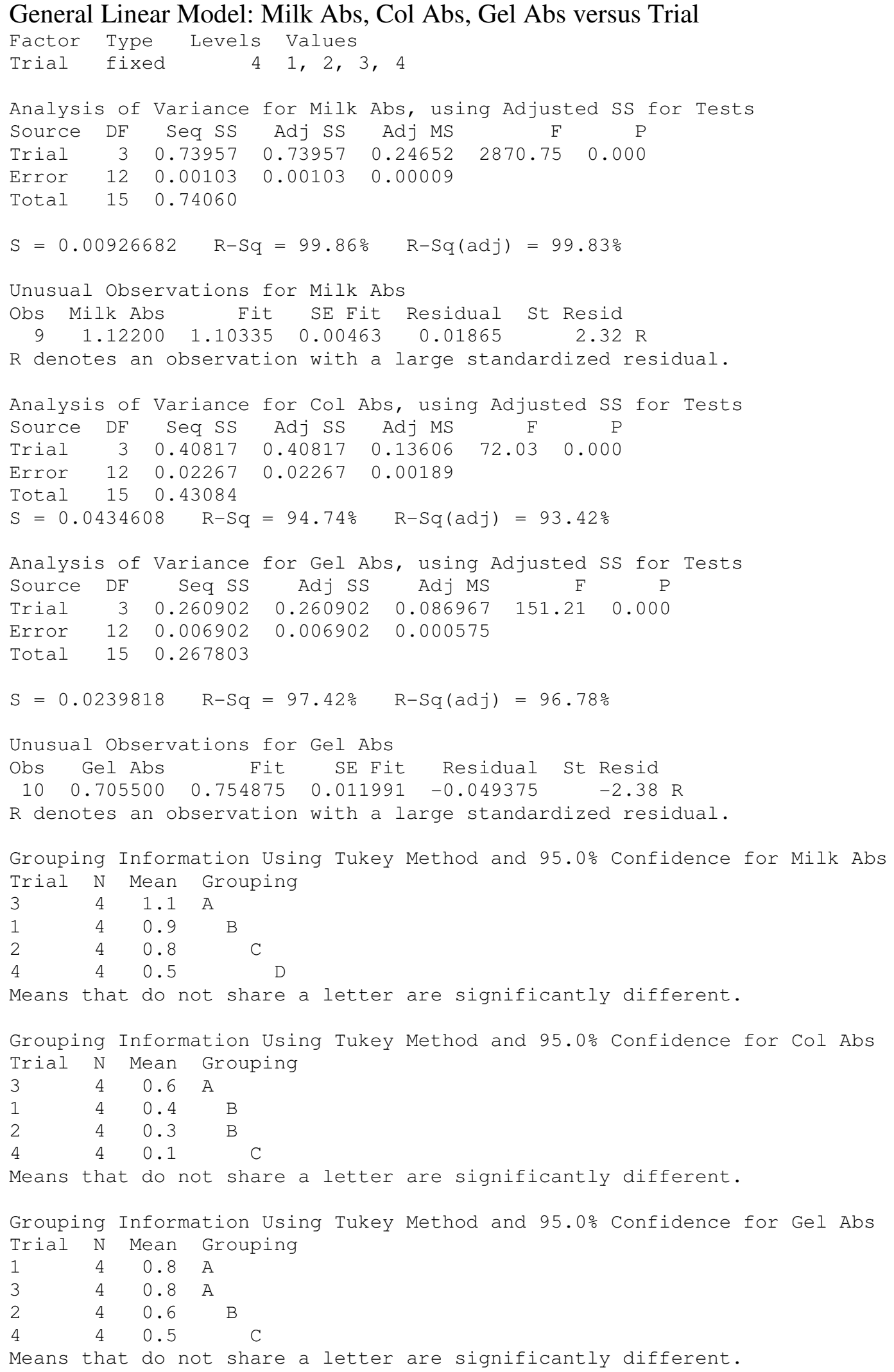




\section{Appendix G: Buffer formulas}

10x PBS pH 7.2

0.017 M potassium phosphate monobasic (cat \#P-0662, Fisher Sci.)

0.1 M potassium phosphate dibasic (cat \#PX1570-2, EMD Chemicals)

1.49 M NaCl (cat \#S640-3, Fisher Sci.)

10x TBS-Tween-20 pH 8.0

$50 \mathrm{mM}$ Tris $\mathrm{HCl}$ (cat \#9310, EMD Chemicals)

140 mM NaCl (cat \#S640-3, Fisher Sci.)

0.05\% Tween-20 (cat \#BP337, Fisher Sci.)

0.05M carbonate-bicarbonate $\mathrm{pH} 9.6$

29 mM sodium carbonate (cat \#BP357-1, Fisher Sci)

$71 \mathrm{mM}$ sodium bicarbonate (cat \#S-8875, Sigma Aldrich)

$0.05 \mathrm{M}$ citrate-phosphate $\mathrm{pH} 5.0$

$24 \mathrm{mM}$ citrate, anhydrous (cat \#BP339, Fisher Sci.)

$51 \mathrm{mM}$ potassium phosphate dibasic (cat \#PX1570-2, EMD Chemicals) 